\title{
Algoritmos e Implementações Paralelas para Florestas Geradoras Mínimas
}

\author{
Marco Aurélio Stefanes
}

\author{
DISSERTAÇÃO APRESENTADA \\ AO \\ INSTITUTO DE MATEMÁTICA E ESTATISTTICA \\ DA \\ UNIVERSIDADE DE SÃO PAULO \\ PARA \\ OBTENÇÃO DO GRAU DE MESTRE \\ EM \\ MATEMÁTICA APLICADA
}

Área de Concentração: Ciência da Computação Orientador: Prof. Dr. José Augusto R. Soares

Durante a elaboração deste trabalho o autor recebeu apoio financeiro do $C N P q$

-São Paulo, março de 1998- 


\section{Algoritmos e Implementações Paralelas para \\ Florestas Geradoras Mínimas}

Este exemplar corresponde à redação final da dissertação devidamente corrigida e defendida por Marco Aurélio Stefanes e aprovada pela comissão julgadora.

São Paulo, 17 de março de 1998.

Banca examinadora:

- Prof. Dr. José Augusto R. Soares (orientador) - IME-USP

- Prof. Dr. Édson Norberto Cáceres - DCT-UFMS

- Prof. Dr. Marco Dimas Gubitoso - IME-USP 
À minha famitia, em especial, à D. Cleuza. 


\section{Agradecimentos}

Ao Prof. José Augusto, pela paciência e incentivo com que me orientou e pelo esforço dedicado para produzirmos este trabalho.

Ao Prof. Coelho, pelas excelentes dicas que nos foram bastante úteis.

Ao Prof. Siang, por seus ensinamentos e estilo cativante que me fizeram conhecer e gostar da área.

À minha querida Eliany, por ter me suportado durante todo este tempo e pelo carinho que me fez enfrentar esta jornada com mais vigor.

Aos amigos Ayumi, Cao, Claus, Fábio e Marcelo que estiveram sempre presentes e diretamente me ajudaram em diversos momentos difíceis. Aos amigos Carlos, Flávio, Fran, Jair e Orlando pelo companheirismo. 


\section{Resumo}

O principal objetivo desta dissertação é o estudo de implementações de algoritmos paralelos usando estruturas de dados que sejam teoricamente eficientes para o problema da Floresta Geradora Mínima.

Primeiro vimos os principais algoritmos seqüenciais para o problema, tanto determinísticos, quanto probabilísticos. No campo da computação paralela, descrevemos os principais modelos de computação existentes e fizemos uma breve discussão acerca da necessidade da construção de um modelo único. Dentro de cada modelo, buscamos descrever os algoritmos para o Problema da Floresta Geradora Mínima mais eficientes encontrados na literatura. Fizemos, ainda, um estudo de alguns artigos sobre implementações para o problema em máquinas paralelas.

Por fim, implementamos na máquina paralela Parsytec PowerXplorer uma adaptação do Algoritmo de Das, Deo e Prasad. Em seguida, descrevemos um novo algoritmo assíncrono baseado na estratégia de eliminação de arestas, que obteve desempenho melhor que o algoritmo de Das et al. Com a implementação deste algoritmo alcançamos um speedup entre 1,70 e 2,65 com 4 processadores, e um speedup entre 1,06 e 5,23 com 8 processadores para grafos com número de vértices entre 200 e 1500 e densidade entre $10 \%$ e $60 \%$.

\section{Abstract}

The main goal of this dissertation is to study parallel algorithms' implementation using data structures which are theoretically efficient for the minimum spanning forest problem.

First, we describe sequential deterministic and randomized algorithms. Next, we discuss the main models for parallel computing and the attempt to establish an unique model for parallel computing. For each model, we report the most efficient algorithm for minimum spanning forest problem found in literature. We also make a description of some articles about implementations in parallel machines.

Finally, we implement an adaptation of the Algorithm of Das, Deo and Prosad in Parsitec's PowerXplorer parallel machine. Next, we report a new asynchronous algorithm based in an edge elimination strategy. This algorithm has better performance than the Algorithm of Das, Deo and Prosad. With this implementation we obtain speedup ranging from 1.70 to 2.65 with 4 processors and from 1.06 to 5.23 with 8 processors in graphs with number of vertices between 200 and 1500 and density between $10 \%$ and $60 \%$. 


\section{Conteúdo}

1 Introdução 1

1.1 Introdução . . . . . . . . . . . . . . . . . . . . . 1

1.2 Estrutura e Objetivos da Dissertação . . . . . . . . . . . . . . . . 2

1.3 Notação e Preliminares . . . . . . . . . . . . . . . . . . . . 3

1.4 Condições de Otimalidade . . . . . . . . . . . . . . . . . . . 4

2 Algoritmos Seqüenciais $\quad 7$

2.1 Algoritmo de Borůvka . . . . . . . . . . . . . . . . . . 7

2.1.1 Implementação com Estruturas de Dados Elementares . . . . . . . . 8

2.1.2 Implementação com Heap Esquerdista e Fusão Preguiçosa . . . . . 9

2.2 Algoritmo Prim . . . . . . . . . . . . . . . . . . . 16

2.2 .1 Implementação para Grafos Densos . . . . . . . . . . . . . . 16

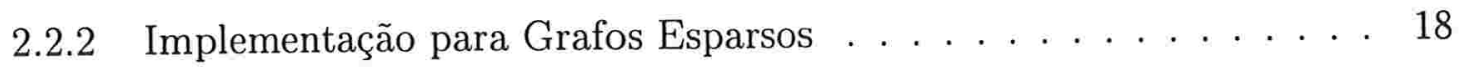

2.3 Algoritmo de Kruskal . . . . . . . . . . . . . . . . . . . . . . . . . . . . . . 19

2.4 Algoritmo Probabilístico . . . . . . . . . . . . . . . 20

3 Algoritmos Paralelos $\quad 26$

3.1 Computação Paralela . . . . . . . . . . . . . . . . . . . 26

3.1 .1 Noções de Otimalidade . . . . . . . . . . . . . . . . . . 27

3.2 Modelos de Computação Paralela . . . . . . . . . . . . . . . . . . 28

3.2 .1 Modelo de Memória Compartilhada . . . . . . . . . . . . . . . 29

3.2 .2 Modelo de Memória Distribuída . . . . . . . . . . . . . . . . 31 
3.2 .3 Modelos Realísticos . . . . . . . . . . . . . . . . . . 33

3.3 Algoritmo Paralelo para PRAM . . . . . . . . . . . . . . . 37

3.4 Algoritmo Paralelo para a Malha . . . . . . . . . . . . . . . . 42

3.5 Algoritmo Probabilístico Paralelo . . . . . . . . . . . . . . . 45

3.6 Implementações Paralelas . . . . . . . . . . . . . . . . . . . . . . . . . . 49

4 Implementações Paralelas na Parsytec $\quad 51$

4.1 Características da Máquina . . . . . . . . . . . . . . . . . . . . 51

4.2 O Algoritmo DDP . . . . . . . . . . . . . . . . . . 53

4.3 O Algoritmo Assíncrono . . . . . . . . . . . . . . . 56

4.4 A Implementação . . . . . . . . . . . . . . . . . . . . . . . . 61

4.4 .1 Grafos Aleatórios . . . . . . . . . . . . . . 61

4.4 Resultados dos Testes Realizados . . . . . . . . . . . . . 62

5 Considerações Finais $\quad 67$

$\begin{array}{ll}\text { Apêndice A } & 69\end{array}$

$\begin{array}{lr}\text { Apêndice B } & 87\end{array}$

$\begin{array}{ll}\text { Bibliografia } & 92\end{array}$ 


\section{Capítulo 1}

\section{Introdução}

\subsection{Introdução}

Esta dissertação, em seus dois primeiros capítulos, é semelhante àquelas feitas por Tarjan [Tar83], Ahuja et al [AMO93] e Cormen et al [CLR90]. Vamos estudar um dos problemas mais conhecidos de otimização em grafos, o problema da Floresta Geradora Mínima - FGM. A sua história data de 1926, quando Borůvka [Bor26] escreveu o primeiro algoritmo para o problema. O mesmo algoritmo foi mais tarde desenvolvido, independentemente, por Choquet [Cho38], Lukasziewics et al $\left[\mathrm{LFP}^{+} 51\right]$ e Sollin [BGH65].

O segundo algoritmo clássico mais recentemente desenvolvido é conhecido como Algoritmo de Kruskal [Kru56]. O terceiro algoritmo foi, inicialmente, descrito em linha gerais por Jarník [Jar30] e, posteriormente, escrito com mais detalhes por Prim [Pri57] e Dijkstra [Dij59] sendo conhecido como Algoritmo de Prim. Para maiores detalhes veja Graham e Hell [GH85], que escreveram um excelente artigo sobre a história do problema da FGM.

Estes algoritmos clássicos podem ser implementados em tempo $O(m \log n)$ para um grafo com $n$ vértices e $m$ arestas usando estruturas de dados elementares e, algumas vezes, melhorados usando estruturas mais elaboradas. Além disso, o Algoritmo de Prim pode ser executado em tempo $O\left(n^{2}\right)$ quanto o grafo é representado por sua matriz de adjacência.

Quanto aos algoritmos paralelos para o problema, encontramos variantes dos algoritmos clássicos descritos para os diversos modelos de computação paralela. No modelo PRAM o problema foi resolvido em tempo $O\left(\log ^{2} n\right)$ usando $n^{2} / \log ^{2} n$ processadores com CREW [CLC82] ou $n^{2}$ processadores com EREW [NM82], e em tempo $O(\log n)$ usando $\max \{m, n\}$ processadores com CRCW-Prioritário [AS87]. Mais recentemente Johnson e Metaxas [JM95] descreveram um algoritmo que roda em tempo $O\left(\log ^{3 / 2} n\right)$ usando $\max \{m, n\}$ processadores com EREW e Cole et al [CKT94] fornecem um algoritmo probabilístico paralelo de trabalho linear. Nesta dissertação apresentamos os algoritmos de 
Awerbuch e Shiloach [AS87] e o de Cole et al.

No modelo de redes, encontramos vários algoritmos nos diversos tipos interconexão: Vetor Linear, Grade [adH89, AK84], Árvore [NMB83], Hipercubo [DDP90], etc. Todos estes algoritmos exploram propriedades da topologia na busca de soluções paralelas ótimas para o problema, o que muitas vezes dificulta a implementação em outras topologias. Alguns destes algoritmos são apresentados no Capítulo 3 deste Trabalho.

O problema FGM freqüentemente ocorre como subproblema na solução de outros problemas. Por exemplo, algoritmos para FGM são usados em várias soluções para o Problema do Caixeiro Viajante, Problema de Fluxos em Redes, Problema de Emparelhamento, etc [Hu61, HK71, Rei79]. Um algoritmo para FGM também implica na existência de um algoritmo para o Problema da Conexidade em Grafos com a mesma complexidade do primeiro, e soluções para problemas relacionados ao último (Decomposição em Orelhas [Rei93, Cap. 7], Biconexidade [TV85], etc).

A generalização deste problema é estudada em Teoria de Matróides [Law76]. Em geral os problemas de otimização associados a esta teoria são resolvidos pelo Método Guloso, e é através deste método que apresentaremos as primeiras soluções para o nosso problema.

Para resolver o problema da FGM usando esta técnica incremental, construímos a floresta, aresta por aresta, da seguinte forma: a cada momento incluímos a aresta mais leve na FGM, quando possível, e/ou excluímos aquela mais pesada do grafo original. Repetimos esta operação até encontrarmos a FGM.

\subsection{Estrutura e Objetivos da Dissertação}

Esta Dissertação está dividida em cinco capítulos. O primeiro trará uma introdução, onde vamos descrever formalmente o problema da Floresta Geradora Mínima e alguns conceitos preliminares. O capítulo conterá ainda um breve histórico sobre o problema bem como um resumo dos principais algoritmos, tanto na computação paralela, quanto na seqüencial. O Capítulo 2 tratará, mais detalhadamente, a descrição dos algoritmos seqüenciais clássicos e terá também uma discussão sobre as estruturas de dados que implementam esses algoritmos.

O Capítulo 3 terá, na primeira parte, a descrição dos modelos de computação paralela e a descrição de alguns algoritmos para estes modelos. Em sua segunda parte, tratará da descrição de algumas implementações paralelas para o problema da Floresta Geradora Mínima.

O Capítulo 4 será o núcleo central da dissertação, tratará da nossa implementação do Algoritmo de Das et al [DDP90] na máquina Parsytec PowerXplorer, discutindo os problemas práticos encontrados nas implementações. Neste Capítulo descrevemos e im- 
plementamos, também, um novo algoritmo paralelo assíncrono para memória distribuída e fazemos uma comparação desta com a implementação que fizemos do Algoritmo de Das et al. Por fim, no Capítulo 5 vamos descrever nossas conclusões sobre o Trabalho.

De um ponto de vista mais geral, esta Dissertação tem como objetivo o estudo de implementações paralelas de algoritmos e estruturas de dados teoricamente eficientes. Com isso pretendemos que o nosso estudo sirva de paradigma para aplicações em outros problemas computacionais. Salientamos, também, que as estruturas de dados usadas no problema da Floresta Geradora Mínima têm ampla utilização em outros problemas, o que, por si só, já justifica seu estudo detalhado.

\subsection{Notação e Preliminares}

As definições relacionadas a Teoria dos Grafos omitidas nesta Seção podem ser encontrdas em Bondy e Murty [BM76]. Seja $G=(V, E)$ um grafo, onde $V$ é o conjunto de vértices e $E$ é o conjunto de arestas. Para evitar ambiguidades, em algumas situações representaremos o conjunto de vértices de um grafo $G$ por $V(G)$ e o seu conjunto de arestas por $E(G)$. Neste texto denotaremos uma aresta por $(i, j)$, onde $i$ e $j \in V$. Dado um subgrafo $H$ de $G$ o subgrafo $H$ é dito gerador se $V(H)=V(G)$.

Seja $w: E \rightarrow \mathbb{R}^{+}$uma função peso. Abusando da notação denotaremos o peso de $(i, j)$ por $w(i, j)$. Consideraremos, ainda, que $n$ será sempre o número de vértices do grafo e $m$ o seu número de arestas, exceto quando explicitado o contrário. Chamaremos um grafo de denso se $m / n$ é grande e esparso caso contrário. Uma noção mais exata deste conceito depende do contexto.

Dados um grafo $G=(V, E)$ e uma função peso $w$ como acima, queremos encontrar um subgrafo acíclico maximal $F^{*}$ de $G$, tal que $\sum_{e \in E\left(F^{*}\right)} w(e)$ seja mínima. Este problema é chamado Problema da Floresta Geradora Mínima. Note que, decorrente da definição, a FGM cobre todos os vértices do grafo $G$ e, se $G$ for conexo, $F^{*}$ também será. Neste caso, $F^{*}$ é chamada Árvore Geradora Mínima.

Dado um grafo $G=(V, E)$, seja $V^{\prime}$ um subconjunto não vazio de $V$. O subgrafo de $G$, cujo conjunto de vértices é $V^{\prime}$ e cujo conjunto de arestas é formado por aquelas arestas de $G$ que têm ambas as pontas em $V^{\prime}$, é chamado de subgrafo de $G$ induzido por $V^{\prime}$ sendo denotado por $G\left[V^{\prime}\right]$. Dizemos que $G\left[V^{\prime}\right]$ é um subgrafo induzido de $G$.

Seja, agora, $E^{\prime}$ um subconjunto não vazio de $E$. O subgrafo de $G$ cujo conjunto de vértices é formado pelas pontas das arestas em $E^{\prime}$ e cujo conjunto de arestas é $E^{\prime}$, é chamado subgrafo de $G$ induzido por $E^{\prime}$ sendo denotado por $G\left[E^{\prime}\right]$. O grafo $G\left[E^{\prime}\right]$ é um subgrafo aresta-induzido de $G$.

Sejam $G=(V, E)$ um grafo conexo e $T$ uma árvore geradora de $G$. Os conceitos a 
seguir nos fornecerão dois resultados que terão um papel fundamental nos algoritmos para a FGM, conforme vamos verificar no decorrer deste Trabalho.

A remoção de qualquer aresta $(i, j)$ de $T$ induz uma partição dos vértices de $G$. As componentes $S$ e $\bar{S}$ de $T-(i, j)$ definem, cada uma, um conjunto desta partição. As arestas de $G$, cujas pontas estão em conjuntos diferentes, constituem um corte. Chamaremos este corte de induzido pela remoção da aresta $(i, j)$ de $T$ e o denotaremos por $[S, \bar{S}]$.

Para toda aresta $(i, j)$ de $G$ que não está em T existe um único caminho em $T$ ligando $i$ e $j$. A aresta $(i, j)$ junto com este caminho define um ciclo em $G$.

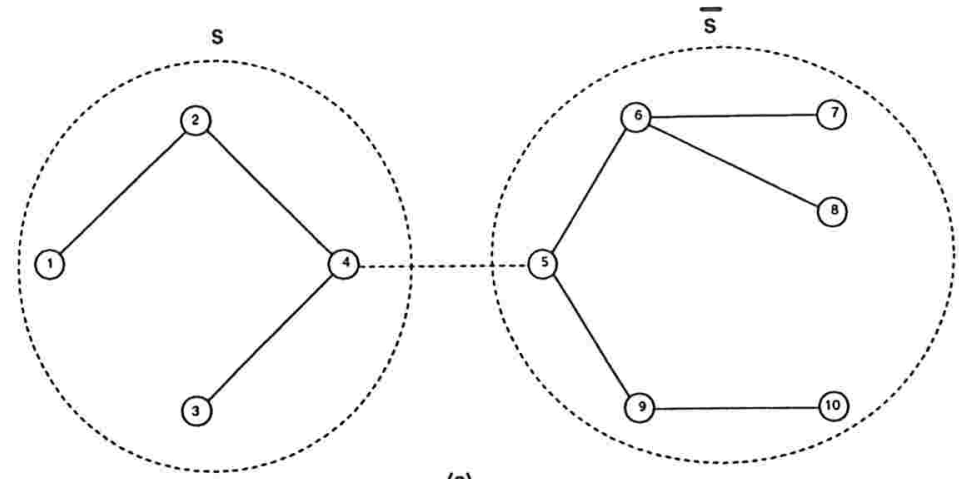

(a)

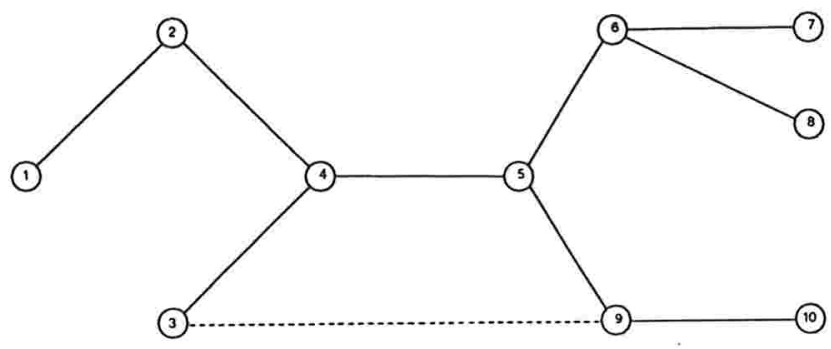

(b)

Figura 1.1: A figura (a) ilustra a definição de corte e (b) de ciclo.

Neste texto a notação "log" representará o logaritmo na base dois. Assumiremos, ainda, que o conjunto de vértices de um grafo é dado por $V=\{1,2, \ldots, n\}$.

\subsection{Condições de Otimalidade}

Antes de detalharmos os algoritmos, vamos discutir as Condições de Otimalidade, uma vez que elas são um ponto central, tanto para o desenvolvimento dos algoritmos, quanto para se estabelecer a sua validade. Há duas formas equivalentes de enunciar estas condições para o problema FGM: a Condição de Otimalidade de um Corte - Teorema 1.4.1 - e a Condição de Otimalidade de um Caminho - Teorema 1.4.2. 
Teorema 1.4.1 Uma árvore geradora T é minima se, e somente se, ela satisfaz a seguinte condição: para toda aresta $(i, j) \in T$ temos $w(i, j) \leq w(k, l)$, para toda aresta $(k, l)$ contida no corte induzido pela remoção da aresta $(i, j)$ de $T$.

Prova. É fácil de ver que toda árvore geradora mínima $T$ deve satisfazer a condição. Se $w(i, j)>w(k, l)$ e a aresta $(k, l)$ está contida no corte formado pela remoção de $(i, j)$ de $T$, então colocamos $(k, l)$ no lugar de $(i, j)$ e criando assim, uma árvore geradora com peso menor que $T$, contradizendo a minimalidade de $T$.

Agora, vamos mostrar que se alguma árvore $T$ satisfaz a condição, ela deve ser mínima. Seja $T^{0}$ uma árvore geradora mínima, tal que, $T \neq T^{0}$. Então $T$ contém uma aresta $(i, j)$ que não está em $T^{0}$. A remoção da aresta $(i, j)$ de $T$ cria um corte $[S, \bar{S}]$. Note que se adicionarmos $(i, j)$ a $T^{0}$, nós criamos um ciclo que deve conter uma aresta $(k, l)$ diferente de $(i, j)$, com $k \in S$ e $l \in \bar{S}$. Como $T^{0}$ é mínima, $w(i, j) \geq w(k, l)$, caso contrário poderíamos melhorar o seu peso trocando $(k, l)$ por $(i, j)$, e além disso $T$ satisfaz a condição, $w(i, j) \leq w(k, l)$, temos, portanto, $w(i, j)=w(k, l)$. Agora, se colocarmos $(k, l)$ em $T$ no lugar de $(i, j)$, produzimos uma outra árvore geradora com mesmo peso que $T$ e com uma aresta a mais em comum com $T^{0}$. Repetindo este argumento, no máximo $n-1$ vezes, transformamos $T$ na árvore geradora mínima $T^{0}$. Esta construção mostra que $T$ também é mínima.

Este teorema implica que toda aresta em uma FGM é uma aresta de peso mínimo que cruza o corte definido pela sua remoção do grafo. O teorema implica, também, que qualquer aresta de peso mínimo de um corte está contida em alguma FGM.

Teorema 1.4.2 Uma árvore geradora $T$ de um grafo $G$ é minima se, e somente se, ela satisfaz a seguinte condição: para toda aresta $(k, l)$ de $G$, tal que $(k, l) \notin T$ temos $w(i, j) \leq w(k, l)$, para toda aresta $(i, j)$ contida no caminho de $T$ ligando os nós $k$ e $l$.

Prova. É facil mostrar a necessidade da condição. Suponhamos que $T$ é uma árvore geradora mínima satisfazendo a condição de que uma aresta $(i, j)$ está contida no caminho de $T$ conectando os nós $k$ e $l$. Se $w(i, j)>w(k, l)$, colocamos $(k, l)$ em T no lugar de $(i, j)$ e criando assim, uma árvore geradora com peso menor que $T$, contradizendo a minimalidade de $T$.

Para estabelecer que a condição é suficiente, vamos usar a suficiência da Condição de Otimalidade de um Corte. Vamos mostrar que se uma árvore $T$ satisfaz a Condição de Otimalidade de um Caminho ela deve satisfazer a Condição de Otimalidade de um Corte. Seja $(i, j)$ uma aresta qualquer de $T$ e seja $[S, \bar{S}]$ um corte produzido pela remoção de $(i, j)$ de $T$. Suponha que $i \in S$ e $j \in \bar{S}$. Considere uma aresta qualquer $(k, l)$ de $[S, \bar{S}]$. 
Como $T$ contém um único caminho ligando $k$ a $l$ e como a aresta $(i, j)$ é a única aresta de $T$ ligando $S$ a $\bar{S}$, a aresta $(i, j)$ deve pertencer a este caminho. A condição implica que, $w(i, j) \leq w(k, l)$; como esta condição vale para toda aresta $(k, l)$ fora da árvore e no corte $[S, \bar{S}]$ formado pela remoção de qualquer aresta $(i, j)$ em $T$, a árvore $T$ satisfaz a Condição de Otimalidade de um Corte. E pelo Teorema 1.4.1 temos que $T$ é mínima.

A Condição de Otimalidade de um Corte - Teorema 1.4.1 - nos fornece uma caracterização externa de uma FGM, no sentido de que considera o relacionamento de uma aresta na floresta com várias arestas fora desta floresta. Já a Condição de Otimalidade de um Caminho - Teorema 1.4.2 - nos fornece uma caracterização interna no sentido de que considera o relacionamento entre uma aresta fora da floresta e várias arestas da floresta, isto é, a relação entre esta aresta e aquelas no circuito formado quando ela é adicionada à FGM. 


\section{Capítulo 2}

\section{Algoritmos Seqüenciais}

Vamos tratar aqui das descrições dos algoritmos clássicos para o problema da FGM de uma forma genérica, com o objetivo de englobar assim as diferentes implementações desses algoritmos. Após estas descrições estudaremos técnicas e estruturas de dados que tornam suas implementações eficientes.

Nestes algoritmos assumimos que os pesos das arestas são distintos. Caso isto não ocorra, o desempate pode ser dado pelos índices dos vértices das arestas. Nestas condições, a Floresta Geradora Mínima é única.

\subsection{Algoritmo de Borůvka}

O Algoritmo de Borůvka inicia com uma floresta com $n$ árvores, cada uma com um vértice de $V$, e nenhuma aresta. O algoritmo trabalha em estágios e em cada um deles encontra, para cada árvore $T_{i}$ da floresta, a aresta $e_{i}$ de peso mínimo ligando esta árvore a alguma outra árvore $T_{j}$. A seguir, $T_{i}$ e $T_{j}$ são substituídas por uma nova árvore contendo $T_{i}, T_{j}$ e a aresta $e_{i}$. Estes estágios são repetidos até encontrar a FGM.

Considere as $k$ componentes conexas de $\mathrm{G}$ e seja $n_{k}$ o número de vértices da maior delas. Observe que, para cada componente, enquanto o algoritmo não encontra a árvore geradora, a quantidade de árvores na floresta correspondente a uma tal componente se reduz a cada estágio, pelo menos, à metade. Portanto, em no máximo $\log n_{k}$ estágios teremos a FGM, que é dada pelo conjunto destas arestas de peso mínimo, tomadas sobre todos os estágios. Devido às suas características, este é o algoritmo mais adequado para ser paralelizado, conforme observou Tarjan [Tar83].

A corretude deste algoritmo é decorrente da condição de otimalidade de um corte dada pelo Teorema 1.4.1. Podemos ver que, em cada estágio, cada aresta inserida na floresta geradora obedece esta condição e, portanto, a floresta gerada desta forma é mínima. 

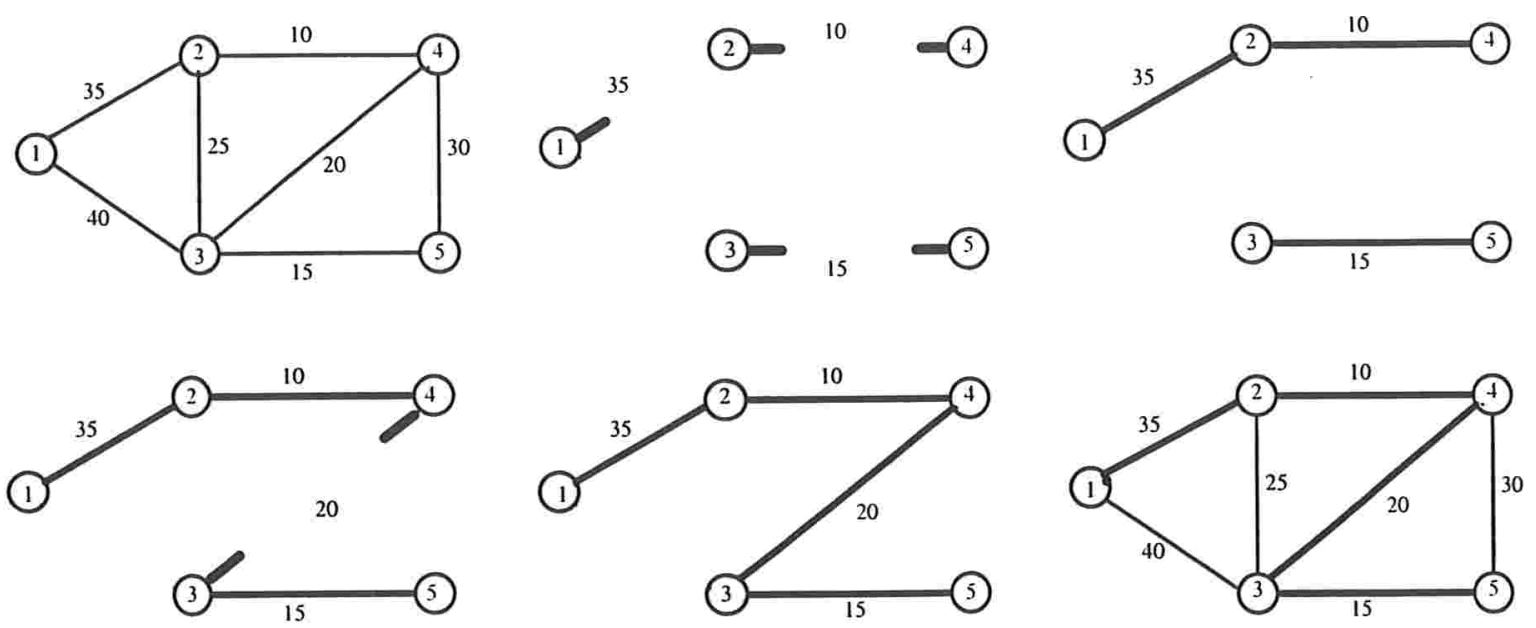

Figura 2.1: Ilustração da execução do Algoritmo de Borůvka

\subsubsection{Implementação com Estruturas de Dados Elementares}

Uma das qualidades do Algoritmo de Borủvka é que ele pode ser implementado de forma eficiente usando estruturas de dados elementares. Abaixo fazemos uma descrição do algoritmo com estas características, e em seguida apresentamos dois procedimentos que são usados por ele para realizar, respectivamente, as operações MenorVizinho e Componentes.

\section{Algoritmo MSF}

Entrada: Grafo $G=(V, E)$ e a função peso $w$.

Saída: Conjunto de arestas $F^{*}$ da FGM de $G$.

Passo 1 Inicialize $n$ árvores $T_{k}, 1 \leq k \leq n$, cada $T_{k}$ contendo o vértice $k$ e nenhuma aresta. Faça $F^{*}=\emptyset$.

Passo 2 Para cada árvore $T_{k}$ encontre o MenorVizinho $\left(T_{k}\right)$.

Passo 3 Para cada árvore $T_{k}$, faça $F^{*}=F^{*} \cup\left\{\left(i_{k}, j_{k}\right)\right\}$.

Passo 4 Encontre as componentes de $F^{*}$, Componente $\left(G\left[F^{*}\right]\right)$, e coloque cada componente em uma lista duplamente ligada.

Passo 5 Caso alguma operação de união foi executada no Passo 3, volte ao Passo 2. Caso contrário retorne $F^{*}$.

MenorVizinho $\left(T_{k}\right)$ : Esta operação toma como entrada uma árvore geradora $T_{k}$ e determina a aresta de peso mínimo $(u, v)$ dentre todas as arestas com uma ponta em $T_{k}$ e outra fora. 
Componente $(G)$ : Esta operação toma como entrada um grafo $\mathrm{G}$ e determina um rótulo para cada vértice de $\mathrm{G}$, tal que dois nós possuem o mesmo rótulo se, e somente se, estão na mesma componente de $G$.

Vamos descrever uma possível estrutura de dados a ser usada na implementação do algoritmo. Podemos usar uma lista circular duplamente ligada para cada árvore da floresta, um vetor para os rótulos dos nós do grafo e uma fila ou pilha de dados para o procedimento Componente.

Desta forma, podemos verificar se dois nós estão na mesma árvore em tempo constante. Isto implica que o procedimento MenorVizinho gasta tempo total $O\left(\sum_{T}|E(T)|\right)=O(m)$, em cada estágio.

O procedimento Componente $(G)$ pode ser implementado usando as técnicas de busca em largura ou profundidade [CLR90, Cap. 23]. Este procedimento tem tempo de execução $O\left(\left|F^{*}\right|\right)=O(n)$, em cada estágio. Com estas estruturas de dados temos o teorema abaixo.

Teorema 2.1.1 Usando o Algoritmo de Boruvka, uma FGM pode ser encontrada em tempo $O(m \log n)$.

\subsubsection{Implementação com Heap Esquerdista e Fusão Preguiçosa}

O desempenho do Algoritmo de Borủvka pode ser melhorado. Para isto, usamos um heap esquerdista com fusão preguiçosa descrito por Tarjan [Tar83]. Com esta estrutura de dados obtemos um método que, para grafos esparsos, é mais rápido que a implementação descrita anteriormente. Esta implementação roda em tempo $O(m \log \log n)$. O primeiro algoritmo de tempo $O(m \log \log n)$ foi desenvolvido por Yao [Yao75], mas ele necessita de um algoritmo de seleção de tempo linear [CLR90, Cap. 10], o que pode torná-lo não muito eficiente na prática. Já, com as estruturas de dados descritas por Tarjan, temos um algoritmo similar com mesma complexidade assintótica, porém com uma constante pequena, o que o torna mais eficiente.

Para a implementação deste algoritmo, precisamos de duas estruturas de dados para cada árvore da floresta. Primeiro, para representar as arestas com pelo menos uma ponta nas árvores que são candidatas, usamos o heap esquerdista com fusão preguiçosa e remoção preguiçosa. Neste contexto, uma aresta é considerada "deletada" se suas pontas estão em uma mesma árvore. Segundo, para representar o conjunto de vértices usamos a estrutura de dados "Union-Find". No Capítulo 2 de Tarjan [Tar83] temos as descrições destas operações, onde as operações MakeSet e LinkSet podem ser executadas em tempo $O(1)$, e a operação FindSet, para $m$ operações com $n$ elementos, pode ser executada com um tempo amortizado de $O(m \alpha(m, n))$, onde $\alpha(m, n)$ é a inversa da função de Ackerman. Para $i, j \geq 1$, definimos a função de Ackerman por 


$$
\begin{aligned}
& A(1, j)=2^{j}, \quad j \geq 1 \\
& A(i, 1)=A(i-1,2), \quad i \geq 2 \\
& A(i, j)=A(i-1, A(i, j-1)), \quad i, j \geq 2 \\
& \text { Definimos a função inversa } \alpha(m, n) \text { para } m \geq n \geq 1 \text { por } \\
& \qquad \alpha(m, n)=\min \{i \geq 1 \mid A(i,\lfloor m / n\rfloor)>\log n\} .
\end{aligned}
$$

A principal característica da função de Ackerman é o seu crescimento explosivo. Observe que $A(2, j)=2^{2 \cdot{ }^{2}}$, onde $j \geq 1$ indica a altura da pilha de potências. Para $i>2$ a função tem um crescimento mais rápido ainda. A função $\alpha(m, n)$ não é a inversa da função de Ackerman no sentido matemático exato, mas ela reflete o inverso de seu crescimento. Para um $n$ fixo, $\alpha(m, n)$ decresce quando $m / n$ cresce. Observe que $\alpha(m, n) \leq 3$, para $n<2^{16}$. Assim, para propósitos práticos, $\alpha(m, n)$ é um fator constante não maior que quatro.

Necessitamos, também, de uma forma de selecionar as árvores que aplicaremos estas operações. Para isto, usamos uma fila contendo todas as árvores. Para realizarmos um passo, removemos a primeira árvore, digamos $T_{i}$, do início da fila e fazemos a remoção da aresta mínima de seu heap. A aresta $e$ obtida pela remoção é adicionada a FGM. Em seguida, removemos da fila a outra árvore, digamos $T_{j}$, incidente a $e$. Então, atualizamos o conjunto de vértices e arestas refletindo a combinação de $T_{i}$ e $T_{j}$, e adicionamos ao final da fila uma nova árvore resultante desta combinação.

Abaixo, mostramos o algoritmo com estas estruturas de dados. Durante toda a execução do algoritmo, toda aresta $(v, w)$ no heap $i$ satisfaz FindSet $(v)=i$.

\section{Algoritmo MST}

Entrada: Grafo $G=(V, E)$ e a função peso $w$.

Saída: Conjunto de arestas $F^{*}$ da FGM de $G$.

Passo 1 Crie $n$ conjuntos, cada um contendo um nó de $V$.

Passo 2 Para cada nó de $V$, crie um heap com as arestas incidentes a ele e coloque este heap na fila.

Passo 3 3.1 Remova a aresta mínima $e=(v, w)$ do heap que se encontra no início da fila. 3.2 Adicione a aresta $e$ à FGM. 3.3 Retire da fila os dois heaps que tenham a aresta $e$ incidente. 3.4 Faça a união do conjunto contendo $v$ com o conjunto contendo $w$. 3.5 Combine os dois heaps e insira o heap resultante no final da fila.

Passo 4 Repita o Passo 3 até restar apenas um heap na fila. 
Vamos agora, fazer uma discussão mais detalhada acerca da estrutuda de dados heap esquerdista bem como das implementações de suas principais operações.

Um heap é uma estrutura de dados abstrata consistindo de uma coleção de itens, cada um com um valor chave associado, tal que qualquer item do heap tem chave menor ou igual as chaves de seus filhos.

Um heap, geralmente, suporta as seguintes operações:

Insert $(i, h)$ : Insere um item $i$ no heap $h$ que não contém o item $i$.

$\operatorname{DeleteMin}(h)$ : Remove e retorna o item de chave mínima do heap $h$.

FindMin $(h)$ : Retorna o item de chave mínima do heap $h$ sem removê-lo.

Delete $(i, h)$ : Remove o item $i$ do heap $h$.

$\operatorname{Meld}\left(h_{1}, h_{2}\right)$ : Retorna o heap formado pela combinação dos heaps disjuntos $h_{1}$ e $h_{2}$. Esta operação elimina $h_{1}$ e $h_{2}$.

MakeHeap $(S)$ : Constrói e retorna um novo heap cujos itens são os elementos de um conjunto $S$.

Seja $x$ um nó de uma árvore binária, definimos o $\operatorname{Rank}(x)$ como sendo o comprimento do menor caminho de $x$ a alguma folha da árvore. Ou seja, $\operatorname{Rank}(x)=0$, se $x$ é uma folha; $\operatorname{Rank}(x)=1+\min \{\operatorname{Rank}(\operatorname{esq}(x)), \operatorname{Rank}(\operatorname{dir}(x))\}$, se $x$ é um nó interno da árvore, isto é $\{x \in T \mid x$ não é folha $\}$, onde $\operatorname{esq}(x)$ e $\operatorname{dir}(x)$ denotam os filhos esquerdo e direito de $x$ respectivamente.

Uma árvore binária é esquerdista se $\operatorname{Rank}(\operatorname{esq}(x)) \geq \operatorname{Rank}(\operatorname{dir}(x))$, para todo nó interno $x$. Um heap esquerdista é uma árvore esquerdista contendo um item por nó interno, com os itens arranjados em forma de heap. Neste heap as folhas não contêm informações.

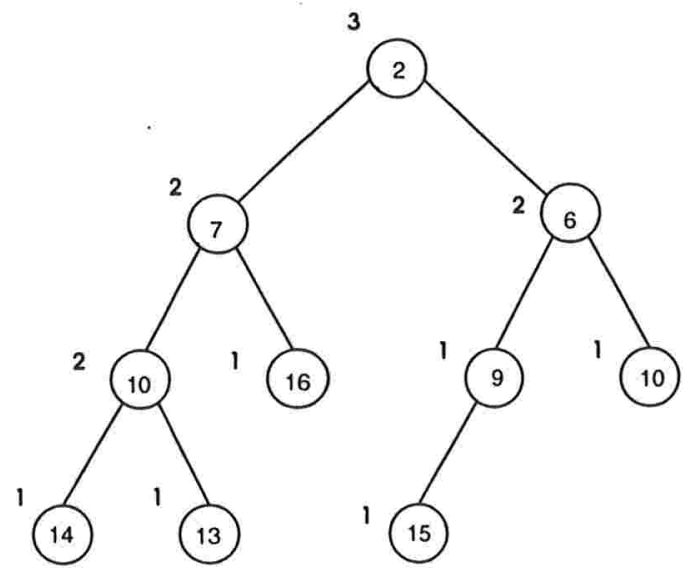

Figura 2.2: Um heap esquerdista: Os Ranks estão indicados à esquerda de cada nó e as folhas são omitidas. 
A operação fundamental no heap esquerdista é o Meld. Para combinar dois heaps, encontramos, em cada árvore, um caminho de comprimento mínimo da raiz até uma folha. Note que este caminho é sempre o mais à direita no heap esquerdista. A seguir, fazemos a intercalação destes dois caminhos em um único caminho, no qual os nós são ordenados pela chave; ligamos as subárvores restantes de cada árvore original aos nós apropriados no caminho combinado, e trocamos os filhos esquerdo e direito (se necessário) ao longo deste caminho, de forma a manter esta nova árvore esquerdista. Para implementar esta operação, cada nó deve armazenar quatro parâmetros: (1) seu valor chave, (2) um ponteiro para seu filho direito, (3) um ponteiro para seu filho esquerdo e (4) o Rank do nó. Pelo fato de que uma árvore binária esquerdista com $m_{i}$ nós tem o caminho mais à direita com no máximo $\log m_{i}$ nós, o tempo requerido para a operação $\operatorname{Meld}(i, j)$ é $O\left(\log m_{i}+\log m_{j}\right)$.

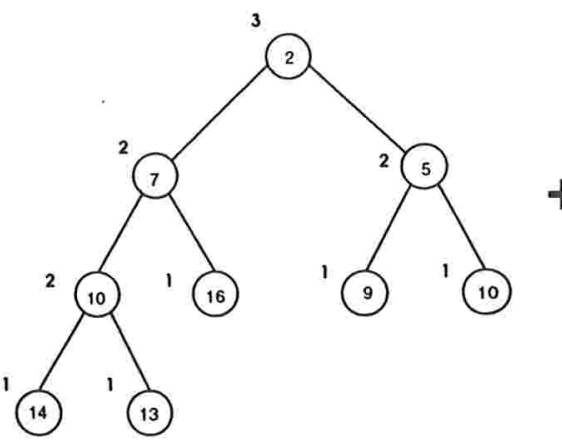

a)

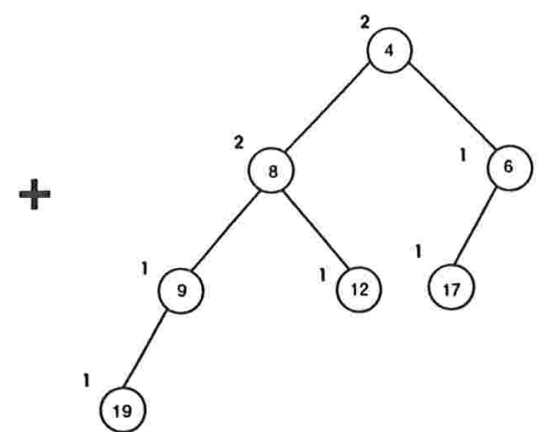

b)

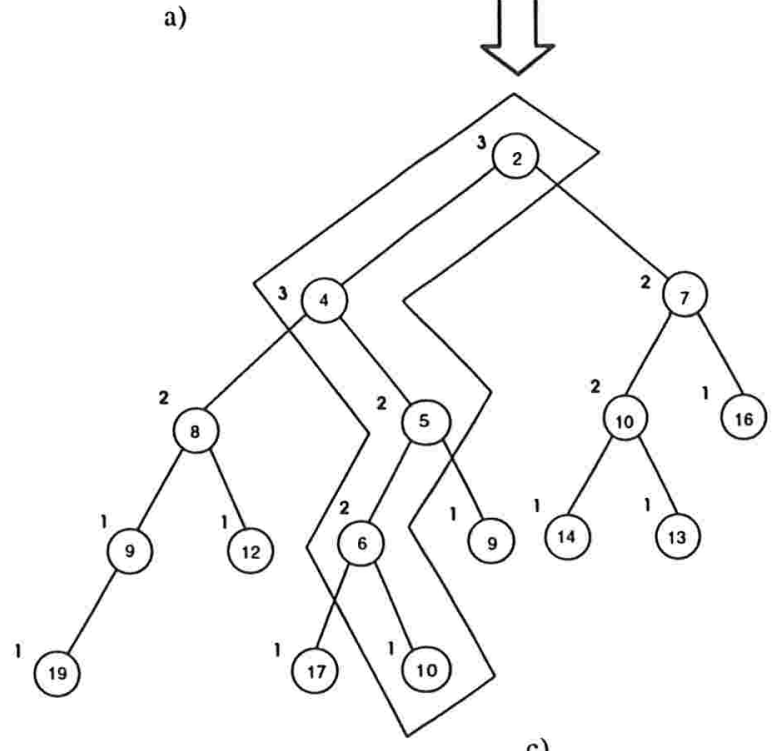

c)

Figura 2.3: Os heaps a) e b) combinados resultam no heap c)

Para inserir um item em um heap esquerdista com $m_{i}$ itens, fazemos um heap esquerdista com este único item e combinamos com o heap existente. Para remover um item mínimo do heap, removemos a raiz e combinamos suas subárvores esquerda e direita. 
Ambas as operações tomam tempo $O\left(\log m_{i}\right)$.

\section{Procedimento Meld $\left(h_{1}, h_{2}\right)$}

Entrada : Dois heaps $h_{1}$ e $h_{2}$ não nulos.

Saída : Um ponteiro para a raiz do heap resultante de $h_{1}$ e $h_{2}$.

Passo 1 Caso chave $\left(h_{1}\right)>\operatorname{chave}\left(h_{2}\right)$ troque $h_{1}$ com $h_{2}$.

Passo 2 Caso $\operatorname{dir}\left(h_{1}\right)=$ Nulo faça $\operatorname{dir}\left(h_{1}\right)=h_{2}$.

Caso contrário faça $\operatorname{dir}\left(h_{1}\right)=\operatorname{Meld}\left(\operatorname{dir}\left(h_{1}\right), h_{2}\right)$.

Passo 3 Caso $\operatorname{Rank}\left(\operatorname{esq}\left(h_{1}\right)\right)<\operatorname{Rank}\left(\operatorname{dir}\left(h_{1}\right)\right)$ troque esq $\left(h_{1}\right)$ com $\operatorname{dir}\left(h_{1}\right)$.

Passo 4 Faça $\operatorname{Rank}\left(h_{1}\right)=\operatorname{Rank}\left(\operatorname{dir}\left(h_{1}\right)\right)+1$ e retorne $h_{1}$.

Para realizar a operação MakeHeap, tratamos a entrada como uma fila onde cada item é um heap unitátio. Repetimos o seguinte passo até que permaneça somente um heap na fila: Remova os dois primeiros heaps da fila, combine-os e adicione o novo heap no final da fila.

Para analisar o tempo de execução desta operação, vamos considerar o processo de combinação dos heaps. Seja $k$ o número de heaps na fila e $m$ o número total de itens que eles contêm. Depois de $\lceil k / 2\rceil$ operações de Meld, cada heap foi combinado com algum outro, deixando, no máximo, $\lfloor k / 2\rfloor$ heaps. O tempo total para estas operações Meld é

$$
O\left(\sum_{i=1}^{\lceil k / 2\rceil} \log \left(n_{i}+1\right)\right)
$$

onde $n_{i}$ é o número de itens do $i$-ésimo heap. Estes heaps são combinados aos pares, e o processo continua até restar apenas um heap. Seja $b=\lfloor\log k\rfloor$. Segue, que o tempo total é dado por

$$
O\left(\sum_{j=0}^{b} \max \left\{\sum_{i=1}^{2^{b-j}} \log \left(n_{i}+1\right)\right\}\right)
$$

Como temos a restrição de que $\sum_{i=1}^{2^{b-j}} n_{i} \leq m, n_{i} \geq 0$, para todo $i$, o somatório tem valor máximo quando todos os seus termos são iguais. Assim, o tempo total para o MakeHeap é

$$
O\left(\sum_{i=1}^{2^{b-j}} 2^{b-j} \log \left(\frac{m}{2^{b-j}}+1\right)\right)=O(k \log (m / k+1))
$$


Isto significa que podemos construir um heap esquerdista em tempo linear, uma vez que $k=m$.

Em algumas situações pode ser mais adequado usar estas operações com pequenas alterações com o intuito de melhorar o desempenho de algumas delas. O LazyMeld fusão proguiçosa - é um artifício com este propósito. Nesta técnica, cada item do heap possui um parâmetro extra que representa uma aresta ou um nó fictício. Com isto, para combinarmos dois heaps, criamos um novo nó fictício com chave de valor menos infinito; fazemos as raízes dos heaps se tornarem os filhos esquerdo e direito do novo heap e marcamos o novo nó como sendo a raiz deste heap. Esta operação, claramente, toma tempo $O(1)$.

Aqui, as operações Insert e MakeHeap não sofrem alterações substanciais, de forma que suas complexidades permanecem inalteradas. No entanto, é importante salientar que, estas operações continuam usando a versão original do Meld.

Vamos descrever a operação DeleteMin(i). Suponha que há $d$ nós fictícios no heap $i$. Primeiro, realizamos uma busca em pré-ordem no heap fazendo uma lista $L$ dos nós do heap, que correspondam a arestas conectando duas diferentes árvores na floresta. Isto é, localizamos o conjunto de nós não-fictícios $\{v \mid v \in i, v$ representa uma aresta conectando árvores diferentes e nenhum ancestral de $v$ representa uma aresta desta forma $\}$. Descartamos todos os ancestrais de tal elemento mínimo. Note que estes nós descartados, ou são nós fictícios, ou representam arestas "deletadas". O número de nós descartados é $d+l-1$, onde $l$ é o número total de arestas que foram removidas.

Agora, a lista $L$ tem, no máximo, $d+l$ elementos, onde cada elemento representa um heap esquerdista cuja raiz de cada um é um elemento do conjunto $L$. Colocamos estes heaps em uma fila e, como no procedimento MakeHeap, removemos e combinamos os dois primeiros heaps da fila usando o Meld e inserimos o heap esquerdista resultante no final da fila. Repetimos este passo até restar apenas um heap na fila. A raiz deste heap esquerdista é o nó de chave mínima desejado. Retornamos este elemento e transformamos esta raiz em um nó fictício de chave menos infinito. O procedimento FindMin é realizado de forma similar, a menos da transformação da raiz em nó fictício.

A operação DeleteMin tem o efeito de descartar do heap todos os nós, fictícios ou não, que são ancestrais de um nó de valor mínimo que conecte duas árvores diferentes, e gerar um único heap esquerdista a partir da combinação dos nós restantes do heap original. Este heap possui um único nó fictício chamado de raiz. A complexidade de tempo desta operação, como na operação MakeHeap, é $O\left((d+l) \log \left(m_{i} /(d+l)\right)\right)$.

Já estamos prontos para analisar o tempo de execução do Algoritmo MST. O tempo de execução é $O(m)$ não contados os tempos das operações sobre conjunto e das operações de heap. O tempo de todas as operações MakeSet e LinkSet é $O(n)$. Podemos assumir que o tempo por FindSet é $O(1)$ e então as operações de heap dominam o tempo, como veremos a seguir. 
Para efeito de análise, vamos dividir o algoritmo em $n-1$ passos. No algoritmo notamos que em cada passo uma aresta da FGM é escolhida. Para $i=1, \ldots, n$ definimos $T_{i}$ como sendo a árvore selecionada durante o $i$-ésimo passo do algoritmo, $m_{i}$ como sendo o número de arestas no heap associado a $T_{i}$ quando $T_{i}$ é selecionado, e $k_{i}$ como sendo o número de arestas eliminadas deste heap durante a $i$-ésima operação DeleteMin. Com esta definição, $T_{n}$ é a FGM construída pelo algoritmo. Dividimos a execução do algoritmo em estágios como segue. O estágio zero consiste da seleção e processamento das árvores que se encontram na fila no ínicio do algoritmo. Para $j>0$, o estágio $j$ consiste da seleção e processamento daquelas árvores adicionadas à fila no estágio $j-1$.

Lema 2.1.2 Durante o estágio j, cada árvore da fila contém, pelo menos, $2^{j}$ vértices. Assim, após, no máximo, $\lfloor\log n\rfloor$ estágios há uma única árvore e o algoritmo termina.

Prova. Imediatamente por indução em $j$, uma vez que para $j>0$ uma árvore da fila durante o $j$-ésimo estágio consiste da combinação de duas ou mais árvores da fila no estágio $j-1$.

Lema 2.1.3

$$
\sum_{i=1}^{n-1} m_{i} \leq\left(2 m_{n}-1\right)\lfloor\log n\rfloor
$$

Prova. Qualquer duas árvores selecionadas e processadas durante um mesmo estágio são disjuntas nos vértices, pois elas estão na fila simultaneamente. Assim, o tamanho total de todos os heaps processados durante um único estágio é, no máximo, $2 m+n-1$, pois cada arestas ocorre em, no máximo, dois heaps e há, no máximo, $n-1$ itens fictícios no heap correspondentes as operações LazyMeld. Isto posto, o lema segue do lema anterior.

Teorema 2.1.4 O Algoritmo de Borüvka, usando heap esquerdista com fusão preguiçosa pode encontrar uma FGM em tempo $O(m \log \log n)$.

Prova. O tempo do MakeHeap é $O(m)$. O tempo para cada Meld é $O(1)$, totalizando $O(n)$. O tempo para o $i$-ésimo DeleteMin é $O\left(k_{i} \log m_{i} /\left(k_{i}+1\right)\right)$. Para estimar o tempo total das operações DeleteMin, dividimo-nas em dois tipos: O $i$-ésimo DeleteMin é dito pequeno se $k_{i} \leq m_{i} /(\log n)^{2}-1$ e grande caso contrário. O tempo total para o DeleteMin pequeno é 


$$
O\left(\sum_{i=1}^{n-1} m_{i} /(\log n)^{2} \log m_{i}\right)=O\left(\sum_{i=1}^{n-1} m_{i} / \log n\right)=O(m)
$$

pelo Lema 2.1.3. O tempo total para o DeleteMin grande é

$$
O\left(\sum_{i=1}^{n-1} \frac{k_{i} \log m_{i}}{m_{i} /(\log n)^{2}}\right)=O\left(\sum_{i=1}^{n-1} k_{i} \log \log n\right)=O(m \log \log n)
$$

uma vez que $\sum_{i=1}^{n-1} k_{i} \leq 2 m+n-1$ incluindo os $n-1$ nós fictícios criados pelas operações Meld. Isto significa que há $O(m \log \log n)$ operações Find, as quais tomam tempo $O(m \log \log n) \alpha(m \log \log n, n))$ que é igual a $O(m \log \log n)$.

Para grafos esparsos, o algoritmo acima é assintoticamente mais rápido que o algoritmo anterior. Como objeto de interesse teórico, este algoritmo pode ter seu tempo melhorado para $O\left(m \log \log _{(2+m / n)} n\right)$. Para isto, fazemos a "condensação" do grafo em intervalos apropriados, descartando do heap toda aresta com ambas as pontas em uma mesma árvore e toda, exceto aquela de menor peso, entre cada par de árvores diferentes. Com esta condensação, este algoritmo é assintoticamente mais rápido que os demais algoritmos descritos neste tabalho, para grafos de qualquer densidade.

\subsection{Algoritmo Prim}

Este algoritmo é uma espécie de "busca pelo menor peso" onde, a partir de um vértice inicial qualquer, o qual forma uma floresta $F$, o Algoritmo de Prim vai construir a FGM da seguinte forma: escolhe a aresta de menor peso pertencente ao corte $[F, \bar{F}]$. A seguir, a aresta escolhida e o vértice que está em $\bar{F}$ associado a esta aresta são adicionados a floresta $F$. Este passo é repetido até que se tenha $n$ vértices em $F$.

Como no Algoritmo de Borůvka, a corretude do Algoritmo de Prim está baseada na condição de otimalidade de um corte, pois a cada passo tomamos o corte $[F, \bar{F}]$ e a aresta de menor peso deste corte é adicionada a floresta geradora.

\subsubsection{Implementação para Grafos Densos}

Esta implementação, original de Prim [Pri57], pode ser vista como uma conseqüência direta da Condição de Otimalidade de um Corte - Teorema 1.4.1. Como vemos abaixo, este teorema nos leva a um algoritmo simples e eficiente. 

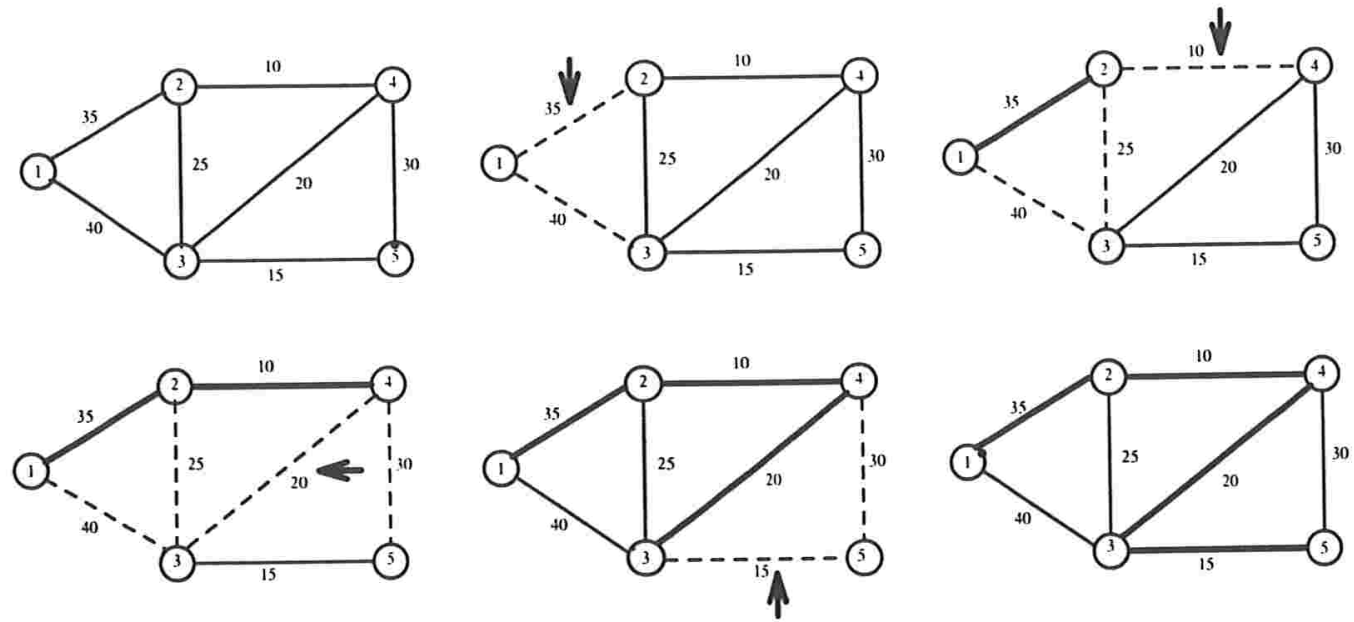

Figura 2.4: Ilustração da execução do Algoritmo de Prim

\section{Algoritmo DPrim}

Entrada : Grafo $G=(V, E)$ e a função peso $w$ em uma matriz $n \times n$.

Saída : Conjunto de arestas $T^{*}$ da FGM de $G$.

Passo 1 Seja $T=(U, A)$, onde $A=\emptyset$ e $U=\{1\}$.

Passo 2 Para cada nó $v \in V-U$ faça $\operatorname{Maisleve}(v)=1$.

Passo 3 Faça $M I N=\infty$;

3.1 Para cada $v \in V-U$ faça

Se $w(v$, Maisleve $(v))<M I N$ então

$M I N=w(v$, Maisleve $(v)) ; M E N O R=v$.

\{Encontra o nó em $V-U$ cuja aresta é a mais leve em $[T, \bar{T}]\}$

$3.2 U=U \cup\{M E N O R\}$;

$A=A \cup\{(M E N O R$, Maisleve $(M E N O R))\}$.

3.3 Se $w(v$, Maisleve $(v))>w(v, M E N O R)$ então

Maisleve $(v)=M E N O R$;

\{Atualiza o vetor Maisleve\}.

Passo 4 Caso $U \neq V$ volte ao Passo 3. Caso contrário, retorne $T$.

No sentido de facilitar a tarefa de encontrar a aresta de peso mínimo saindo de $U$, mantemos o vetor Maisleve. Para cada vértice de $v \in V-U$, Maisleve(v) é igual ao vértice de $U$ que tem a aresta mais leve ligada a $v$. Assim, para encontrar a aresta de peso mínimo deixando $U$, precisamos apenas encontrar a aresta mais leve dentre aquelas do tipo $(v$, Maisleve $(v))$, para $v \notin U$. Naturalmente, Maisleve deve ser atualizado cada vez que um nó é adicionado a $U$. Isto é feito pelo algoritmo no Passo 3.3. 
Teorema 2.2.1 Usando o Algoritmo de Prim, uma FGM pode ser encontrada em tempo $O\left(n^{2}\right)$.

O algorimo acima não pode ser melhorado se a entrada for uma matriz de adjacência $w$ de dimensão $n \times n$. A razão é que para encontrar a FGM devemos examinar cada entrada $w(i, j)$ da matriz pelo menos uma vez. Caso contrário, se a entrada $w(i, j)$ não for consultada pelo algoritmo, não podemos garantir se a aresta em questão deva ser ou não excluida da FGM. Por exemplo, poderíamos desconsiderar a aresta mais leve em $w$ e conseqüentemente não teríamos a FGM. Portanto, o algoritmo é assintoticamente ótimo para grafos densos.

\subsubsection{Implementação para Grafos Esparsos}

Para grafos esparsos, a principal dificuldade encontrada na implementação do Algoritmo de Prim é a identificação de uma aresta de peso mínimo no corte $[F, \bar{F}]$. No algoritmo abaixo mantemos dois vetores indexados pelos nós em $\bar{F}$ : (1) a distância $d(j)$, que representa o peso mínimo dentre as arestas que liga o nó $j$ a qualquer nó de $F$ (i.e, $d(j)=\min \{w(i, j):(i, j) \in[F, \bar{F}]\})$, e (2) $\operatorname{Pred}(j)$, que representa a outra extremidade da aresta de peso mínimo ligando $j$ a algum nó em $F$. Usamos, também, uma fila de prioridade do tipo heap para fazer a seleção da aresta de peso mínimo de $[F, \bar{F}]$. Este heap utiliza $d(i)$ como chave para cada vértice $i$.

Com estas estruturas de dados podemos facilmente encontrar o peso mínimo de uma aresta no corte. Simplesmente computamos $\min \{d(j): j \in \bar{F}\}$. Se o nó $i$ produz tal mínimo, $(\operatorname{Pred}(i), i)$ é a aresta de peso mínimo no corte.

$\mathrm{Na}$ descrição do Algoritmo de Prim a seguir, inicialmente, assumimos que $d(j)=\infty$ e $\operatorname{pred}(j)=0$ para $1 \leq j \leq n$.

\section{Algoritmo EPrim}

Entrada: Grafo $G=(V, E)$ e a função peso $w$.

Saída: Conjunto de arestas $F^{*}$ da FGM de $G$.

Passo 1 Construa um heap $H$ com os vértices de $G$. Faça $F^{*}=\emptyset$.

Passo 2 Extraia o mínimo de $H$. Seja $i$ tal nó. Faça $F^{*}=F^{*} \cup\{(\operatorname{Pred}(i), i)\}$.

Passo 3 Para cada nó $j \in H$ adjacente ao nó $i$ do Passo 2 , se $d(j)>w(i, j)$ faça as seguintes operações: $(1) d(j)=w(i, j),(2) \operatorname{Pred}(j)=i$ e (3) decremente a chave de $j$ em $H$ para $d(j)$.

Passo 4 Caso $H \neq \emptyset$ volte ao Passo 2. Caso contrário, retorne $F^{*}$. 
Para a complexidade assintótica deste algoritmo o heap de Fibonacci [CLR90, Cap. 21] é uma das melhores estrutura de dados conhecidas. Usando esta estrutura, o Passo 1 gasta tempo $O(n)$, cada operação extrai mínimo do Passo 2 toma tempo $O(\log n)$ e, como é executado $n$ vezes, gasta tempo total $O(n \log n)$. O Passo 3 é executado um vez para cada aresta e o tempo amortizado para cada operação de decremento é $O(1)$, totalizando, assim, este passo $O(m)$. Portanto, com o heap de Fibonacci temos o teorema abaixo.

Teorema 2.2.2 O Algoritmo de Prim pode ser executado em tempo $O(m+n \log n)$.

Como a constante desta complexidadade pode ser muito grande, na prática pode ser mais adequado usar outras estuturas de dados nas quais temos os tempos descritos na tabela abaixo.

\begin{tabular}{||l|l|l||}
\hline \hline Estrutura & Tempo & Referência \\
\hline \hline heap - bin & $O(m \log n)$ & [AMO93, Apêndice A] \\
\hline$d-$ heap & $O\left(m \log _{d} n\right), d=\max \{2, m / n\}$ & [AMO93, Apêndice A] \\
\hline heap - Fibonacci & $O(m+n \log n)$ & [CLR90, Cap. 21] \\
\hline
\end{tabular}

\subsection{Algoritmo de Kruskal}

O Algoritmo de Kruskal é a aplicação mais direta do Método Guloso. Ele verifica em ordem não decrescente de peso se uma dada aresta forma ciclo quando adicionada às anteriores. Se negativo, esta aresta é adiciona a $F^{*}$. Caso contrário, ela é descartada.

A forma mais eficiente de implementar a verificação de ciclo encontrada na literatura é usando operações sobre conjuntos disjuntos. O Algoritmo de Kruskal usando estas operações é dado abaixo.

\section{Algoritmo Kruskal}

Entrada : Grafo $G=(V, E)$ e a função peso $w$.

Saída : Conjunto de arestas $F^{*}$ da FGM de $G$.

Passo 1 Ordene $E$ e faça $F^{*}$ inicialmente vazio.

Passo 2 Crie $n$ conjuntos disjuntos, cada um contendo um nó de $V$.

Passo 3 Percorra o conjunto $E$ ordenadamente verificando para cada aresta $(u, v) \in E$ se os nós $u$ e $v$ pertencem a conjuntos disjuntos. Caso afirmativo, faça a união do conjunto que contém $u$ com o conjunto que contém $v$, e adicione $(u, v)$ a $F^{*}$. 

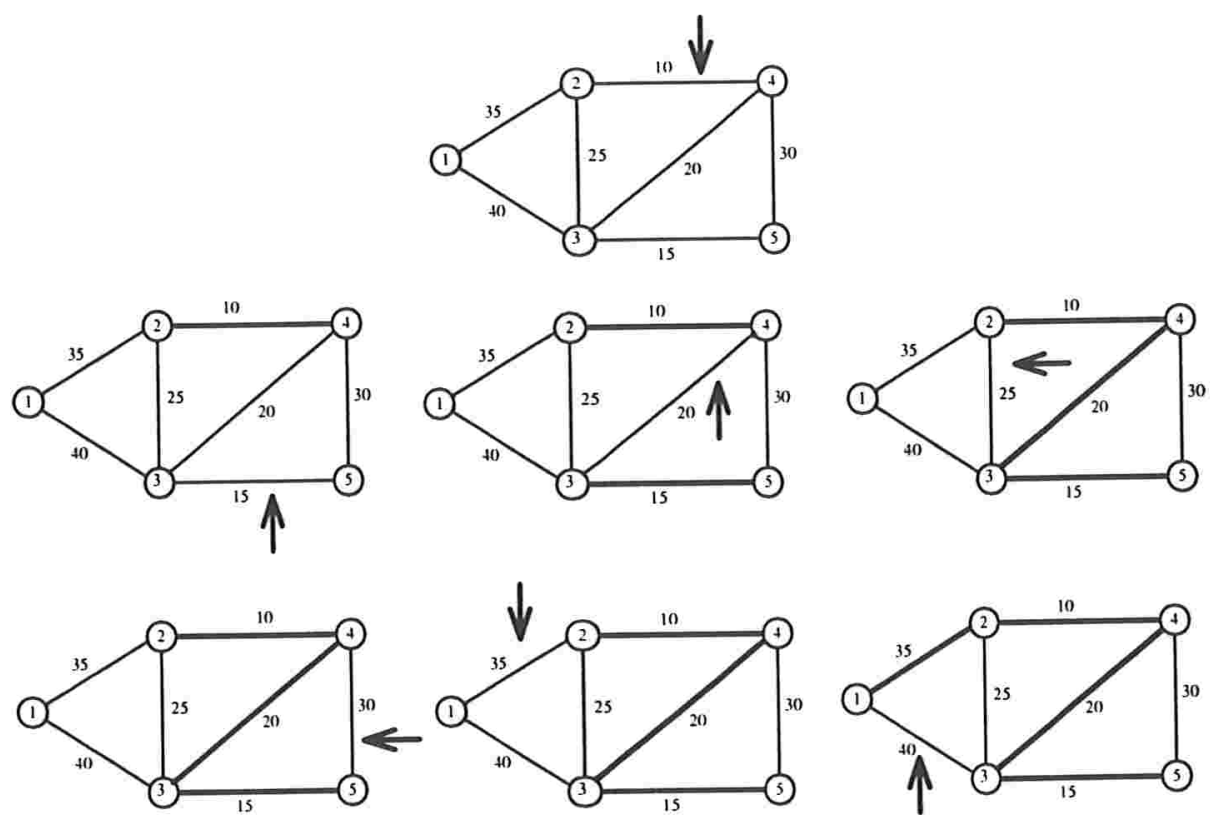

Figura 2.5: Execução do Algoritmo de Kruskal

A corretude do Algoritmo de Kruskal segue do fato que nós descartamos uma aresta $(u, v)$ quando ela forma ciclo com as arestas já selecionadas. Porém, o peso desta aresta $(u, v)$ é maior ou igual a qualquer outra aresta daquele ciclo, uma vez que as arestas são examinadas em ordem não decrescente de peso. Logo, pelo Teorema 1.2, todas as arestas selecionadas pertencem a FGM.

Teorema 2.3.1 O Algoritmo de Kruskal pode ser executado em tempo $O(m \log n)$.

Prova. A ordenação poder ser feita em tempo $O(m \log m)$. O Passo 2 gasta $O(n)$, pois são $n$ operações de MakeSet. Verificar a formação de ciclo, no Passo 3, pode ser executado usando a operação União, em tempo $O(m \alpha(m, n))$.

Note ainda que se a lista de arestas já se encontra ordenada, o Algoritmo de Kruskal tem complexidade de tempo $O(m \alpha(m, n))$, apresentando, assim, o melhor desempenho dentre todos os algoritmos anteriores.

\subsection{Algoritmo Probabilístico}

Nesta seção, apresentamos um algoritmo probabilístico para encontrar a FGM. Este algoritmo foi descrito por Karger et al [KKT95]. Ele roda em tempo $O(m)$ com alta 
probabilidade. Este algoritmo é uma modificação daquele proposto por Karger [Kar93], o qual obteve um limite de tempo de $O(n \log n+m)$.

Antes da descrição do algoritmo, vamos ver algumas definições necessárias para a compreensão do mesmo. Seja $G=(V, E)$ um grafo e $w$ uma função peso. Se $F$ é uma floresta de $G$, denotamos por $F(x, y)$ o caminho (se o mesmo existe) conectando $x$ a $y$ em $F$, e por $w_{F}(x, y)$ o maior peso de uma aresta em $F(x, y)$, sendo $w_{F}(x, y)=\infty$ se $x$ e $y$ não estão conectados em $F$. Dizemos que uma aresta $(x, y)$ é $F$-pesada se $w(x, y)>w_{F}(x, y)$ e $F$-leve caso contrário. Como conseqüência da Condição de Otimalidade de um Caminho - Teorema 1.4.2 - temos que as arestas em uma FGM de $G$ são todas $F$-leves.

O algoritmo intercala passos do algoritmo de Borůvka, chamado Passo de Boruikva, com passos de amostragens aleatórias. Cada Passo de Borủvka reduz o número de vértices a um fator de pelo menos dois, e cada passo de amostragem aleatória descarta arestas, reduzindo a densidade do grafo a um fator fixo com alta probabilidade. Este Passo de Borủvka é ligeiramente diferente daquele visto na Seção 2.1. Aqui ele é dado da seguinte forma:

Passo de Borůvka : Para cada vértice, selecione a aresta de peso mínimo incidente a ele. Contraia, sucessivamente, todas as arestas selecionadas removendo todos os vértices isolados e laços que, porventura, resultarem da contração. Para cada conjunto de arestas múltiplas de um mesmo par de nós, remova todas, exceto a de menor peso.

Note que cada vértice do grafo resultante acima, representa uma componente do grafo original. $\mathrm{O}$ algoritmo é dado da seguinte forma:

\section{Algoritmo de Karger}

Entrada: Grafo $G=(V, E)$ e a função peso $w$.

Saída: Conjunto de arestas $F^{*}$ da FGM de $G$.

Passo 1 Aplique dois Passos de Borůvka sucessivamente.

Passo 2 No grafo contraído escolha um subgrafo $H$, selecionando cada aresta independentemente com probabilidade $1 / 2$. Aplique o algoritmo recursivamente para $H$ produzindo uma floresta geradora mínima $F$ de $H$. Encontre todas as arestas $F$ pesadas em relação ao grafo contraído (estando ou não em $H$ ) e remova-as do grafo contraído.

Passo 3 Aplique o algoritmo recursivamente ao grafo resultante para computar uma floresta geradora $F^{*}$. Retorne as arestas de $F^{*}$ junto com as arestas contraídas no Passo 1. 
Vamos provar a corretude do algoritmo usando indução. Pela Condição de Otimalidade de um Corte - Teorema 1.4.1 - toda aresta contraída no Passo 1 está na FGM. Assim, as arestas restantes da FGM do grafo original formam uma FGM do grafo contraído. Restanos mostrar que a chamada recursiva do Passo 3 encontra a FGM do grafo contraído.

Pelo Teorema 1.4.2, as arestas removidas no Passo 2 não pertencem a FGM. Pela hipótese da indução, a FGM do grafo resultante é determinada corretamente na chamada recursiva do Passo 3.

No Passo 2, encontrar as arestas $F$-pesadas de $G$ pode ser computado em tempo linear no número de arestas usando uma adaptação do algoritmo de verificação de Dixon [DT93] ou de King [Kin95]. O limite de tempo linear do Algoritmo de Karger está fortemente baseado no lema sobre amostragem abaixo.

Lema 2.4.1 Seja $H$ um subgrafo obtido de $G$ pela inclusão de cada aresta independentemente com probabilidade p e seja F a FGM de $H$. O número esperado de arestas $F$-leves em $G$ é, no máximo, $n / p$.

Prova. Seja $G$ um grafo. Vamos descrever simultaneamente a construção do subgrafo amostral $H$ de $G$ e sua FGM $F$. A computação é uma variante do Algoritmo de Kruskal. Comece com $H$ e $F$ vazios. Processe as arestas em ordem crescente de peso. Para processar uma aresta $e$, primeiro teste se as duas pontas de $e$ estão na mesma componente de $F$. Caso afirmativo, a aresta $e$ é $F$-pesada, pois toda aresta em $F$ é mais leve que $e$. A seguir, jogue uma moeda que tem probabilidade $p$ de ocorrer cara. Inclua a aresta $e$ em $H$ se, e somente se, a moeda der cara. Finalmente, se $e$ está em $H$ e é $F$-leve, adicione $e$ à floresta $F$.

A floresta $F$ produzida desta forma é a floresta que seria produzida pelo Algoritmo de Kruskal aplicado às arestas do grafo $H$. Portanto, ela é exatamente a FGM de $H$. Como apenas adicionamos arestas à $F$, uma aresta que é $F$-pesada quando é processada, permanece $F$-pesada até o final da computação. Da mesma forma, uma aresta $F$-leve permanece $F$-leve, pois somente arestas mais pesadas que $e$ são adicionadas a $F$ após o processamento de $e$.

Vamos mostrar que o número de arestas $F$-leves é provavelmente pequeno. Quando processamos uma aresta $e$, sabemos se $e$ é $F$-pesada antes de jogar a moeda. Para efeito de análise, vamos desconsiderar se uma aresta $F$-pesada é, ou não, incluída em $H$. Desta forma, consideremos somente quando a aresta for $F$-leve. Para tais arestas, se a moeda der cara ela é colocada em $F$. O tamanho de $F$ é, no máximo, $n-1$. Assim, no máximo, $n-1$ moedas darão cara até o final da computação.

Agora, suponha que continuamos jogando moedas para arestas $F$-leves até que tenha ocorrido $n$ caras e seja $Y$ o número total de jogadas. Então, $Y$ é o limite superior do número de arestas $F$-leves. A expectativa de uma variável aleatória que tem uma distribuição 
binomial negativa com parâmetros $n$ e $p$ é $n / p$ [Fel68]. Segue que o número esperado de arestas $F$-leves é no máximo $n / p$.

Vamos fazer a análise do algoritmo. Considere uma única chamada do algoritmo. O tempo total dos Passos 1 a 3 , excluindo as chamadas recursivas, é linear no número de arestas: o Passo 1 é simplesmente dois Passos de Borủvka, o qual toma tempo linear; e o Passo 2 toma tempo linear usando uma modificação do algoritmo de Dixon [DT93]. O tempo total é assim limitado por um fator constante vezes o número total de arestas no problema original mais o número de arestas em todas as chamadas recursivas. Nosso objetivo é estimar este número total de arestas.

Apliquemos o algoritmo a um grafo. Como o grafo não contém vértices isolados, $m \geq n / 2$. Cada chamada do algoritmo gera, no máximo, dois subproblemas. Considere a árvore binária de execução. A raiz é o grafo original. Consideramos o filho esquerdo de um problema pai a chamada recursiva do Passo 2 e o filho direito a chamada recursiva do Passo 3. Na profundidade $d$, a árvore de execução tem, no máximo, $2^{d}$ nós, cada qual com um grafo de, no máximo, $n / 4^{d}$ vértices. Assim a profundidade da árvore é, no máximo, $\log _{4} n$.

Os dois teoremas seguintes mostram, respectivamente, o tempo de pior caso e o tempo esperado do algoritmo.

Teorema 2.4.2 O tempo de execução do pior caso do algoritmo é $O\left(\min \left\{n^{2}, m \log n\right\}\right)$.

Prova. Estimamos o número de arestas do pior caso de duas formas diferentes. Primeiro, como não há arestas múltiplas, um subproblema na profundidade $d$ contém, no máximo, $\left(n / 4^{d}\right)^{2} / 2$ arestas. Somando sobre todos os subproblemas teremos um limitante superior no número de arestas dados por:

$$
\sum_{d=0}^{\infty} 2^{d}\left(n / 4^{d}\right)^{2} / 2=\sum_{d=0}^{\infty} 2 n^{2} / 2^{3 d}=O\left(n^{2}\right) .
$$

Agora, considere os filhos esquerdo e direito de um mesmo problema pai. Suponha que o problema pai tem um grafo de $v$ vértices. Cada aresta no problema pai acaba em exatamente um dos filhos, com exceção das arestas na FGM $F$ do grafo amostral $H$, as quais acabam em ambos os subproblemas, e daquelas removidas no Passo 1, as quais não acabam em nenhum subproblema. Se $v^{\prime}$ é o número de vértices no grafo após o Passo 1 , então $F$ contém $v^{\prime}-1 \leq v / 4$ arestas. Uma vez que, pelo menos, $v / 2$ arestas são removidas no Passo 1, o número total de arestas nos dois subproblemas é, no máximo, o número de arestas do problema pai. 
Segue que, o número total de arestas em todos os subproblemas de qualquer profundidade $d$ é no máximo $m$. Como a altura da árvore é $O(\log n)$, o número total de arestas em todos os subproblemas é $O(m \log n)$.

Teorema 2.4.3 O algoritmo é executado em tempo $O(m)$ com probabilidade $1-e^{-\Omega(m)}$.

Prova. Primeiro, vamos mostrar que o tempo esperado é $O(m)$. Considere uma partição da árvore de recursão em caminhos esquerdos. Cada caminho consiste da raiz da árvore ou de um filho direito e todos os nós acessíveis a partir deste nó através de um filho esquerdo. Considere, também, um problema pai com um grafo de $X$ arestas e seja $Y$ o número de arestas de seu filho esquerdo. Uma vez que, cada aresta no problema pai ou é removida no Passo 1 , ou tem probabilidade $1 / 2$ de ser selecionada no Passo $2, E[Y \mid X] \leq X / 2$. Segue, pela linearidade da esperança, que o número de arestas esperado em um subproblema esquerdo é, no máximo, metade do número de arestas esperado em seu pai. Segue que, se o número de arestas esperado de um subproblema é $k$, então a soma dos números esperados de arestas em cada subproblema ao longo do caminho esquerdo descendente deste problema é, no máximo, $\sum_{i=0}^{\infty} k / 2^{i}=2 k$.

Assim, o número total de arestas esperado é limitado por $2 m$ mais o número total de arestas esperado em todos os subproblemas à direita. Pelo Lema 2.4.1, o número de arestas esperado de um subproblema à direita é, no maximo, duas vezes o número de vértices do problema pai. Uma vez que o número total de vértices de todos os subproblemas à direita é, no máximo, $\sum_{d=1}^{\infty} n 2^{d-1} / 4^{d}=\sum_{d=1}^{\infty} n / 2^{d+1}=n / 2$, o número esperado de arestas no problema original mais em todos os subproblemas é, no máximo, $2 m+n$.

Agora, vamos mostrar que o algoritmo roda em tempo linear com alta probabilidade. Para isto, inicialmente limitamos o número total de arestas em todos os subproblemas à direita.

Estas arestas são exatamente aquelas arestas $F$-leves encontradas no Passo 2 do problema pai. Lembrando da prova do Lema 2.4.1, vamos considerar os lançamentos de moedas correspondentes a estas arestas. Cada jogada que ocorrer cara corresponde a uma aresta da floresta geradora no subproblema à direita. O número total de arestas em todas estas florestas geradoras de todos os subproblemas à direita é, no máximo, o número de vértices destes subproblemas, o qual, por sua vez, é no máximo $n / 2$, conforme visto acima. Assim, $n / 2$ é um limite superior no número total de ocorrências de cara nestes lançamentos. A probabilidade de que haja mais que $3 m$ arestas $F$-leves é, no máximo, a probabilidade que haja menos que $n / 2$ ocorrências de cara em uma seqüência de $3 m$ jogadas. Pelo limite de Chernoff [AS92], esta probabilidade é $e^{-\Omega(m)}$, pois $m \geq n / 2$.

A seguir, consideramos as arestas nos subproblemas à esquerda. As arestas de um subproblema à esquerda são obtidas por amostragem. Isto é, uma moeda é lançada para cada aresta no problema pai não removida no Passo 1, e a aresta é copiada para o 
subproblema se ocorrer cara e não é copiada se ocorrer coroa. Vamos olhar por outro lado. L'ma aresta na raiz ou em um subproblema à direita dá origem a uma seqüência de cópias nos subproblemas à esquerda, cada cópia resultando de uma ocorrência de cara. A seqüência termina quando uma jogada der coroa. O número de ocorrências de coroa é, no máximo, o número de seqüências, a qual, por sua vez, é, no máximo, o número de arestas $m^{\prime}$ no problema raiz e em todos os subproblemas à direita. O número total de ocorrências de cara é, por sua vez, no máximo, o número total de jogadas. Assim, a probabilidade que este número exceda $3 m^{\prime}$ é a probabilidade que, no máximo $m^{\prime}$ coroas ocorra em uma sequiência de mais de $3 m^{\prime}$ jogadas. Como $m^{\prime} \geq m$, esta probabilidade é $e^{-\Omega(m)}$, pelo limite de Chernoff. Portanto, o número total de arestas é $O(m)$ com probabilidade $1-e^{-\Omega(m)}$. 


\section{Capítulo 3}

\section{Algoritmos Paralelos}

Após a descrição dos principais modelos de computação paralela, vamos apresentar neste capítulo alguns algoritmos paralelos para encontrar a FGM. Procuraremos aqui mostrar aqueles algoritmos que apresentam os melhores desempenhos dentro de seus respectivos modelos.

Como muitos modelos são fundamentalmente teóricos, a implementação se torna de suma importância na computação paralela, pois é esta quem vai identificar as deficiências de cada modelo e estabelecer novas perspectivas de pesquisa. Em virtude disto, em seguida estudaremos algumas implementações para o nosso problema.

\subsection{Computação Paralela}

A computação paralela tem como objetivo usar simultaneamente um conjunto de processadores interligados, de modo a resolver um problema conjuntamente mais rápido que a computação seqüencial usando somente um processador. As principais motivações da computação paralela são a busca de soluções cada vez mais rápidas e a necessidade de se resolver problemas com grande quantidade de informação, que aparecem em várias áreas tais como: previsão de tempo, processamento de imagens, inteligência artificial, modelagem e simulação de grandes sistemas, etc.

O modelo RA.M é um modelo conceitual sólido que incorpora as principais características da computação seqüencial. O modelo RAM consiste de uma unidade central de processamento e uma unidade de controle conectadas a uma memória de acesso aleatório. A grande vantagem deste modelo é sua capacidade de assimilar os impactos da tecnologia para computadores do tipo von Neumann. 
Na computação paralela, diferentemente da computação seqüencial, não temos um modelo de computação único amplamente aceito. Isto faz com que cada algoritmo só faça sentido ser analisado, em termos de complexidade de tempo e uso de recursos, dentro de seu modelo.

Devido ao desgaste maior de esforço para se resolver um problema causado por esta heterogeneidade, há algumas tentativas de se criar um modelo que sirva de paradigma único para toda a área, como veremos adiante. Estas tentativas, chamadas modelos realísticos, têm como principal objetivo produzir resultados universalmente eficientes. Ou seja, modelo simples em que o mapeamento de linguagens de alto nível para máquinas reais em uma grande variedade de contextos tenham pequena perda de eficiência. Este modelo buscaria dar suporte a projetos de máquinas de propósitos gerais, bem como a softwares portáteis.

\subsubsection{Noções de Otimalidade}

Trabalho é a quantidade total de operações realizadas por um dado algoritmo. O trabalho mede o esforço efetivamente realizado pelo algoritmo para resolver um problema. Um algoritmo paralelo é considerado ótimo, se o trabalho realizado por ele for assintoticamente equivalente ao tempo de pior caso do melhor algoritmo seqüencial conhecido para este problema. Se, além disso, um algoritmo paralelo ótimo possui o melhor desempenho de tempo dentre todos os possíveis algoritmos paralelos ótimos para o problema, então este algoritmo é ótimo no sentido forte.

Dado um problema qualquer, seja $T^{*}(n)$ o tempo do melhor algoritmo seqüencial para este problema, onde $n$ é o tamanho da entrada do problema. Seja $T_{p}(n)$ o tempo de um algoritmo paralelo para o problema usando $p$ processadores. O Speedup ou Ganho $S_{p}(n)$ de um algoritmo paralelo é definido pela seguinte fórmula:

$$
S_{p}(n)=\frac{T^{*}(n)}{T_{p}(n)}
$$

O Speedup mede o fator de ganho obtido pelo algoritmo paralelo quando comparado ao melhor algoritmo seqüencial para o problema. Como $S_{p}(n) \leq p$, gostaríamos de obter um algoritmo paralelo que produzisse $S_{p}(n)=\Theta(p)$. Dizemos, neste caso, que o algoritmo produz um Speedup Ótimo $\left(S_{p}(n)=\Theta(p)\right)$ sempre que $p=\Theta\left(T^{*}(n) / T_{p}(n)\right)$.

No modelo PRAM, que veremos em detalhes adiante, podemos definir uma classe de complexidade que nos permite estudar o potencial de paralelismo de um dado problema. Isto é, uma classe de problemas que são "satisfatoriamente" resolvidos por computadores paralelos. 
A classe de complexidade $\mathrm{NC}$ consiste de todos os problemas que podem ser solucionados por um algoritmo em tempo polilogarítmico no modelo PRAM utilizando um número polinomial de processadores. Esta classe de complexidade captura a nossa noção de problemas que possuem soluções paralelas satisfatórias.

Assim como a classe $\mathrm{P}$, classe de complexidade que consiste de todos os problemas que podem ser resolvidos em tempo polinomial por uma RAM, corresponde aos problemas cujas soluções são aceitáveis na computação seqüencial, a classe NC corresponde aos problemas cujas soluções paralelas são aceitáveis. Os algoritmos paralelos que descrevemos adiante demonstram que o Problema da FGM pertence a classe NC.

Granularidade é a medida da quantidade de computação realizada entre dois pontos de comunicação ou sincronização. Esta medida não está diretamente envolvida com a otimização de algoritmo paralelos, porém as tendências atuais de máquinas paralelas incentivam o uso de algoritmos com granularidade grossa, com o intuito de minimizar comunicação e aumentar a eficiência.

\subsection{Modelos de Computação Paralela}

Apresentamos nesta seção uma visão geral dos modelos de computação paralela. As duas primeiras subseções são baseadas nos livros de Jájá [Jáj92] e de Reif [Rei93] e a terceira é baseada em Maggs et al [MMT95]. Começamos com aqueles modelos mais intrinsecamente ligados às arquiteturas físicas da máquina, e por fim descrevemos brevemente os modelos mais voltados à descrição de algoritmos, buscando uma maior independência da máquina.

Um computador paralelo é uma coleção de processadores interligados com o objetivo de permitir a coordenação de suas atividades e a troca de informação entre si. Os processadores, localizados em uma mesma máquina, são usados para resolver conjuntamente um dado problema.

Os computadores paralelos podem ser classificados de acordo com suas características de arquitetura e modos de operação. Estes critérios incluem interconexão entre processadores e seus respectivos esquemas de comunicação, controle e sincronismo das operações, entre outros.

Um computador paralelo é sincrono se, a cada passo, todos os processadores executam uma instrução (não necessariamente idêntica) sob controle de um relógio comum. Caso isto não ocorra, ele é assíncrono.

No modo de operação assíncrono é responsabilidade do programador a inclusão de pontos de sincronização, quando necessários. Para isto, existem os mecanismos de sincro- 
nização que permitem estabelecer certos pontos de sincronismo entre os processadores. A barreira é um tipo de sincronismo que não inclui a troca de dados. O uso de chaves de travamento e troca de mensagem entre processadores são outros mecanismos de sincronização geralmente usados.

Um computador paralelo é SIMD - Simples Instrução em Múltiplos Dados - se todos os processadores executam sincronamente a mesma instrução usando, possivelmente, diferentes informações nesta instrução. Uma variação deste modelo é o SPMD - Mesmo Programa em Múltiplo Dados. O SPMD é um tipo de paralelismo assíncrono que permite a execução de diferentes instruções em uma mesma unidade de tempo. O SIMD possui apenas um contador de instruções enquanto o SPMD possui vários.

O MIMD - Múltiplas Instruções em Múltiplos Dados - é um computador paralelo onde os processadores podem executar diferentes programas simultaneamente. Cada processador armazena em sua memória local o seu próprio programa. Os computadores MIMD podem operar de forma síncrona ou assíncrona.

Os processadores podem se comunicar via uma memória global compartilhada onde todos os processadores têm acesso ou via uma rede de interconexão fixa. Os primeiros tipos são mais conhecidos como modelo de memória compartilhada e o segundo como modelo de memória distribuída.

\subsubsection{Modelo de Memória Compartilhada}

O modelo de memória compartilhada é uma extensão natural do modelo seqüencial. Mais precisamente, este modelo consiste de um número de processadores, cada um com uma memória local que pode executar seu próprio programa local, e toda comunicação é feita pela troca de informações através da memória global. Cada processador $P_{i}, 1 \leq i \leq n$, é unicamente identificado pelo seu índice.

O modelo PRAM - Máquina Paralela com Memória de Acesso Aleatório - é uma coleção de processadores síncronos executando em paralelo e se comunicando via memória compartilhada. Como cada processador pode executar seu próprio programa, o modelo PRAM é do tipo MIMD, isto é, cada processador pode executar uma instrução distinta daquela executada por qualquer outro processador, em uma mesma unidade de tempo. Para um dado algoritmo, a quantidade de informação transferida entre a memória local de cada processador e a memória global é a quantidade de comunicação usada pelo algoritmo.

Há algumas variações no modelo PRAM baseadas na forma como a manipulação de acesso concorrente é efetuado em uma mesma posição da memória global. O PRAMEREW - PRAM de Leitura e Escrita Exclusivas - não permite qualquer acesso concorrente a uma mesma posição de memória. O PRAM-CREW - PRAM de Leitura 
Concorrente e Escrita Exclusiva - permite o acesso concorrente a uma mesma posição de memória, mas não permite a alteração concorrente. O acesso para leitura e escrita concorrentes é permitida no modelo PRAM-CRCW - PRAM com Leitura e Escrita Concorrentes.

Neste último caso há a necessidade se estabelecer critérios para resolver o problema de escrita concorrente. Várias políticas podem ser adotadas para decidir qual dos processadores efetivamente efetuará a escrita. Numa destas políticas temos o PRAM-CRCW Comum que permite a escrita concorrente somente quando todos os processadores tentarem escrever o mesmo valor. O modelo PRAM-CRCW Arbitrário permite que algum processador arbitrário tenha sucesso na escrita. O modelo PRAM-CRCW Prioritário estabelece uma prioridade entre os processadores e aquele que tiver a maior prioridade é que terá sucesso na escrita.

O poder computacional do modelo PRAM-CRCW Prioritário é nitidamente maior que o dos demais e o modelo PRAM-EREW é, por sua vez, o mais fraco dentre todos. Apesar disso, não há uma diferença substancial entre estes modelos como podemos ver pelos teoremas abaixo.

Teorema 3.2.1 Uma instrução de leitura ou escrita concorrente da PRAM-CRCW Prioritária com p processadores pode ser implementada em uma PRAM-EREW com p processadores em tempo $O(\log p)$.

Teorema 3.2.2 Qualquer algoritmo sendo executado em uma PRAM-CRCW Prioritária com $p$ processadores em tempo $T$ pode ser simulado em uma PRAM-CRCW Comum com $O(p \log p)$ processadores em tempo $O(T)$.

O fato do modelo PRAM ignorar os custos associados à exploração do paralelismo incentiva o desenvolvimento de algoritmos paralelos, uma vez que pode-se extrair o máximo possível de paralelismo de um problema. Desta forma, o modelo fornece uma medida da complexidade de tempo paralelo ideal.

Os críticos do modelo não compartilham deste ponto de vista [Man79]. Para eles, sem associar um custo prático e razoável para o uso de um recurso, o modelo acaba por incentivar o uso excessivo deste recurso. Desta forma os aspectos de computação práticos escondidos distorcem o processo de desenvolvimento. Abaixo apresentamos amostras das variações do modelo PRAM com a tentativa de aproximá-lo das características de máquinas práticas. 
O acesso concorrente a memória com custo unitário é talvez o aspecto mais difícil de se atingir no modelo PRAM. Muitas variantes tentam restringir este acesso. O MPC [MV84] é uma variante do PRAM que divide a memória global em $d$ módulos. Somente um acesso à memória pode ocorrer em cada módulo em uma unidade de tempo. O LPRAM [ACS90] propõe adicionar ao PRAM-CREW uma memória local ilimitada para cada processador. O PRAM-QRQW [GMR94] fornece uma fila para gerenciar o acesso à memória, onde o custo de acesso é função do tamanho desta fila. Todos estes modelos tentam penalizar o uso abusivo de acesso concorrente.

Apesar do modelo PRAM assumir o modo síncrono, algumas de suas variantes permitem a execução assíncrona. O modelo APRAM - PRAM Assíncrona - estabelece um modo assíncrono com pontos de sincronização [CZ89]. Uma sincronização periódica entre intervalos assíncronos é também incorporada no XPRAM [Val90b]. Apesar de não alterar explicitamente o custo de comunicação, este modelos permitem reduzir o impacto da comunicação, uma vez que o processador não pára sua execução para esperar outro processador a cada passo.

Como se tornou claro que o custo de acesso à memória não-local tem um forte impacto no desempenho de computadores paralelos, vários modelos surgiram com a intenção de remediar estes problemas. O modelo LPRAM acima sugere que cada acesso à memória global teria um custo de $l$ unidades de tempo. Semelhantemente, o BPRAM [ACS89] atribui $l$ unidades de tempo para o primeiro acesso e um custo variante $b$ para cada acesso adicional a um bloco contíguo.

Uma outra variante, a qual assume duas classes de memória e inclui um custo nãounitário ao acesso remoto, é o DPRAM [LM88]. Este modelo elimina a memória global e introduz uma memória distribuída em uma topologia qualquer. Este modelo propõe uma função custo de acesso à memória não-local que é baseada no congestionamento máximo posssível para uma dada porção de dados e seqüência de execução. Este modelo incentiva o respeito ao acesso à memória não-local.

\subsubsection{Modelo de Memória Distribuída}

O modelo de memória distribuída, também chamado modelo de redes, é um conjunto de processadores onde a memória está distribuída entre os processadores e nenhuma memória global está disponível. Este modelo pode ser visto como um grafo $G=(V, E)$ onde cada $i \in V$ representa um processador e cada $(i, j) \in E$ representa uma linha de comunicação de mão dupla entre os processadores $i$ e $j$. Como no caso dos modelos de memória compartilhada, o modelo de memória distribuída pode operar nos modos síncronos ou assíncronos. 
No modelo de memória distribuída a comunicação é feita via troca de mensagem. A comunicação deve ser feita explicitamente quando necessária. Note que, neste caso, a troca de mensagem não é necessariamente entre processadores adjacentes. O processo de entrega de mensagem da origem para o destino é chamado roteamento.

A topologia de interconexão é incorporada pelo próprio modelo. Entre os vários parâmetros para analisar uma topologia podemos citar o diâmetro, que é a distância máxima entre quaisquer dois processadores, e o grau máximo de qualquer nó em $G$.

Devido à inviabilidade de acesso em tempo constante a uma memória global, muitas topologias têm sido extensivamente estudadas pela sua utilidade na computação paralela. Vamos descrever resumidamente as principais topologias usadas no modelo de memória distribuída: Vetor Linear e Anel, Malha, Árvore Binária e Hipercubo.

\section{Vetor Linear e Anel}

A topologia em Vetor Linear consiste de $p$ processadores $P_{1}, P_{2}, \ldots, P_{p}$ conectados em uma lista linear, ou seja, cada processador $P_{i}$ está conectado aos processadores $P_{i-1}$ e $P_{i+1}$ sempre que estes existirem. O diâmetro do Vetor Linear é $p-1$ e seu grau máximo é dois.

Um Anel é um Vetor Linear onde os processadores $P_{1}$ e $P_{p}$ estão ligados diretamente.

\section{Malha}

A topologia em Malha é uma versão bidimensional do Vetor Linear. Ela consiste de $p=l^{2}$ processadores conectados em uma grade $l \times l$, tal que, cada processador $P_{i, j}$ está ligado aos processadores $P_{i \pm 1, j}$ e $P_{i, j \pm 1}$ quando estes existirem.

$\mathrm{O}$ diâmetro de uma Malha com $p=l^{2}$ processadores é $2(\sqrt{p}-1)$. Os principais atrativos desta topologia são: simplicidade, regularidade e extensibilidade. Entretanto, muitas computações não-triviais necessitam de $\Omega(\sqrt{p})$ passos paralelos na malha, devido ao seu diâmetro.

\section{Árvore Binária}

Uma topologia em Árvore Binária consiste de $p=2^{d}-1$ processadores onde cada $P_{i}$ está conectado aos processadores $P_{2 i}$ e $P_{2 i+1}$ chamados filhos de $P_{i}$ e ao processador $P_{\lfloor i / 2\rfloor}$ chamado pai de $P_{i}$, sempre que estes existem. O diâmetro de uma Árvore Binária é $2(\lfloor\log p\rfloor-1)$ e seu grau máximo é três. 


\section{Hipercubo}

Uma topologia em Hipercubo consiste de $p=2^{d}$ processadores interligados em um cubo $d$-dimensional definido como segue. Seja $i_{d-1}, i_{d-2}, \ldots, i_{0}$ a representação binária de um inteiro $i$, onde $0 \leq i \leq p-1$. Então o processador $P_{i}$ está conectado aos processadores $P_{i^{(j)}}$, onde $i^{(j)}=i_{d-1}, \ldots, \overline{i_{j}}, \ldots, i_{0}$ e $\overline{i_{j}}=1-i_{j}$ para $0 \leq j \leq d-1$. Em outras palavras, dois processadores estão conectados se, e somente se, seus índices diferem em apenas um bit.

O Hipercubo possui uma estrutura recursiva. Podemos estender um cubo $d$-dimensional para um cubo $(d+1)$-dimensional através de uma conexão apropriada de dois cubos $d$ dimensionais. Um dos cubos terá o bit mais significativo igual a um e o outro terá este bit igual a zero. Uma nova conexão será efetivada entre os processadores correspondentes.

O diâmetro bem como o grau máximo de cada vértice de um hipercubo $d$-dimensional é $d=\log p$. O hipercubo é interessante por seu pequeno diâmetro, sua regularidade, dentre outras propriedades.

Os modelos de redes refletem as primeiras máquinas paralelas desenvolvidas. Estas máquinas tendiam a ter granularidade fina, composta por um número relativamente grande de pequemos processadores. O custo de acesso remoto é uma função da topologia e do roteamento. A função tende a ser variável e sem um custo inicial fixo para a comunicação. A comunicação entre vizinhos e a execução de uma instrução requerem custo unitário.

Com respeito aos atributos práticos, estes modelos introduzem uma importante discussão acerca do acesso a processadores não-adjacentes e sobre as funções de roteamento. Estes modelos atribuem ao programador a responsabilidade pela otimização da solução de um problema dentro da topologia. Ou seja, o programador faz uso das características da topologia com o intuito de otimizar a solução de um problema.

\subsubsection{Modelos Realísticos}

O modelo PRAM - extensão natural do modelo RAM - que poderia ser um padrão único para a computação paralela, não consegue capturar com exatidão a noção de paralelismo. As características não incorporadas ao modelo, tais como custo adicional para referência a memória não-local e latência, têm um grande impacto no desempenho dos algoritmos. Os modelos de redes, por sua vez, são felizes na solução da inviabilidade de acesso em tempo constante a uma memória global. Mas os algoritmos, por um lado, tendem a ser específicos para uma determinada topologia, perdendo assim generalidade. Por outro, a comunicação em tempo constante entre vizinhos não reflete a realidade dos computadores paralelos. 
Na computação seqüencial, o modelo RAM e as medidas através de análises assintóticas refletem o desempenho dos algoritmos seqüenciais e servem de referência para as implementações. Na computação paralela, entretanto, esta relação do desempenho dos algoritmos com o desempenho das respectivas implementações não encontrou ainda um modelo adequado.

A busca de um modelo adequado, ou modelos, necessita da compreensão e da incorporação em tal modelo de características intrínsecas à computação paralela, bem como de ignorar aquelas características secundárias superáveis através da tecnologia. Este modelo, embora difícil de ser atingido em um ambiente de aceleradas inovações tecnológicas, poderia ser alcançado através de um poderoso modelo de máquina abstrato. Este modelo precisaria, de certa forma, balancear simplicidade com precisão e abstração com praticidade. Maggs et al [MMT95] fornecem um bom panorama do estado da arte da computação paralela e sugerem algumas direções.

Apresentamos em seguida alguns modelos que buscam estabelecer padrões amplamente aceitos que reflitam as dificuldades inerentes do próprio paralelismo. Estes modelos são denominados Realísticos.

\section{Modelo BSP}

O modelo BSP (Bulk Synchronous Parallel) - Modelo Paralelo Síncrono Volumoso proposto por Valiant [Val90a], é um dos principais modelos realísticos. Foi um dos primeiros modelos a considerar os custos de comunicação como característica de um modelo de computação paralela. O objetivo principal deste modelo é servir de modelo ponte entre o desenvolvimento de algoritmos e o mundo do hardware. Segundo Valiant, este requisito é fundamental para um modelo que deseja desempenhar o mesmo papel do modelo RAM na computação seqüencial.

Uma máquina BSP consiste de $p$ processadores com memória local. Os processadores se comunicam através de algum meio de interconexão, gerenciados por um roteador e com facilidade de sincronização periódica global. O modelo possui os seguintes parâmetros:

- L: periodicidade é o tempo máximo de um superpasso.

- $g$ : descreve a taxa de eficiência de computação e comunicação, isto é, a razão entre o tempo de computação local e o tempo de transmissão ou recebimento de uma mensagem.

Um algoritmo BSP consiste de uma seqüência de superpassos. Em cada superpasso os processadores operam independentemente realizando computações locais e comunicações globais através de operações de envio e recebimento. Uma mensagem enviada é recebida no 
próximo superpasso. No final de um superpasso uma barreira de sincronização é realizada. O valor de $L$ pode ser controlado pelo algoritmo, ou mesmo em tempo de execução. Claramente o hardware fornece o limite inferior de $L$ e a granularidade de paralelismo do algoritmo fornece o seu limite superior.

O mecanismo de sincronização pode ser desativado de um subconjunto qualquer de processadores de modo que estes processadores não necessitam atrasar sua computação em função de outros. Contudo, eles continuam a poder trocar mensagens com qualquer outro processador.

Valiant discute ainda a simulação de algoritmos PRAM no modelo BSP. Esta simulação pode ser feita de forma ótima considerando uma folga suficiente nos processadores e o parâmetro $g$ como sendo constante. Porém, a simulação não é recomendada quando $g$ é grande. Infelizmente, esta é a maioria dos casos das máquinas paralelas atuais.

Uma extensão do modelo BSP, chamado BSP*, foi proposto por Bäumker et al[BDadH95]. Eles adicionaram aos parâmeros $p, L$ e $g$ um parâmetro $B$, que é o tamanho mínimo que uma mensagem pode ter, de modo a explorar completamente a largura de banda do roteador. As mensagens menores que $B$ são tratadas como sendo de tamanho $B$. Assim, o modelo gratifica a comunicação em bloco.

Isto se deve ao fato que o envio de grande mensagens são geralmente suportadas pelas máquinas atuais, e que o tempo de inicialização de uma mensagem geralmente contribui em grande parte para o custo de comunicação.

\section{Modelo CGM}

O modelo CGM (Coarse Granularity Multicomputer) - Multicomputador com Granularidade Grossa - foi proposto por Dehne et al [DFRC93]. Um CGM( $s, p)$ consiste de $p$ processadores $P_{1}, P_{2}, \ldots, P_{p}$, onde cada processador tem $O(s / p)$ memória local. Os processadores podem ser conectados através de um meio de intercomunicação qualquer, rede de interconexão ou memória compartilhada. A memória local é consideravelmente maior que $O(1)$, ex. $s / p \geq p$. Um algoritmo CGM consiste de computação local alternada com rodadas de comunicação global. Em uma rodada de comunicação uma única $h$-relação é roteada $(h=O(n / p))$. Isto é, cada processador envia e recebe $O(n / p)$ dados. O tempo de um algoritmo CGM é a soma dos tempos para rodadas de comunicação e de computação.

Comparado ao modelo BSP, uma rodada de comunicação/computação no modelo CGM é equivalente a um superpasso no modelo BSP com $h=g \cdot n / p$, mas incluindo também a exigência de empacotamento e granularidade grossa (aqui definida como memória local consideravelmente maior que $O(1))$. 


\section{Modelo LogP}

O modelo $\log \mathrm{P}\left[\mathrm{CKS}^{+}\right.$93] busca incorporar mais exatamente os atributos das máquinas existentes. Ele é resultado do esforço de diversos grupos de pesquisadores em áreas teóricas, de software e de hardware no sentido de se produzir um modelo único de computação paralela.

Os parâmetros do modelo são dados por:

- L: limite superior da latência, espera necessária para a comunicação de uma mensagem ir de sua origem ao seu destino.

- o: overhead, tempo que o processador fica comprometido na transmisssão e recepção de cada mensagem. Durante este tempo o processador permanece parado.

- $g$ : gap, intervalo de tempo mínimo entre a transmissão ou recepção de mensagens consecutivas em um processador.

- $p$ : O número de processadores e módulos de memória. O tempo é unitário para operações locais que é chamado de ciclo.

O modelo assume que a rede tem capacidade limitada, tal que, no máximo, $\lfloor L / g\rfloor$ mensagens possam estar em transição entre quaisquer dois processadores ao mesmo tempo. Se um processador tenta enviar uma mensagem que extrapole este limite, ele pára e espera até que a mensagem possa ser enviada.

Este modelo é semelhante ao BSP divergindo do mesmo em dois aspectos. O primeiro é a execução assíncrona. O parâmetro $L$ é usado como medida de latência das mensagens. O segundo é a introdução de um novo parâmetro $o$, que captura o tempo gasto por um processador para colocar ou receber uma mensagem da rede. Este parâmetro mede o tempo desperdiçado pelo processador que não pode ser medido através de técnica de latência escondida. Devido às variações na latência, as mensagens enviadas por um processador podem não chegar a um mesmo destino na mesma ordem que foram enviadas.

A escolha dos parâmetros representam um compromisso de capturar as características de máquinas reais e fornecer uma ferramenta razoável para projeto e análise de algoritmos. Os parâmetros não são igualmentes importantes em todas as situações. Em alguns casos é possível ignorar um ou mais parâmetros.

Em algoritmos que trocam poucos dados, por exemplo, pode-se ignorar a largura de banda e os limites de capacidade. Por outro lado, em algoritmos que enviam mensagens muito longas, estas mensagens podem ser quebradas em blocos pela rede, tal que o tempo de transmissão da mensagem é dominado pelos gaps inter-mensagens e a latência pode ser desconsiderada. Em algumas máquinas o overhead domina o gap, assim $g$ pode ser 
descartado. Apesar do avanço das arquiteturas paralelas, a possibilidade da eliminação do parâmetro $o$ parece ainda prematuro.

O modelo encoraja o escalonamento cuidadoso de computação e a sobreposição de computação e comunicação de acordo com os limites da capacidade da rede. Embora o modelo esteja descrito em termos de máquinas de memória distribuída, os algoritmos não necessitam explicitar operações de troca de mensagens. Algoritmos para memória compartilhada podem ser implementados no modelo através de troca implícita de mensagem.

Tanto o modelo LogP quanto o BSP discutem a possibilidade de introduzir nos algoritmos folgas paralelas. Ou seja, um algoritmo seria descrito para $v$ processadores virtuais e rodaria em $p$ processadores físicos, onde $v$ é maior que $p$. Esta folga permitiria ao compilador e ao hardware explorar eficientemente a computação.

Exemplificando, cada processador poderia ter mais de uma tarefa em execução. Caso uma tarefa fosse interrompida por uma espera de dados remotos, o processador seria usado por outra de suas tarefas. Esta técnica, no entanto, é limitada pela largura de banda (congestionamento de comunicação) e pela espera envolvida na mudança de contexto, que oneraria demasiadamente o Sistema Operacional.

\subsection{Algoritmo Paralelo para PRAM}

Nesta seção vamos descrever o algoritmo paralelo desenvolvido por Awerbuch e Shiloach [AS87] para o Problema da FGM. O mesmo roda no modelo PRAM CRCIV-Prioritário em tempo $O(\log n)$ usando $\max (m, n)$ processadores. Este algoritmo é uma modificação do algoritmo para componentes conexas dos mesmos autores apresentados em [Rei93, Cap.2]. Ele usa as técnicas bem conhecidas de hooking e shortcutting.

Uma árvore com raiz é uma árvore dirigida com um de seus vértices chamado raiz, que pode ser alcançado de qualquer outro vértice através de um caminho dirigido. Uma estrela é uma árvore com raiz de altura 1, onde altura é o número máximo de arestas em um caminho de um vértice até a raiz. Cada vértice $i \in V$ mantém a função $p(i)$, a qual indica o vértice que é o pai de $i$ na árvore com raiz. A raiz de uma tal árvore tem $p(i)=i$.

Neste algoritmo, cada processador $P_{i, j}$ é associado a uma aresta $(i, j)$ e o peso desta aresta é quem determina a prioridade de escrita. Quanto menor o peso da aresta maior a prioridade de escrita do processador. A forma da entrada não é crucial para o desempenho do algoritmo. Caso a entrada seja uma matriz de adjacência, teremos $n^{2}$ processadores lendo a matriz e aqueles que possuirem valor zero não trabalharão. Outros formatos de entrada também são aceitáveis. 
O algoritmo para encontrar a FGM desta seção é baseado na idéia do Algoritmo de Borủvka, que usa a característica local de uma FGM de que, para qualquer subconjunto de vértices, a aresta mais leve do corte induzido por este subconjunto de vértices pertence a FGM - Teorema 1.4.1.

Um conjunto de arestas $F$ é mantido pelo algoritmo. Tal conjunto é sempre uma subfloresta da FGM. Durante a execução a floresta $F$ crescerá até tornar-se ela própria a FGM. Uma floresta dirigida $F_{G}$ é usada como uma estrutura de dados auxiliar, onde para cada vértice $i \in V$ temos $p(i)$ indicando o pai do vértice $i$. A identidade de $p(i)$ pode mudar no transcorrer do algoritmo. Esta relação pai-filho forma a floresta dirigida $F_{G}$.

Em qualquer iteração do algoritmo, as componentes da floresta dirigida são idênticas às componentes de $F$, isto é, para cada árvore com raiz de $F_{G}$ existe uma árvore na floresta $F$, gerando exatamente o mesmo conjunto de vértices.

O algoritmo itera sobre três passos. O Passo 1 é aplicação da técnica de hooking. Todos os processadores que correspondam a arestas deixando uma estrela tentam se enganchar a alguma outra árvore com raiz. Entretanto, pelo modelo de computação usado, no caso de escrita concorrente, a maior prioridade é do processador que tiver a aresta de menor peso, portanto, vencerá apenas aquele processador que tiver esta aresta. Uma vez que esta aresta pertence a FGM, ela é adicionada à floresta $F$.

Como resultado deste passo, podem ser formados ciclos dirigidos no grafo $F_{G}$. Isto acontece se existir uma aresta com duas extremidades pertencentes a duas diferentes estrelas e ela é a mais leve saindo de ambas. Abaixo, mostraremos que estes ciclos têm comprimento dois. No Passo 2, eles são removidos pela retirada da aresta que tiver com sentido do menor para o maior vértice. Assim, o grafo $F_{G}$ é novamente uma floresta no início do Passo 3.

O Passo 3 faz a redução da altura das árvores de $F_{G}$ usando a técnica de shortcutting também conhecida como pointer jumping. Na descrição do algoritmo abaixo usamos: (1) um vetor lógico $F(i, j)$ para dizer se a aresta $(i, j)$ está, ou não na FGM, (2) O vetor $p(i)$ como a função respectiva definida acima e (3) um vetor de ponteiros $V E N C E(i)$ que aponta para a aresta vencedora da escrita concorrente entre os processadores da estrela com raiz $i$.

\section{Algoritmo FGM}

Entrada : Grafo $G=(V, E)$ e a função peso $w$.

Saída : Conjunto de arestas da FGM de $G$ no vetor $F$.

$$
\begin{gathered}
\text { Passo } 0 F(i, j)=0 ; \quad P(i)=i ; \\
\operatorname{VENCE}(i)=\text { Nulo; }
\end{gathered}
$$


Passo 1 Se $i$ pertence a uma estrela e $p(i) \neq p(j)$ então $p(p(i))=p(j) ; \operatorname{VENCE}(p(i))=(i, j)$;

Se $\operatorname{VENCE}(p(i))=(i, j)$ então $F(i, j)=1$;

Passo 2 Se $i<p(i)$ e $i=p(p(i))$ então $p(i)=i$

Passo 3 Se $i$ não pertence a uma estrela então $p(i)=p(p(i))$ senão PARE.

Passo 4 Enquanto houver processador ativo execute os Passos 1-3.

Para fazer a verificação se um vértice pertence ou não a uma estrela, nos Passos 1 e 3, observamos que um vértice não pertence a uma estrela se, e somente se, ele tem um avô não-trivial, ou ele tem um neto não-trivial, ou seu pai tem um neto não-trivial. Aqui, característica não-trivial é aquela que se mantém quando desconsideramos o laço existente na raiz da árvore. O procedimento é dado abaixo e claramente é executado em tempo constante. Este procedimento deve ser executado por todos os processadores antes de cada teste ser realmente efetivado.

\section{Procedimento Estrela}

Passo $1 \operatorname{Star}(v)=$ True

Passo 2 Se $p(v) \neq p(p(v))$ então $\operatorname{Star}(v)=$ False; $\operatorname{Star}(p(p(v)))=$ False

Passo 3 Se Não $\operatorname{Star}(p(v))$ então $\operatorname{Star}(v)=$ False

As provas da corretude do algoritmo bem como de sua complexidade de tempo estão baseadas no seguite lema.

Lema 3.3.1 Em cada passo do algoritmo

i) A floresta $F$ é um subconjunto da FGM.

ii) As componentes de $F_{G}$ são sempre idênticas às componentes de $F$.

iii) $F_{G}$ é uma floresta dirigida com exceção do ciclo de comprimento 2 existente somente entre os Passos 1 e 2.

\section{Prova.}

i) Inicialmente $F(i, j)=0$ para toda $(i, j) \in E$. Sempre que $F(i, j)$ é alterado para 1 , a aresta $(i, j)$ é a mais leve saindo do conjunto de vértices determinado pela estrela cuja raiz é $p(i)$. Assim a aresta $(i, j)$ pertence a FG.I. 
ii) Pode ser provado usando indução, pois sempre que duas componentes de $F_{G}$ são conectadas, as componentes correspondentes em $F$ também são.

iii) A expressão é válida inicialmente. A única forma de se produzir algum ciclo em $F_{G}$ é pelo fechamento de um ciclo entre as raízes das estrelas durante o Passo 1.

Pelo item $i i)$, as componentes de $F_{G}$ e $F$ são idênticas durante todo o algoritmo, e as componentes de $F$ correspondentes àquelas estrelas de $F_{G}$, também são fechadas em ciclos pelas arestas de $F$ respectivas. Se o ciclo tem comprimento 2, então este ciclo consiste de uma única aresta de $F$ e ele é aberto no Passo 2. No caso do ciclo ter comprimento maior, no entanto, ele corresponde a um ciclo na floresta $F$. Uma contradição com o item $i$ ).

Teorema 3.3.2 Quando o algoritmo termina, a floresta $F$ é uma FGM do grafo $G$.

Prova. É fácil de ver que no final do algoritmo as componentes de $G$ correspondem as componentes de $F_{G}$. Assim, pelo item $i$ ) acima, a floresta $F$ gera as componentes do grafo e pelo item $i$ ) ela é uma FGM.

Cada passo do algoritmo é executado em tempo constante no modelo PRAM-CRCWPrioritário, assim o número de iterações do laço determina o tempo de execução. Os lemas a seguir nos ajudarão a mostrar a complexidade de tempo do algoritmo.

Lema 3.3.3 Seja h a altura de uma árvore não-estrela antes do Passo 3. Após o Passo 3, sua altura é no máximo $2 h / 3$.

Prova. De fato a altura é reduzida à metade após o Passo 3. Podemos provar por indução que se $h$ for par a altura se reduz exatamente à metade, e se $h$ for ímpar, a altura após o Passo 3 será $(h+1) / 2$. O pior caso ocorre quando $h=3$. Neste caso a nova altura será 2 , a qual é $2 h / 3$.

Lema 3.3.4 Seja $C$ uma componente de $G$. Então a soma das alturas das árvores em $F_{G}$ que consistem de vértices de $C$ decresce por um fator de pelo menos $2 / 3$ a cada iteração, até estas árvores formarem uma estrela.

Prova. Considere C uma componente qualquer de $G$. Seja $h_{C}(t)$ a soma das alturas de todas as árvores de $\mathrm{C}$ no final da $t$-ésima iteração. Considere, agora, o que acontece às árvores de $\mathrm{C}$ durante a $t$-ésima iteração. Uma vez que uma árvore nunca é enganchada a 
uma folha na iteração, a altura da árvore resultante da operação hooking é, no máximo. a soma das árvores que foram enganchadas. Pelo Lema 3.3.3, depois do Passo 3 a altura é, no máximo, $2 / 3$ da anterior. Assim, a soma das alturas é, no máximo, $2 / 3$ da soma anterior. Ou seja. $h_{C}(t) \leq 2 h_{C}(t-1) / 3$, para $t \geq 1$.

Teorema 3.3.5 O algoritmo acima tem complexidade de tempo de $O(\log n)$ no modelo PRAM-CRCW Prioritário usando $\max (m, n)$ processadores.

Prova. Pelo Lema 3.3.4 temos

$$
h_{C}(t-1) \geq \frac{3}{2} h_{C}(t) .
$$

Iterando esta recorrência temos

$$
h_{C}(0) \geq(3 / 2)^{t} h_{C}(t) .
$$

Como há $n$ vértices em $G, h_{C}(t)<n$ para todo $\mathrm{C}$ e $t$, assim $h_{C}(0)<n$. Seja $T$ o número de iterações após os quais os vértices de $\mathrm{C}$ estão em uma estrela. Segue que $h_{C}(T)=1$. Assim

$$
n>h_{C}(0) \geq(3 / 2)^{T} h_{C}(T)=(3 / 2)^{T},
$$

ou seja,

$$
n>(3 / 2)^{T} .
$$

Portanto $T<\log _{3 / 2} n$.

Com apenas $m$ processadores atribuímos a cada processador duas arestas. Cada passo de hooking é executado duas vezes por cada processador, uma vez para cada aresta. Obviamente cada passo permanece com tempo constante.

Johnson e Metaxas [JM95] fornecem um algoritmo determinístico no modelo PRAM EREW com tempo $O\left(\log ^{3 / 2} n\right)$ usando $m+n$ processadores. Este algoritmo é baseado no algoritmo de componentes conexas descrito em [JM91]. A descrição do algoritmo é feita usando rotinas conhecidas como ordenação e list ranking.

A maior inovação deste algoritmo está na forma de extrair informações sobre as componentes. Ao invés de, explicitamente, encolher as componentes, como a maioria dos algoritmos paralelos para a FGM, o algoritmo mantém um subconjunto de arestas que contém todas as arestas que devem ser consideradas em alguma das fases do algoritmo. Este subconjunto controla o número de arestas candidatas a serem testadas promovendo. com isto, o bom desempenho do algoritmo. 


\subsection{Algoritmo Paralelo para a Malha}

Atallah e Kosaraju desenvolvem em [AK84] um algoritmo para encontrar a FGM de um grafo com $n$ vértices baseado no Algoritmo de Borüvka - Seção 2.1, que roda em $O(n)$ passos, em um modelo de computação com memória distribuída em uma malha $n \times n$. No modelo considerado há um único fluxo de instrução: em uma unidade de tempo a mesma instrução é espalhada por todos os processadores que, por sua vez, a executa e espera a proxima instrução. Sob este modelo, receber ou enviar uma palavra a um processador vizinho consiste em uma simples instrução da mesma forma que uma operação aritmética.

Apesar de muitos problemas em grafos serem resolvidos em $O(n)$ passos em uma malha $n \times n$, os problemas em grafos em que a solução seqüencial usa a técnica de busca em largura ou busca em profundidade, como é o caso do Algoritmo de Borủvka, não resultam diretamente em algoritmos paralelos de tempo $O(n)$. Assim, é necessário uma nova abordagem para o nosso problema.

Descrevemos abaixo os procedimento de movimentos de dados que serão usados na abordagem apresendada em seguida.

Rotação Horizontal: Cada processador cria uma cópia de seu conteúdo. Em seguida todas as cópias sofrem os seguintes movimentos: Cada linha move-se para o vizinho da esquerda (o elemento mais a esquerda salta para o vizinho da direita), a partir de então a cada novo salto, os dados que saltaram para a direita saltarão novamente para a direita. Este movimento é repetido até que o conteúdo que está no processador $P_{i, 1}$ chegue a $P_{i, n}$. Neste ponto, eles saltam de volta à esquerda até voltarem a sua posição inicial. Com este movimento em $O(n)$ passos todos os dados de $P_{i, j}, \quad i, j \leq n$, visitam todos os processadores da linha $i$.

Rotação Vertical: É similar à Rotação Horizontal, desta vez, os dados em cada $P_{i, j}, \quad i, j \leq n$, visitam todos os processadores da coluna $j$ em $O(n)$ passos.

Escrita com Acesso Aleatório: Alguns processadores $P_{i, j}$ contêm o endereço $\left(i^{\prime}, j^{\prime}\right)$ de outro processador $P_{i^{\prime}, j^{\prime}}$. Esta operação envia o conteúdo de cada um destes processadores $P_{i, j}$ para os seus correspondentes $P_{i^{\prime}, j^{\prime}}$ assumindo que quaisquer dois processadores não enviarão dados para o mesmo processador destino. Em [NS79] temos a implementação desta operação em $O(n)$ passos.

Escrita com Acesso Aleatório e com Conflito: Como a operação anterior, mas com a possibilidade dos processadores enviarem dados para o mesmo destino. Neste caso, somente o processador com maior prioridade é que terá sucesso na escrita. Esta operação, como a anterior, pode ser realizada em $O(n)$ passos [NS79].

Esta abordagem, baseada no Algoritmo de Borủvka, é combinada em estágios. Observe que depois de cada estágio $t$ podemos descartar as arestas de $G$ cujas pontas estão em uma mesma componente de $F$, e se houver mais de uma aresta de $G$ ligando duas componentes 
de $F$, precisamos manter somente aquela de menor peso. Podemos contrair em $G$ cada componente de $F$ em um único vértice. Esta contração cria laços e arestas múltiplas. Criamos um novo grafo $G_{t}$ a partir da contração de $\mathrm{G}$, da remoção de todos os laços gerados e da remoção dos conjuntos de arestas múltiplas, mantendo apenas a de menor peso. Devemos lembrar em cada contração qual aresta $\left(i^{\prime}, j^{\prime}\right)$ de $G$ cada aresta $(i, j)$ de $G_{t}$ representa. Podemos formular o algoritmo da seguinte forma:

\section{Algoritmo Malha}

Entrada: Grafo $G=(V, E)$ e a função peso $w$.

Saída : Conjunto de arestas da FGM de $G$.

Passo 1 Para cada $v \in G_{t-1}$ escolha a aresta mais leve $(v, x)$ que é incidente a ele em $G_{t-1}$. Seja $H_{t}$ o conjunto de arestas escolhidas.

Passo 2 Adicione a $F$ as arestas de $G$ representadas pelas arestas de $H_{t}$.

Passo 3 Transforme $G_{t-1}$ em $G_{t}$ da seguinte forma: Contraia todos os vértices de $G_{t-1}$ que estão em uma mesma componente de $H_{t}$ no menor vértice da componente. Remova todos os laços e mantenha apenas a arestas de menor peso para cada conjunto de arestas múltiplas. Chame o grafo resultante de $G_{t}$.

Passo 4 Repita os Passos 1-3 enquanto houver aresta em $G_{t}$.

Como no início do estágio $t$ o número de vértices $G_{t-1}$ é igual ao número de componentes de $F$, se cada componente de $G_{t}$ tem $l_{i}$ vértices, então $l \leq n / 2^{t-1}$, onde $l=\sum l_{i}$. Podemos encolher a matriz de adjacência de $G_{t-1}$ em uma submatriz $l^{\prime} \times l^{\prime}$ de processadores onde $l^{\prime} \leq l / 2$. Se pudermos realizar o $t$-ésimo estágio em $O(l)$ passos, o algoritmo rodará em $\sum_{t=1}^{\log n} O\left(n / 2^{t-1}\right)=O(n)$ passos. Portanto, é suficiente mostrar que cada estágio pode ser feito em $O(l)$ passos.

No começo de estágio $t$, a matriz de adjacência de $G_{t-1}$ está nos $l \times l$ processadores do canto superior esquerdo da malha. Se $G_{t-1}(i, j)=1$, então $P_{i, j}$ contém a aresta $\left(i^{\prime}, j^{\prime}\right)$ de $G$ que a aresta $(i, j)$ de $G_{t-1}$ representa, bem como o peso $w(i, j)=w\left(i^{\prime}, j^{\prime}\right)$. Além disso, as arestas de $F$ escolhidas antes do estágio $t$ estão em pares especiais $(x, y)$ fora da malha $l \times l$. Quando o estágio $t$ termina, a matriz de adjacência deve estar nos $l^{\prime} \times l^{\prime}, l \leq l^{\prime} / 2$, processadores do canto superior esquerdo da malha e os pares especiais são armazenados fora da malha $l^{\prime} \times l^{\prime}$ e dentro da malha $l \times l$. Depois do último estágio a FGM pode ser obtida com duas Escritas com Acessos Aleatórios, em cada um dos quais $P_{i, j}$ contendo o par especial $(x, y)$ envia a informação para $P_{x, y}$.

O estágio $t$ é iniciado com uma Rotação Horizontal aplicada aos $l \times l$ processadores do canto superior esquerdo. Nesta rotação $P_{i, i}(i \leq l)$ escolhe a menor aresta $(i, x)$ de $G_{t-1}$. Com outra Rotação Horizontal seguida de uma Rotação Vertical $P_{i, i}$ envia a $P_{i, x}$ e a $P_{x, i}$ 
que $H_{t}(i, x)=1$ e $H_{t}(x, i)=1$ respectivamente. A seguir cada $P_{i, j} \operatorname{com} H_{t}(i, j)=1$ cria o par especial $\left(i^{\prime}, j^{\prime}\right)$ e retira-os da malha de $l / 2 \times l / 2$ processadores. Isto pode ser feito em $l / 2$ passos movendo o par do processador $P_{x, y}$ para o processador $P_{x+l / 2, y}$.

A matriz de adjacência de $G_{t}$ é criada da seguinte forma: compute o fecho transitivo de $H_{t}$ em $\mathrm{O}(\mathrm{n})$ passos usando o algoritmo de [Sco80]. Em seguida, com uma Rotação Horizontal cada $P_{i, i}$ calcula $C(i)=$ menor vértice da componente $H_{t}$ que contém o vértice $i$. Então, cada $P_{i, i}$ envia $C(i)$ para todos os processadores da linha $i$ e da coluna $i$ através de uma Rotação Horizontal e outra Vertical. Agora cada $P_{i, j}, i, j \leq l$, que contém $C(i)$ e $C(j)$ e no qual $G_{t-1}(i, j)=1$ e $C(i) \neq C(j)$, envia uma mensagem para $P_{C(i), C(j)}$ que $G_{t}(C(i), C(j))=1$ e que $(C(i), C(j))$ representa a aresta $\left(i^{\prime}, j^{\prime}\right)$ de peso $w\left(i^{\prime}, j^{\prime}\right)$. Em seguida $P_{i, j}$ remove todas as informações sobre $G_{t-1}$. Como muitos processadores podem enviar mensagens para o mesmo destino, a Escrita de Acesso Aleatório com Conflito permite que apenas o processador que enviar a menor tripla $\left(w\left(i^{\prime}, j^{\prime}\right), i^{\prime}, j^{\prime}\right)$ terá sucesso na escrita. Depois desta operação a matriz de adjacência de $G_{t}$ está armazenada nos $l \times l$ processadores do canto superior esquerdo.

Mas $G_{t}$ tem $l^{\prime} \leq l / 2$ vértices e devemos então comprimir sua matriz de adjacência na malha $l^{\prime} \times l^{\prime}$. Isto é feito da seguinte forma:

(i) Com uma Rotação Horizontal cada $P_{i, i}$ para o qual $C(i)=i$ determina o Rank do vértice $i$ em $G_{t}$. Isto é $r(i)=\mid\{k \mid C(k)=k$ e $k \leq i\} \mid$.

(ii) Com uma Rotação Horizontal e uma Rotação Vertical $P_{i, i} \operatorname{com} C(i)=i$ envia $r(i)$ para toda a linha $i$ e toda a coluna $i$.

(iii) Cada $P_{i, j}$ para o qual $G_{t}(i, j)=1$ envia com Escrita de Acesso Aleatório a mensagem para $P_{r(i), r(j)}$ que $G_{t}(r(i), r(j))=1$ e que $(r(i), r(j))$ representa a aresta $\left(i^{\prime}, j^{\prime}\right)$ de peso $w\left(i^{\prime}, j^{\prime}\right)$ removendo todas as informações de $G_{t}$ sobre $(i, j)$.

Assim, $G_{t}$ está localizada nos $l^{\prime} \times l^{\prime}$ processadores do canto superior esquerdo da malha após estas operações. Como cada estágio pode ser implementado em $O(l)$ passos como descrevemos, pelos argumentos anteriores temos que o algortimo roda em $O(n)$ passos.

Heide [adH89] descreve os limitantes inferior e superior do problema da FGM em uma malha $l \times l, \sqrt{n} \leq l \leq n$. Neste modelo é calculado apenas as rodadas de comunicação, pois, segundo os autores, isto parece capturar o paralelismo inerente à computação do problema.

São apresentadas duas formas de entradas para as quais a computação necessita número de rodadas de computação diferentes. Na convenção $\mathrm{A}$, a malha $l \times l$ é particionada em $n$ malhas $l^{\prime} \times l^{\prime}, l^{\prime}=l / \sqrt{n}$, cada uma das quais guarda uma lista de adjacência de vértice. $\mathrm{Na}$ convenção B, a matriz de adjacência é particionada em $l^{2}$ submatrizes de tamanho $n / l \times n / l$. Cada processador é associado a submatriz respectiva. 
A convenção B mostra-se mais rápida que a convenção $\mathrm{A}$. Os limites inferiores para as duas convenções são:

- O número de rodadas necessárias por uma malha $l \times l, \sqrt{n} \leq l \leq n$, para computar a FGM de uma grafo de $n$ nós dado pela convenção $\mathrm{B}$ é $\Omega(l)$. Isto é justo, a menos de um fator logarítmico.

- Para a convenção $\mathrm{A}$, o número de rodadas é $\Omega\left(n^{3 / 2} / l+l\right)$. Isto é justo, a menos de um fator logarítmico.

Para a convenção A devemos notar que o número de rodadas de comunicação é $\Omega(n)$, para $l=\sqrt{n}$ e $l=n$, e tem seu mínimo $\Omega\left(n^{3 / 4}\right)$, para $l=n^{3 / 4}$.

\subsection{Algoritmo Probabilístico Paralelo}

Este algoritmo, descrito por Cole et al [CKT94], é baseado no algoritmo probabilístico seqüencial de tempo linear que foi desenvolvido por Karger et al, apresentado na Seção 2.4. O modelo de computação considerado aqui é o PRAM-CRCW Arbitrário.

A principal dificuldade de se obter um algoritmo paralelo rápido, partindo do algoritmo seqüencial de Karger, está na amostragem probabilística associada a cada nível da recursão. A saída da primeira chamada é usada como entrada para a segunda chamada recursiva. Esta dependência de dados impõe uma característica seqüencial no processo.

Para reduzirmos a profundidade da árvore de recursão, temos que garantir que a soma dos tamanhos de todos os grafos (na recursão) decresça muito mais que geometricamente. Ao invés de executarmos um Passo de Borůvka, vamos aqui executar um número de passos de contração, reduzindo o número de vértices por um fator bem maior. O número de passos de contração vai depender da profundidade da recursão. Quanto maior a profundidade maior será o número de passos.

O procedimento Contract $(G, k)$ vai contrair arestas da FGM em quantidade suficiente, de modo que o grafo resultante tenha o número de vértices não-isolados, no máximo, $1 / k$ vezes o número de vértices de $\mathrm{G}$. Este procedimento tem tempo de execução esperado $O(\log m)$ e trabalho $O(m \log k)$. O passo de eliminar as arestas $F$-pesadas pode ser executado usando o Algoritmo de Dixon e et al [DT93] que roda em tempo $O(\log n) \operatorname{com}$ $(m+n) / \log n$ processadores.

Vamos definir algumas recorrências, que serão usadas pelo algoritmo, expressando os parâmetros em termos da profundidade $d$ da recursão. O primeiro, $r(d)$, reflete a probabilidade da amostragem, o segundo, $s(d)$, reflete a soma dos tamanhos de todos os grafos na profundidade $d$, e finalmente, $w(d)$, controla a quantidade de trabalho feito pelo procedimento Contract. 


$$
\begin{aligned}
& r(0)=2^{2}, \quad r(d+1)=2^{r(d)} \\
& s(0)=1, \quad s(d+1)=s(d) \cdot r(d) / 4 \\
& w(d)=32 s(d) 2^{-d}
\end{aligned}
$$

Denotaremos por $G_{d}$ um grafo da profundidade $d$, e por $m_{d}$ o seu número de arestas. Assim, o grafo de entrada do algoritmo é denotado por $G_{0}$ e a primeira chamada é feita por $M S F\left(G_{0}, 0\right)$. A constante $c$ é relacionada com a profundidade esperada da árvore de recursão. $\mathrm{O}$ algoritmo assume que $G_{0}$ não tem vértices isolados.

\section{Algoritmo CKT(G,d)}

Entrada: Grafo $G$ e sua profundidade $d$.

Saída: Conjunto de arestas da FGM de $G_{0}$.

Passo 1 Se $|E(G)|<c m_{0} / \log m_{0} \log \log m_{0}$ então Chame $\operatorname{Contract}(G, n)$ e retorne as arestas contraídas. Caso contrário continue.

Passo 2 Seja $G^{\prime}$ o resultado de $\operatorname{Contract}\left(G, 2^{w(d)}\right)$.

Passo 3 Seja $H$ um grafo obtido de $G$ por amostragem de arestas com probabilidade $p=1 / r(d)$ e então remova os vértices isolados.

Passo 4 Recursivamente chame $\operatorname{MSF}(H, d+1)$, obtendo uma floresta $F$.

Passo 5 Seja $G^{\prime \prime}$ o grafo obtido de $G^{\prime}$ por descartar as arestas $F$-pesadas e então remova os vértices isolados.

Passo 6 Recursivamente chame $\operatorname{MSF}\left(G^{\prime \prime}, d+1\right)$.

Passo 7 Retorne as arestas da árvore encontrada pela chamada recursiva no Passo 6 junto com as arestas contraídas no Passo 2.

A corretude do algoritmo segue da corretude do procedimento Contract e do fato que as arestas $F$-pesadas não pertencem a FGM.

Vamos computar o tempo esperado do algoritmo. O tempo por chamada (não incluindo as chamadas recursivas) é dominado pelos Passos 1, 2 e 5 . O Passo 5 pode ser executado em tempo $O(\log n)$ usando o algoritmo de trabalho linear de Dixon e Tarjan [DT93]. O tempo esperado do procedimento Contract é, no máximo, logarítmico no tamanho do grafo. Podemos garantir que, com probabilidade $1-e^{-\Omega\left(\sqrt{m}_{0}\right)}$ há, no máximo, $2^{\log ^{*} m}$ chamadas [CKT94]. Portanto, o tempo total do algoritmo é $O\left(2^{\log ^{*} m} \log m\right)$.

O trabalho esperado do algoritmo será analisado em duas etapas. Primeiro, limitaremos o trabalho realizado no Passo 1 para chamadas com valores de $m_{d}$ pequenos. Como no Passo 1 o procedimento Contract só é chamado se $m_{d} \leq m / \log m \log \log m$, podemos 
limitar o trabalho por $O(\mathrm{~m} / \log \log m)$. para cada chamada. Com alta probabilidade há, no máximo, $2^{\log ^{*} m}$ chamadas [CKT94]. Assim o trabalho total realizado pelo Passo 1 é $O(m)$

Para chamadas com grandes valores de $m_{d}$, considere a chamada de $\operatorname{MSF}(G, d)$ na profundidade $d$. Para cada passo não recursivo do algoritmo, exceto no Passo 2, o algoritmo é linear em $m$. O trabalho no Passo 2 é $O\left(m_{d} w(d)\right)$. Somando sobre todas as chamadas temos que $\sum_{d} m_{d} w(d) \leq \sum_{d} 32 m_{d} 2^{-d}=O(m)$.

\section{O procedimento Contract}

O procedimento de contração é realizado em fases. Em cada fase para alguns vértices aleatórios, as arestas mais leves saindo das componentes representadas por este vértices são determinadas probabilisticamente. Para realizar a contração em cada fase representamos as componentes que vão sendo formadas através da estrutura de dados de árvore com raiz como na Seção 3.3 - Algoritmo para PRAM.

Cada processador é associado a uma aresta ou a um vértice. Diferente do Algoritmo da Seção 3.3. Este procedimento mantém a invariante que, no início de cada fase, cada árvore é uma estrela. Uma estrela aceitável é aquela que contém um nó com uma aresta incidente cuja outra extremidade pertence a outra estrela. Depois da última fase, cada estrela é contraída em um único vértice através da contração de aresta. O número de nós não-isolados depois da contração é o número de estrelas aceitáveis. Desta forma, o procedimento itera até que o número de estrelas aceitáveis seja no máximo $1 / k$ vezes o número de vértices de $G$.

\section{Procedimento Contract $(\mathrm{G}, \mathrm{k})$}

Entrada: $O$ grafo $G$ e o valor de redução $k$.

Saída: O grafo contraído pelo menos $n / k$ vezes.

Passo 1 Para Cada $v \in V$ faça $p(v)=v$

Passo 2 Repita $\log _{c} k$ vezes

2.1 Para cada estrela sorteie aleatoriamente cara ou coroa.

2.2 Para algumas estrelas $S$

2.2.1 Escolha a aresta mais leve $(u, v)$ ligando o nó $u \in S$ ao nó $v \notin S$

2.2.2 Caso $S$ seja cara e a outra estrela coroa, faça $p(p(u))=p(v)$, e guarde $(u, v)$ como aresta contraída.

2.3 Para cada nó $v$ faça $p(p(v))=p(v)$ 
Passo 3 Se o número de estrelas aceitáveis for maior que $n / k$ volte ao Passo 2. Caso contrário contraia cada estrela em um único vértice e pare.

O Passo 2.2.1 seleciona a aresta mais leve incidente a uma estrela aceitável baseado em um método probabilístico. Este método seleciona a aresta mais leve para uma proporção suficientemente grande de estrelas aceitáveis, como garante o Lema 3.5.1. Com este lema e o limite de Chernoff é possível demonstrar usando indução no número de iterações, que o algoritmo mantém a seguinte invariante:

Depois de $i$ iterações, o número de arestas aceitáveis é, no máximo, $n / c^{i}$ com probabilidade $1-e^{-\Omega\left(n / c^{i}\right)}$, onde c é uma constante determinada pela análise.

O número de iterações igual a $\log _{c} k$ garante que no fim da primeira fase, o número de estrelas aceitáveis restante é, no máximo, $n / k$ com probabilidade $1-e^{-\Omega(1)}$. Como a probabilidade de sucesso é $1-e^{-\Omega(1)}$, o número esperado de fases é constante.

\section{O método de seleção de arestas}

Pela invariante temos que, depois de $i$ iterações o número de estrelas aceitáveis é, no máximo, $n / c^{i}$. Seja $s=n / c^{i}$ e seja $m$ o número de arestas na iteração seguinte a iteração $i$. O procedimento é descrito abaixo.

Passo 1 Algumas estrelas são alocadas em, no máximo, $c_{2} s$ blocos de memória de tamanho $c_{1} m / s$ da seguinte forma: Atribua inteiros distintos entre 1 e $c_{2} s$ para as estrelas e aloque um vetor auxiliar de tamanho $c_{2} s$. Cada estrela, aleatoriamente, escolhe um destes inteiros e tenta escrever o número do vértice de sua raiz nesta posição do vetor. Em seguida, cada estrela lê a mesma posição e verifica se teve sucesso na escrita. Cada estrela que teve sucesso tem um inteiro que representa um índice de um bloco de memória. Por fim, todas as posições dos blocos são inicializadas com valor infinito. As estrelas que não tiveram sucesso ficam inativas no restante do procedimento.

Passo 2 Para cada estrela alocada em um bloco de memória, cada uma das arestas incidentes a ela tenta escrever seu custo em uma posição aleatória daquele bloco.

Passo 3 Compute a aresta de custo mínimo de cada bloco usando o algoritmo de Meggido [Meg82].

Passo 4 Para cada estrela, as arestas incidentes verificam se o mínimo computado é de fato a arestas de custo mínimo daquela estrela. Se negativo ela é marcada como inválida.

O primeiro passo pode ser executado em tempo constante usando um processador por estrela. O segundo e o quarto têm tempo de execução constante com um processador 
por aresta. O Algoritmo de Meggido tem tempo esperado contante. Podemos escolher esta contante de tempo para garantir que ele termine com sucesso com probabilidade de uma constante $c_{3}$, pelo menos. Assim, podemos executar o terceiro passo com $c_{1} m$ processadores por blocos e portanto com um número total de $O(m)$ processadores.

Lema 3.5.1 Suponha que o número de arestas aceitáveis é, no máximo, s. Então, com probabilidade, pelo menos, $1-e^{-\Omega(s)}$ há, no máximo, (4/5)s estrelas aceitáveis cuja aresta incidente mínima não é determinada.

\subsection{Implementações Paralelas}

Barr et al [BHK89] fazem implementações para testar empiricamente algoritmos paralelos para encontrar a FGM. A máquina usada foi a Symmetry S81 de memória compartilhada da Sequent Computer Systems que contém doze processadores. Estas implementações são feitas a partir de três versões seqüenciais do Algoritmo de Prim, uma versão do Algoritmo de Kruskal e uma versão de Algoritmo de Borủvka.

Os testes das implementações seqüenciais foram realizados em grafos gerados aleatoriamente com o número de vértices variando entre 200 e 1200 e densidade entre 0,5 e $100 \%$. Estes testes apontaram o Algortimo de Prim como o de melhor de desempenho para grafos completos. Para grafos de baixa densidade (densidade entre 0,5 e $2 \%$ ) o Algoritmo de Borủvka apresentou o melhor desempenho. O Algoritmo de Kruskal apresentou a maior robustez dentre todos, obteve a melhor performance nos grafos intermediários (densidade entre 5 e $80 \%$ ). Nenhum dos códigos foi sensível a variação de pesos das arestas.

A implementação do Algoritmo de Kruskal usou uma modificação do Algoritmo Quicksort. Apesar da robustez do Algoritmo de Kruskal, o Quicksort é difícil de paralelizar. Desta forma, os códigos paralelizados foram o Algoritmo de Prim para grafos densos e o Algoritmo de Borủvka para grafos esparsos. Aqui, o número de processadores variou entre 1 e 10 e o speedup foi sempre crescente como número de processadores.

Já os testes das implementações paralelas para grafos densos contou com dois grafos aleatórios com $|V|=900$ e $|E|=404000$. Para o primeiro grafo o Algorimo de Prim teve o melhor speedup de 2,79 alcançado com 10 processadores e para o segundo grafo o melhor speedup foi de 4,79 também com 10 processadores. Para testar o Algoritmo de Borủvka foram usados dois grafos esparsos em forma de grade com dimensões de $350 \times 350$ sendo $|V|=122500$ e $|E|=244300$. Com o primeiro grafo o algoritmo obteve um speedup de 5,89 e no segundo de 6,81 , ambos com 10 processadores.

Chung e Condon [CC96] estudam a implementação da FGM, baseada no Algoritmo de Borúvka, para um modelo de computação com memória distribuída, onde a comunicação 
entre os processadores é feita usando troca de mensagens. Os parâmetros do modelo usado por eles são: $p$, o número de processadores, $\operatorname{com} p<<n, t_{s}$, o tempo para inicializar a transmissão de uma mensagem e $t_{w}$, o tempo de transmissão por palavra. Geralmente, $t_{s}$ pode ser bem maior que $t_{w}$. Por exemplo, o sistema de comunicação da CM-5, $t_{s}=$ $8-300 \mu s$ e $t_{w}=1-3 \mu s$.

Esta implementação foi realizada na máquina CM-5 da Thinking Machines e o número de processadores variou de 1 a 64 . Vários tipos de grafos esparsos foram testados.

Além dos custos de comunicação, dois outros fatores degradaram o desempenho do algoritmo. O primeiro foi o desbalanceamento na distribuição dos dados entre os processadores no decorrer da execução. Os testes mostraram que o desbalanceamento cresce com o número de processadores. Entretanto, mesmo com 64 processadores, o desbalancemento é moderado até próximo das últimas iterações e a partir daí cresce rapidamente. Apesar de não ter sido implementado, o rebalanceamento dificilmente sutiria efeito para os intervalos considerados, pois exigiria muitas trocas de mensagens e, além disso, encontrar a melhor distribuição de arestas entre os procesadores é NP-difícil.

O segundo fator é o uso de pointer jumping ao invés da técnica seqüencial de busca em largura que é mais eficiente, porém difícil de paralelizar. Para resolver este problema os autores desenvolveram um novo algoritmo de pointer jumping probabilístico mais eficiente que os algoritmos conhecidos. Além do novo algoritmo, o empacotamento de mensagens se mostrou como um dos principais fatores de redução dos custos de comunicação. Com empacotamento, cada processador envia, no máximo, $p-1$ pacotes grandes ao invés de $\Theta(n / p)$ mensagens pequenas quando o empacotamento não é usado. Considerando $p<<n$ o empacotamento é mais eficiente, mas se $p$ for grande a vantagem pode ser perdida.

Como resultado o artigo mostrou que a implementação roda assintoticamente em tempo $\Theta\left(\left(t_{s}+t_{w}\right)(m \log n / p)\right)$. O que em princípio um speedup p pode ser alcançado, mas a constante $t_{s}+t_{w}$ pode ser muito grande. Nos testes o speedup, a partir de 4 processadores, foi sempre maior que um e crescente até 32 processadores. Entre 4 e 32 processadores um speedup médio de 4 foi alcançado. Para 64 processadores os speedups's são semelhantes aos alcançados com 32 processadores. 


\section{Capítulo 4}

\section{Implementações Paralelas na Parsytec}

Neste capítulo tratamos de nossas implementações na máquina Parsytec PowerXplorer de algoritmos paralelos para memória distribuída para encontrar a FGM. Realizamos três implementações de algoritmos paralelos. As duas primeiras implementações são baseadas no algoritmo descrito por Das et al [DDP90], onde o modelo considerado é de memória distribuída na topologia de hipercubo. A terceira está baseada em um novo algoritmo assíncrono que desenvolvemos e descrevemos neste Capítulo.

Dos algoritmos encontrados na literatura poucos são de granularidade grossa, e dentre eles, o algoritmo de Das et al é o que mais se adequa às características da Parsytec PowerXplorer. Este fato aliado a seu bom desempenho nos levaram a sua implementação. Dois algoritmos são apresentados no artigo. Nossas implementações são baseadas naquele mais adequado para grafos esparsos, muito embora com algumas alterações este algoritmo possa ser adaptado para grafos densos.

A primeira seção trata das características da máquina Parsytec PowerXplorer. Esta seção está baseada no Manual de Referêncial da máquina [Par95]. A Seção 4.2 trata da descrição e análise do Algoritmo de Das et al. Na Seção 4.3 descrevemos um novo algoritmo assíncrono para memória distribuída e sua respectiva complexidade. Por fim, a Seção 4.4 descreve as implementações e seus resultados.

\subsection{Características da Máquina}

A máquina paralela Parsytec PowerXplorer, sob a qual foi realizada a experiência, contém 16 processadores Power PC 601, cada um com uma memória de 16 Mbytes. Cada nó tem uma unidade de execução, a sua memória local e uma unidade de comunicação com 
conexão para os processadores vizinhos. Na arquitetura física da máquina a interconexão dos processadores é baseada na topologia de grade bidimensional, muito embora ela possa simular outras topologias, como veremos mais adiante.

O PARIX é uma extensão paralela para o sistema operacional UNIX usado pela Parsytec PowerXplorer. Trata-se de um ambiente operacional, onde o usuário tem acesso a todo o suporte do UNIX, bem como das ferramentas de apoio ao desenvolvimento de aplicações paralelas (compilador, assembler, etc.) fornecidas pelo PARIX. O desenvovimento é feito em um ambiente híbrido, onde as ferramentas rodam em um host e o código produzido roda na Parsytec PowerXplorer.

Sob o PARIX, o mesmo código é executado por todos os processadores e cada um trabalha com uma cópia do programa até o fim da execução. O comportamento de cada cópia depende do código do programa, que poderá ser estabelecido de acordo com a posição do processador, e depende também da porção de dados de entrada de cada processador. Não há memória global onde os dados possam ser compartilhados. As informações entre processadores devem ser distribuídas via troca de mensagem quando necessário.

Cada processador pertence a uma partição e sua alocação é feita através de partições de quatro processadores, aqui chamadas A, B, C e D. É possível, assim, a alocação de quatro, oito ou dezesseis processadores para uma mesma aplicação. Uma vez alocada uma partição, seus processadores não são compartilhados por outras aplicações. As partições não utilizadas ficam liberadas para outras aplicações.

A comunicação no PARIX está baseada no conceito de links virtuais, que fornecem conexões ponto-a-ponto entre nós arbitrários da grade. Uma combinação de links virtuais pode ser feita com o intuito de se estabelecer uma Topologia Virtual. Isto é, algoritmos de imersões são usados para fazer o mapeamento ponto-a-ponto da topologia virtual para a topologia física da grade. Uma biblioteca básica fornece suporte às principais topologias: Anel, Árvore, Clique, Hipercubo, etc.

A criação de links virtuais pode ser feita diretamente entre dois processadores. Para facilitar a manipulação de grandes quantidades de links virtuais por processadores, os links podem ser organizados em topologias virtuais. Neste caso. as conexões são realizadas através das orientações relativas dentro de uma topologia, ao invés da manipulação direta dos links. Desta forma, podemos associar nomes simbólicos aos links. Em uma topologia de Árvore, por exemplo, podemos ter os links "pai" ou "filho".

A quantidade de topologias definidas em um processador é ilimitada. Um grande número de topologias podem co-existir em um mesmo processador, sem que uma interfira na outra. Além disso, a construção de uma topologia virtual otimiza o mapeamento dos links virtuais para a estrutura física de comunicação.

Quanto aos modos de comunicação há quatro tipos disponíveis: 
- Link Virtual Síncrono É a forma nativa de comunicação da Parsystec. Os dois processadores que vão estabelecer comunicação são conectados e sincronizados. A transferência de dados ocorre quando ambos os processadores estão prontos para a comunicação. Um processador pode esperar comunicação de um ou mais links simultaneamente. Contudo o uso de tais recursos, que são baseados em RPC entre os processadores e host, degradam significativamente o desempenho da comunicação.

- Comunicação Randômica Síncrona Não requer a definição de links virtuais, embora, para mensagens grandes, o sistema internamente usa o link virtual por razões de performance.

- Link Virtual Assíncrono Pode ser realizado concomitantemente com a computação. Esta conexão otimiza o uso dos processadores, pois o envio e recebimento de dados fica rodando em background enquanto o processador continua trabalhando.

- Comunicação Randômica Assíncrona É baseada em caixa de correio (MailBo$x e s)$. Não há necessidade de um link para a comunicação entre dois processadores, mas o tamanho da mensagem deve ser limitado. O processador receptor pode consultar a caixa de correio para receber uma mensagem enviada ou esperar pela chegada de uma nova mensagem.

Com relação à eficiência, as comunicações baseadas em links virtuais fornecem melhores desempenhos, enquanto que as baseadas em caixa de correio são flexíveis apesar de adicionarem um overhead considerável.

\subsection{O Algoritmo DDP}

Nesta Seção descrevemos o algoritmo de Das et al [DDP90] para o modelo de rede na topologia de hipercubo. Apresentamos, a seguir, um teorema que nos servirá de base para o desenvolvimento do algoritmo.

Seja um grafo $G$ e seja $F$ a FGM de $G$. Seja $H=(V(H), E(H))$ um subgrafo de G e $H^{\prime}=\left(V\left(H^{\prime}\right), E\left(H^{\prime}\right)\right)$ a FGM de $H$. Claramente, podemos ver que $V\left(H^{\prime}\right)=V(H)$ e $E\left(H^{\prime}\right) \subseteq E(H)$.

Teorema 4.2.1 $E(F) \cap E(H) \subseteq E\left(H^{\prime}\right)$

Prova. Considere uma aresta $x \in E(F) \cap E(H)$ e assuma, por absurdo, que $x \notin E\left(H^{\prime}\right)$. Como $x$ é uma aresta de $H$ mas não está em $H^{\prime}$, a adição de $x$ cria um circuito em $H^{\prime}$. 
Seja $x, y_{1}, \ldots, y_{i}$ as arestas deste circuito, tal que $x$ é adjacente a $y_{1}$ e $y_{i}$ e sendo $y_{j}$ adjacente a $y_{j+1}$ para $1 \leq j<i$. Assim, qualquer caminho ligando as extremidades da aresta $x$, exceto a própria aresta $x$, contém pelo menos uma aresta que não está em $F$, tal que quando adicionada a $F$ ela forma um circuito fundamental contendo $x$. Seja $y_{1}, \ldots, y_{i}$ tal caminho e, sem perda de generalidade, seja $y_{j}$ uma aresta deste caminho que não está em $F$. Assim, temos que $x<y_{j}$. Este resultado junto com o fato que a adição de $x$ a $H^{\prime}$ cria um circuito contendo $y_{j}$ implica que $H^{\prime}$ não é a FGM de $H$, uma contradição.

Considere agora um grafo $G$. Este teorema implica que as arestas de um subgrafo arbitrário de $G$ que não pertencem a FGM deste subgrafo, também não pertencem a FGM do grafo $G$. Este fato nos leva a algoritmos paralelos baseados na estratégia de eliminação de arestas. Isto é, podemos sucessivamente remover arestas que não pertencem a FGM do grafo de entrada até atingir a FGM deste grafo.

O algoritmo descrito abaixo, desenvolvido por Das et al, - aqui chamado DDP considera o modelo de memória distribuída com a interconexão entre os processadores baseada na topologia de hipercubo. Apesar do algoritmo estar descrito em função de um número $p$ qualquer de processadores, é para $p<<m$ que ele apresenta melhor speedup e é nestas condições que faremos a análise do algoritmo mais adiante.

Das et al em seu algoritmo apresentam as arestas igualmente distribuídas entre os $p=2^{d}$ processadores. Todos eles aplicam o Algoritmo de Kruskal para sua porção de arestas. Então a segunda fase consiste de $d$ fases de intercalação. No $j$-ésimo passo, $0 \leq j \leq d-1$, o processador $P_{k}$, que tem seus índices representados em binário, verifica se o $j$-ésimo bit de índice é 0 ou 1 . Se o bit é $0, P_{k}$ recebe a lista de seu vizinho que diverge apenas no $j$-ésimo bit. Se o bit é $1, P_{k}$ envia a lista ao seu vizinho que diverge apenas no $j$-ésimo bit, sendo que $P_{k}$ é desativado. A seguir, os processadores ativos intercalam a lista recebida com sua própria e aplicam novamente o Algoritmo de Kruskal, agora sobre uma lista de aresta já ordenadas. Após $d$ passos o processador $P_{0}$ contém a FGM.

\section{Algoritmo DDP}

Entrada: Grafo $G$ em uma lista de arestas.

Saída: As arestas da FGM de $G$.

Passo 1 Distribuir as arestas igualmente entre os $p=2^{d}$ processadores do hipercubo.

Passo 2 Cada processador $P_{k}$ aplica o Algoritmo de Kruskal para suas arestas.

Passo 3 Para $j=0, \ldots, d-1$ faça (4) e (5)

Passo 4 Cada $P_{k}$ verifica se o j-ésimo bit de índice é 0 ou 1 . Se o bit é $0, P_{k}$ recebe a lista de seu vizinho que diverge apenas no j-ésimo bit. Se o bit é $1, P_{k}$ envia a lista ao seu vizinho que diverge apenas no j-ésimo bit, sendo $P_{k}$ desativado. 
Passo 5 Cada processador ativo intercala sua lista com a recebida e aplica novamente o Algoritmo de Kruskal.

A corretude do algoritmo segue diretamente do Teorema 4.2.1 e do Algoritmo de Kruskal, uma vez que todas as arestas removidas em cada iteração do algoritmo não pertencem à FGM e, na última iteração, o processador $P_{0}$ recebe todas as arestas não eliminadas e aplica o Algoritmo de Kruskal a elas.

\section{Complexidade de Tempo do Algoritmo}

Para efeito de análise do algoritmo, vamos assumir que as operações básicas como adição e comparação são realizadas em uma unidade de tempo e que o tempo de transmissão de uma aresta entre processadores vizinhos é realizada em $C_{1}$ unidades de tempo, para alguma constante positiva $C_{1}$. Não consideraremos o tempo de leitura e distribuição das arestas entre os processadores que podem ser realizados em tempo linear no número de arestas. Assumimos que o tempo de ordenação de $l$ arestas é $C_{2} l \log l$ e que a intercalação de duas listas de $l_{1}$ e $l_{2}$ arestas tem tempo de execução $C_{3}\left(l_{1}+l_{2}\right)$. Lembramos ainda da Seção 2.3 que, dadas $l$ arestas pré-ordenadas o Algoritmo de Kruskal tem tempo de execução $O(\alpha(l, n) l)$.

Teorema 4.2.2 O Algoritmo tem tempo de execução $\left.O\left(\frac{m}{p} \log \frac{m}{p}+n \alpha(m, n) \log p\right)\right)$.

Prova. O Passo 2 requer tempo máximo $C_{2}\left\lceil\frac{m}{p}\right\rceil \log \left\lceil\frac{m}{p}\right\rceil$ para ser executado. Em seguida, $d=\log p$ fases de intercalação serão realizadas nos Passos 3-5. No Passo 4 cada processador gasta tempo $C_{1}(n-1)$ para enviar ou receber as arestas de um processador vizinho. A intercalação no Passo 5 é feita em, no máximo, $C_{3}(2 n-2)$ passos. Como as arestas já se encontram ordenadas, o Algoritmo de Kruskal no Passo 5 pode ser realizado em tempo $O(n \alpha(m, n))$. Assim, o tempo de execução $T(m, n)$ do algoritmo é dado por

$$
\begin{gathered}
T(m, n) \leq C_{2}\left\lceil\frac{m}{p}\right\rceil \log \left\lceil\frac{m}{p}\right\rceil+\log p\left(C_{1}(n-1)+C_{3}(2 n-2)+C_{4}(2 n-2) \alpha(m, n)\right) \\
\leq C\left(\frac{m}{p} \log \frac{m}{p}+n \alpha(m, n) \log p\right), \quad C=\max \left\{C_{1}, C_{2}, C_{3}, C 4\right\} \\
\Rightarrow T(m, n)=O\left(\frac{m}{p} \log \frac{m}{p}+n \alpha(m, n) \log p\right)
\end{gathered}
$$

O Algoritmo de Kruskal requer $O(m \log m)$ passos seqüenciais para um grafo com $m$ arestas. Para grafos esparsos, o algoritmo acima produz um speedup $S_{p}(m)=p$, o qual é 
ótimo. Para grafos densos, com $m \simeq n^{2}$, o algoritmo roda em tempo $O(n \alpha(m, n) \log n)$ usando $n$ processadores. Abaixo, descrevemos pequenas alterações neste algoritmo de forma a torná-lo eficiente também para grafos densos.

\section{Algoritmo Para Grafos Densos}

O algoritmo para grafos densos difere do Algoritmo DDP somente nos passos 1 e 2. No Passo 1, este algoritmo difere na forma como as arestas são distribuídas entre os processadores. Considere $w$, de dimensão $n \times n$, a matriz peso como sendo a representação de um dado grafo $G$. A matriz $w$ é particionada em $p$ submatrizes de dimensão $\left\lceil\frac{n}{\sqrt{p}}\right\rceil \times\left\lceil\frac{n}{\sqrt{p}}\right\rceil$. Cada submatriz contém um máximo de $2\left\lceil\frac{n}{\sqrt{p}}\right\rceil$ vértices e $4\left\lceil\frac{n}{\sqrt{p}}\right\rceil^{2}$ arestas. Cada aresta $(i, j), 0 \leq i, j \leq \sqrt{p}-1$, é armazenada em um vetor do processador $P_{i * \sqrt{p}+j}$.

No Passo 2 aplicamos o Algoritmo de Prim para grafos densos - Seção 2.2.1 - ao invés do Algoritmo de Kruskal. Como o Algoritmo de Prim pode não produzir uma lista ordenada de arestas, elas devem ser ordenadas após a aplicação deste algoritmo. Os Passos 3-5 são idênticos ao algoritmo anterior.

\section{Complexidade de Tempo do Algoritmo}

Inicialmente, cada processador recebe, no máximo, $2\left\lceil\frac{n}{\sqrt{p}}\right\rceil$ vértices. O Algoritmo de Prim requer tempo $O\left(n^{2} / p\right)$. O número máximo de arestas produzidas como resultado é $2\left\lceil\frac{n}{\sqrt{p}}-1\right\rceil$, as quais gastam tempo $O\left(\frac{n}{\sqrt{p}} \log \frac{n}{\sqrt{p}}\right)$ para serem ordenadas. Com isto temos o teorema abaixo.

Teorema 4.2.3 O Algoritmo tem tempo de execução $O\left(\frac{n^{2}}{p}+\frac{n}{\sqrt{p}} \log \frac{n}{\sqrt{p}}+n \alpha(m, n) \log p\right)$.

\subsection{O Algoritmo Assíncrono}

Observando o comportamento do Algoritmo DDP, verificamos que, a cada fase, ele desativa metade dos processadores. Isto faz com que os processadores alocados não sejam utilizados efetivamente durante toda a execução do algoritmo. Vemos também que o algoritmo requer sincronismo entre cada uma das fases.

Haja vista o acima exposto, desenvolvemos um novo algoritmo - chamado Assíncrono - que faz um uso mais efetivo dos processadores baseado na estratégia de eliminação de arestas de [DDP90]. Este algoritmo diverge do Algoritmo DDP em dois pontos essenciais: 1) A interconexão entre os processadores é baseada na topologia de Árvore (isto não é restritivo, pois o algoritmo pode ser adaptado para qualquer topologia); 2) Ao invés 
de um dado processador construir sua FGM e em seguida enviá-la para um vizinho como no Algoritmo DDP, neste algoritmo cada processador $P$ contém, no máximo, $d$ filas, onde a primeira fila contém a lista de arestas de entrada do algoritmo e as demais constituem as arestas que vão sendo recebidas dos processadores-filhos de $P$. Note que os processadores-folhas possuem apenas a sua lista de aresta de entrada. O algoritmo, para cada processador, extrai o mínimo dentre os topos das filas e seleciona a aresta que não forma ciclo com as anteriores. As arestas selecionadas vão sendo enviadas, unitariamente ou em pacotes, ao processador-pai de $P$ (exceto a raiz que gera a própria FGM de $G$ ).

\section{Algoritmo Assíncrono}

Entrada: Grafo $G$ em uma lista de arestas.

Saída: As arestas da FGM de $G$.

Passo 1 Distribuir as arestas de $G$ igualmente entre os $p$ processadores.

Passo 2 Cada processador $P_{k}$ constrói um heap com sua porção de arestas usando o peso como chave.

Passo 3 Cada processador-folha, simultaneamente, repete os passos seguintes enquanto houver arestas no heap:

3.1 Extrai a aresta mínima de seu heap e reorganiza-o.

3.2 Verifica se esta aresta mínima forma ciclo com as anteriores.

3.3 Seleciona a aresta que não forma ciclo e a envia para o processador $\operatorname{pai}\left(P_{k}\right)$.

Passo 4 Cada processador interno recebe as arestas enviadas por seus filhos em filas próprias. Em seguida, repete os passos abaixo, paralelamente ao recebimento de arestas, enquanto houver arestas nas filas ou em seu heap:

4.1 Extrai a aresta mínima dentre os topos das filas (incluindo o seu heap e neste caso reorganiza-o se necessário).

4.2 Verifica se esta aresta mínima forma ciclo com as anteriores.

4.3 Seleciona a aresta que não forma ciclo e a envia para o processador $\operatorname{pai}\left(P_{k}\right)$.

Passo $5 \mathrm{~A}$ raiz recebe as arestas enviadas por seus filhos em filas próprias. Em seguida, repete os passos abaixo, paralelamente ao recebimento de arestas, enquanto houver arestas nas filas ou em seu heap:

5.1 Extrai a aresta mínima dentre os topos das filas (incluindo o seu heap e neste caso reorganiza-o se necessário).

5.2 Verifica se esta aresta mínima forma ciclo com as anteriores.

5.3 Seleciona a aresta que não forma ciclo e no final derolve a FGM. 
Observe que o algoritmo possui uma grande flexibilidade quanto ao envio e recebimento de arestas. Ou seja, a quantidade de arestas transferidas entre dois processadores pode variar de 1 a $n-k$, onde $k$ é o número de componentes do grafo. A esta técnica de transferir várias mensagens pequenas em uma única mensagem grande chamamos de empacotamento.

Devido ao assincronismo do algoritmo, devemos estabelecer um protocolo de comunicação entre os processadores, pois há a necessidade de um processador saber quando se dever encerrar o recebimento de arestas. Uma maneira possível é o estabelecimento de um pedido para cada envio de arestas. Isto é, para uma aresta (ou pacote de arestas) ser enviada o processador-pai deve primeiramente solicitá-la. Uma desvantagem desse protocolo é que ele onera ainda mais o custo de comunicação. Em nossa implementação, descrita na próxima seção, estabelecemos um protocolo baseado em um sentinela. Ou seja, um valor sentinela uniforme em todos os processadores é determinado para as arestas e o recebimento ocorre até que uma aresta com este peso chegue ao processador-pai.

Assim como o Algoritmo DDP, o Algoritmo Assíncrono tem sua corretude baseada no Teorema 4.2.1 e no Algoritmo de Kruskal. Observamos que cada processador constrói uma FGM de subgrafo composto por sua porção de arestas de entrada, mais as arestas recebidas de seus processadores-filho. Uma vez que a retirada do heap, bem como o recebimento de arestas em ordem crescente garantem a verificação de ciclo de maneira ordenada, temos que cada processador executa o Algoritmo de Kruskal. Segue pelo Teorema 4.2.1 que no final o processador-raiz construirá a FGM do grafo de entrada $G$.

\section{Análise de Complexidade}

Apesar de nosso algoritmo ter sido desenvolvido com o pensamento voltado para as características dos modelos realísticos, em sua análise não nos atemos a nenhum modelo específico, pois isto demandaria um conhecimento mais detalhado do comportamento da máquina Parsytec em termos dos parâmetros deste modelo e este estudo estava fora do escopo do nosso trabalho.

Vamos dividir a análise do algoritmo em duas partes. Na primeira medimos o tempo de execução de uma folha, o que influencia em parte no tempo de execução dos outros nós. Em seguida, calculamos o tempo de execução dos outros nós, incluindo a raiz, esta que por sua vez dará o tempo de execução total do algoritmo.

$\mathrm{Na}$ análise de complexidade, além de $n$ o número de vértices do grafo e $m$ o seu número de arestas, são acrescentados os seguintes parâmetros: $p$, o número de processadores e $P A C$, o número de arestas em um pacote. Para simplificar, esses parâmetros serão omitidos da notação nas análises que seguem. 


\section{Folha}

Seja $T_{f}$ o tempo da folha $f$. Observando o algoritmo vemos que $T_{f}$ é dado pela seguinte expressão:

$$
T_{f}=T_{h}+\left(T_{m p}+T_{t p}\right)\left\lceil\frac{n-1}{P A C}\right\rceil
$$

onde:

$T_{h}$ : é o tempo de construção do heap

$T_{m p}$ : é o tempo de montagem de um pacote

$T_{t p}$ : é o tempo de transmissão de um pacote.

Na montagem de um pacote com $P A C$ arestas se espera que seja rápido de se construir o pacote no início e mais demorado a medida que a árvore está quase pronta, pois o número de arestas verificadas para cada aresta escolhida tende a ser maior. Uma aproximação para isto é se estimar que o número de arestas a serem consultadas para se montar um pacote seja proporcional a $P A C$. Queremos estimar o tempo de construção do primeiro pacote pois isso influencia no tempo do pai da folha e por conseqüência nos tempos do outros nós internos e da raiz. Desta forma a Expressão 4.1 acima fica

$$
T_{f}=T_{h}+T_{m p 1}+T_{t p 1}+\left(T_{m p}+T_{t p}\right)\left\lceil\frac{n-1}{P A C}-1\right\rceil
$$

onde:

$T_{m p 1}$ : é o tempo de montagem do primeiro pacote

$T_{t p 1}$ : é o tempo de transmissão do primeiro pacote.

O tempo de construção do heap é linear em $m / p$, o número de arestas. O tempo de montagem de um pacote é $O(P A C \log (m / p))$. O tempo de envio e recebimento de pacotes, conforme testes executados - veja Figura 4.1 - pode ser assumido ser linear no tamanho do pacote e, além disso, considerando a forma de comunicação assíncrona que usamos, a constante no tempo de envio é menor que no tempo de recebimento devido a necessidade de espera do último. Assim temos

$T_{f} \leq \overbrace{c_{1} \frac{m}{p}}^{\text {heap }}+\underbrace{\left(c_{2} P A C \log \frac{m}{p}+c_{3} P A C+c_{4}\right)}_{\text {Primeiro Pacote }}+\overbrace{c_{5}\left(\frac{m}{p}-P A C\right) \log \frac{m}{p}}^{\text {Pacotes Restantes }}+\underbrace{\left[\frac{n-1}{P A C}\right\rceil\left(c_{3} P A C+c_{4}\right)}_{\text {Transmissão dos Pacotes }}$

A expressão acima resulta em

$$
T_{f} \leq c_{1} \frac{m}{p}+c_{5} \frac{m}{p} \log \frac{m}{p}+c_{3} n+c_{4} \frac{n}{P A C}+c_{6} .
$$




\begin{tabular}{||r|r|r||}
\hline \hline Inteiros & Tsend & Trecv \\
\hline \hline 1 & 89 & 121 \\
\hline 5 & 89 & 130 \\
\hline 10 & 90 & 150 \\
\hline 20 & 105 & 200 \\
\hline 50 & 200 & 390 \\
\hline 100 & 400 & 545 \\
\hline 200 & 790 & 935 \\
\hline 1000 & 3800 & 4100 \\
\hline 2000 & 7560 & 8030 \\
\hline 10000 & 38030 & 39900 \\
\hline
\end{tabular}

Figura 4.1: Tempo de comunicação síncrona entre vizinhos medido em $\mu s$ na partição A. Os valores são resultados da média de 3 rodadas. Não houve diferenças significativas quando variadas as partições.

A constante $c_{6}$ resume todos os termos constantes que deveriam aparecer para cada operação.

No total para todos os pacotes, o tempo da construção da floresta geradora do subgrafo da folha é $O((m \log n) / p)$.

\section{Nó interno}

Sejam $T_{i}$ o tempo do nó interno $i$ e $h_{i}$ a altura deste nó. O tempo $T_{i}$ é dado por

$$
T_{i} \leq T_{h}+2 T_{r p}+\left(T_{m p}+T_{t p}+T_{r p}\right)\left\lceil\frac{n-1}{P A C}\right\rceil
$$

onde:

$T_{h}$ : é o tempo de construção do heap

$T_{r p}$ : é o tempo de recebimento de um pacote

$T_{t p}$ : é o tempo de transmissão de um pacote.

Note que para um nó interno receber os 2 primeiros pacotes, estes deve estar prontos. Isso inclui o tempo de construção e envio desses pacotes por seus ancestrais. Assim temos que o tempo de um nó interno é dado por

$$
T_{i} \leq \overbrace{c_{1} \frac{m}{p}}^{\text {heap }}+\underbrace{\left(c_{2} P A C \log n+c_{3} P A C+c_{4}+2\left(c_{7} P A C+c_{4}\right)\right) h_{i}}_{\text {Espera do Primeiro Pacote }}+
$$




$$
\begin{gathered}
+\overbrace{c_{8} \frac{m}{p} \log n}^{\text {Pacotes Restantes }}+\underbrace{\left\lceil\frac{n-1}{P A C}\right]\left(c_{3} P A C+c_{4}\right)}_{\text {Recebimento dos Pacotes }}+\overbrace{\left[\frac{n-1}{P A C}\right\rceil\left(c_{7} P A C+c_{4}\right)}^{\text {Transmissão dos Pacotes }} \Rightarrow \\
T_{i} \leq c_{1} \frac{m}{p}+\left(c_{2} P A C \log n+c_{9} P A C+c_{10}\right) h_{i}+c_{8} \frac{m}{p} \log n+c_{11} n+\frac{n}{P A C} c_{12}+c_{13} .
\end{gathered}
$$

O valor das constantes devem ser diferentes para os vários níveis da árvore. O motivo é que cada vez que árvores construídas em nós com altura menor tendem a ter mais arestas da árvore geradora mínima. Com isso, o número de arestas tiradas do heap do nó diminui e aumenta o número de arestas retirada das listas dos filhos.

O tempo total do algoritmo é fornecido pela raiz da árvore. Observe que o tempo da raiz é conseqüência de todas as computações de seus ancestrais mais as suas próprias computações. Note ainda que a análise acima vale também para a raiz, sendo este valor um limitante superior para o tempo da raiz, uma vez que ele está majorado pelos envios de mensagens que a raiz não realiza.

Tomando $P A C \simeq m / \log n$, assintoticamente o Algoritmo Assíncrono possui a mesma complexidade que o Algoritmo DDP (Observe que $h_{i}=O(\log p)$ ). Porém, como os custos de comunicação são elevados, nosso algoritmo, juntamente com o uso de empacotamento, distribui o impacto da comunicação durante o processamento e, como veremos nos testes a seguir, este algoritmo apresenta uma melhora significativa.

\subsection{A Implementação}

Os resultados mostrados nesta Seção foram obtidos a partir da média de três rodadas para cada instância. Os códigos fontes citados a seguir estão no Apêndice A. As tabelas correspondentes aos gráficos mostrados aqui encontram-se no Apêndice B, bem como alguma outras que fazemos referências.

\subsubsection{Grafos Aleatórios}

Os grafos de entrada do programa usados em nossos testes foram gerados de forma aleatória. Estes grafos foram gerados em uma lista de arestas, onde decidimos com probabilidade $p$ se uma aresta estaria no grafo gerado, e sorteamos aleatoriamente suas extremidades de forma a produzir um embaralhamento destas arestas. O peso das arestas são inteiros positivos, aleatoriamente escolhidos em um dado intervalo. Denotamos tais grafos da forma Gn.p, onde $n$ é o número de vértices do grafo e $p / 10$ é a probabilidade. Por exemplo, G200.2 é um grafo com 200 vértices e cada aresta sorteada com probabilidade de $20 \%$. 
Em nossos testes os grafos variaram o número de vértices entre 200 e 1500. O número de arestas variou entre 20 e $60 \%$ para grafos com até 600 vértices e entre 5 e $20 \%$ para grafos com número de vértices entre 1000 e 1500.

\subsubsection{Resultados dos Testes Realizados}

Inicialmente, trabalhamos na implementação do Algoritmo de Das et al, tanto no sentido de otimizar o tempo de processamento, quanto na busca de diminuir o impacto do tempo de comunicação no desempenho global do algoritmo. Na busca de diminuir o tempo de comunicação criamos uma nova simulação do hipercubo na topologia de grade e executamos o mesmo algoritmo. Houve com isso, uma melhora significativa no custo de comunicação e, por conseqüência, no tempo de execução, conforme podemos verificar nas Figuras 4.2 e 4.3. Quanto ao tempo processamento elaboramos o Algoritmo Assíncrono descrito anteriormente e os resultados são discutidos nesta Seção.

\begin{tabular}{||l|r|r|r|r|r|r|r|r|r||}
\hline \hline \multirow{2}{*}{ Grafos } & \multicolumn{1}{|c|}{ MSF-S } & \multicolumn{3}{|c|}{ MSF-H } & \multicolumn{3}{|c|}{ MSF-M } & \multicolumn{2}{c||}{ MSF-A } \\
\cline { 2 - 10 } & \multicolumn{1}{|c|}{ P1 } & P4 & P8 & P16 & P4 & P8 & P16 & P4 & P8 \\
\hline \hline$G 200.2$ & 25 & 43 & 71 & 492 & 41 & 53 & 71 & 14 & 13 \\
\hline$G 200.4$ & 36 & 44 & 78 & 526 & 42 & 56 & 75 & 16 & 25 \\
\hline$G 200.6$ & 49 & 54 & 77 & 499 & 53 & 58 & 81 & 23 & 19 \\
\hline$G 400.2$ & 75 & 84 & 113 & 609 & 77 & 85 & 103 & 44 & 45 \\
\hline$G 400.4$ & 134 & 99 & 117 & 843 & 91 & 112 & 122 & 60 & 61 \\
\hline$G 400.6$ & 151 & 123 & 122 & 768 & 112 & 102 & 118 & 86 & 50 \\
\hline$G 600.2$ & 162 & 143 & 157 & 716 & 129 & 152 & 151 & 117 & 86 \\
\hline$G 600.4$ & 260 & 163 & 166 & 855 & 146 & 167 & 163 & 107 & 87 \\
\hline$G 600.6$ & 330 & 194 & 183 & 835 & 175 & 155 & 174 & 138 & 63 \\
\hline
\end{tabular}

Figura 4.2: Tempo de execução do algoritmo medido em $m s$. MSF-S é a implementação seqüencial, MSF-H usa a simulação do Hipercubo, MSF-M usa a topologia de Malha e MSF-A é o novo Algoritmo Assíncrono.

Verificamos que a máquina apresenta uma boa robustez quanto ao tempo de processamento. O comportamento de todos os processadores para uma mesma instância são muito similares em termos desta medida. Identificamos, por outro lado, que o custo de comunicação comparado ao custo de processamento é muito elevado - veja Figura 5.1 no Apêndice B.

Na Figura 4.3 podemos observar o tempo de execução quando crescemos o número de processadores. Note que os tempos do algoritmo paralelo começam a ser menor que o seqüencial, a partir de $G 400.4$ e, para os grafos com mais de 1000 vértices e pouca densidade, o custo de comunicação é mais determinante que o processamento. Podemos deduzir da tabela 5.1 do Apêndice B que aumentando a densidade dos grafos o desempenho do algoritmo paralelo tende a ser melhor, pois a comunicação do algoritmo é fixa para 


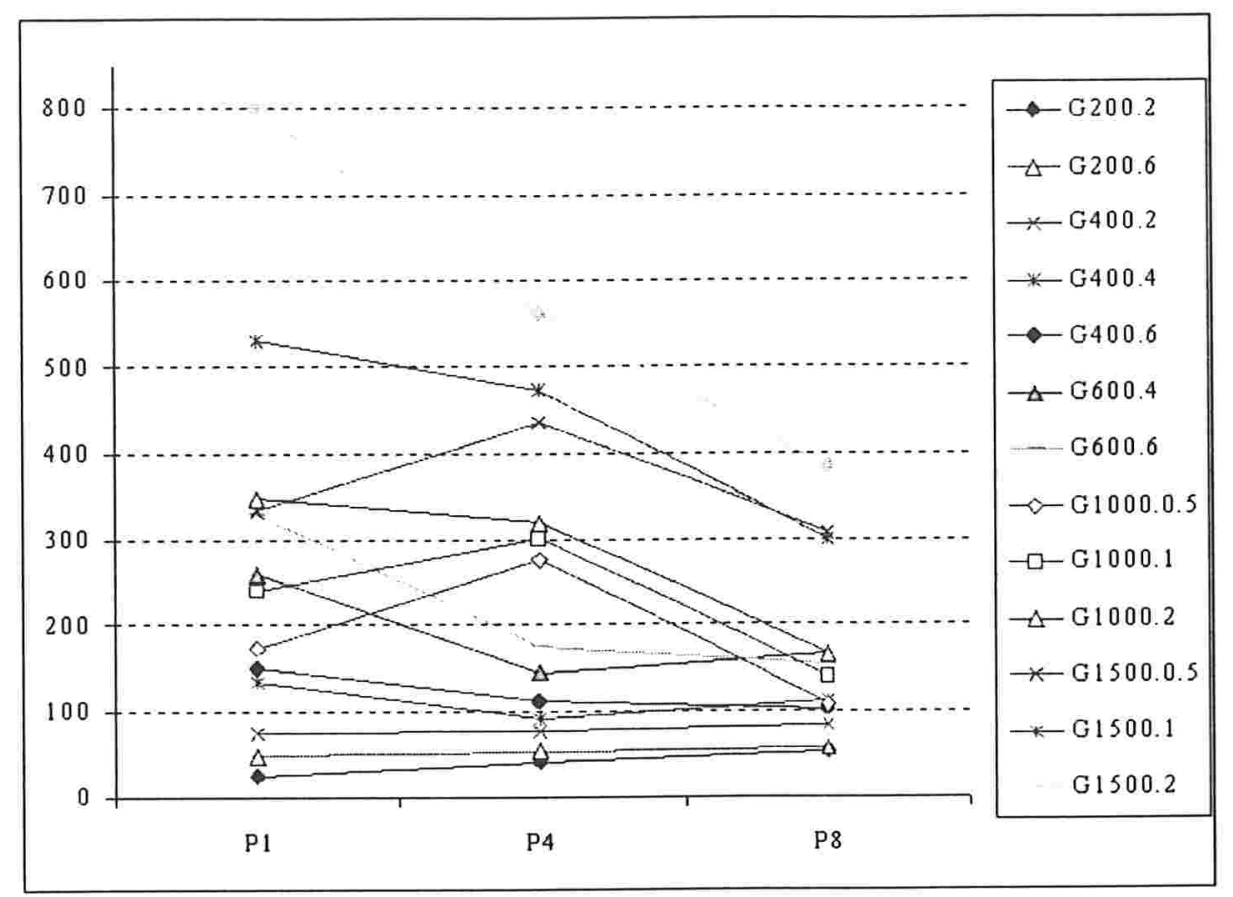

Figura 4.3: Tempo do Algoritmo MSF-M

grafos com a mesma quantidade de vértices.

O estudo do Algoritmo de Das et al nos levou a elaboração do Algoritmo Assíncrono, conforme descrito na seção anterior. O primeiro problema que atacamos foi o tempo de processamento, pois verificamos um desperdício no uso dos processadores pelo Algoritmo DDP no decorrer da execução. O Algoritmo Assíncrono, que funciona similarmente a técnica de pipe-line, reduz ao mínimo este desperdício.

No tocante a comunicação testamos os vários modos de links existentes na máquina e implementamos o modo assíncrono que se apresentou mais recomendado para a aplicação. Usamos, ainda, a técnica de empacotamento de mensagem, que se mostrou de suma importância para reduzir os custos de comunicação. Nos testes realizados - veja Figura 4.4 - os tamanhos dos pacotes são relativamente grandes. Mas, na medida em que os custos de comunicação forem reduzidos, esperamos que o Algoritmo Assíncrono melhore seu desempelho com pacotes pequenos e, conseqüentemente, amplie a vantagem sobre o algoritmo original. Além disso, comparando o tempo de execução vemos que nosso algoritmo tem melhor performance que o Algorimo DDP para todos os grafos testados tanto com 4 como com 8 processadores. A Figura 4.5 mostra o desempenho do algoritmo quando variado o número de processadores.

Apesar das vantagens do uso de pacotes, não podemos fazer uso deste recurso irrestitamente, pois aumentar o tamanho do pacote significa aumentar também o tempo de espera 


\begin{tabular}{|c|c|c|c|c|c|c|c|c|c|c|c|c|}
\hline \multirow[b]{2}{*}{ Grafos } & \multicolumn{6}{|c|}{ P4 } & \multicolumn{6}{|c|}{ P8 } \\
\hline & 25 & 50 & 100 & 200 & 300 & 400 & 25 & 50 & 100 & 200 & 300 & 400 \\
\hline$\overline{~ G 200.2}$ & 41 & 17 & 14 & 19 & & & 35 & 13 & 15 & 24 & & \\
\hline$G 200.4$ & 43 & 21 & 16 & 22 & & & 28 & 25 & 26 & 36 & & \\
\hline$G 200.6$ & 39 & 27 & 23 & 29 & & & 62 & 19 & 21 & 31 & & \\
\hline$G 400.2$ & 95 & 63 & 45 & 44 & & 54 & 100 & 57 & 45 & 54 & & 73 \\
\hline G400.4 & 109 & 60 & 72 & 82 & & 88 & 113 & 78 & 61 & 68 & & 87 \\
\hline G400.6 & 177 & 98 & 87 & 86 & & 105 & 120 & 72 & 50 & 65 & & 84 \\
\hline$G 600.2$ & 178 & 149 & 117 & 121 & 124 & & 217 & 96 & 86 & 88 & 96 & \\
\hline$G 600.4$ & 187 & 125 & 107 & 142 & 113 & & 140 & 114 & 87 & 108 & 105 & \\
\hline$G 600.6$ & 274 & 168 & 139 & 138 & 145 & & 159 & 126 & 63 & 118 & 127 & \\
\hline
\end{tabular}

Figura 4.4: Tempo de execução do Algoritmo Assíncrono, medido em $m s$, variando com o tamanho dos pacotes entre 25 e 400 arestas. Os melhores desempenhos estão destacados em negrito.

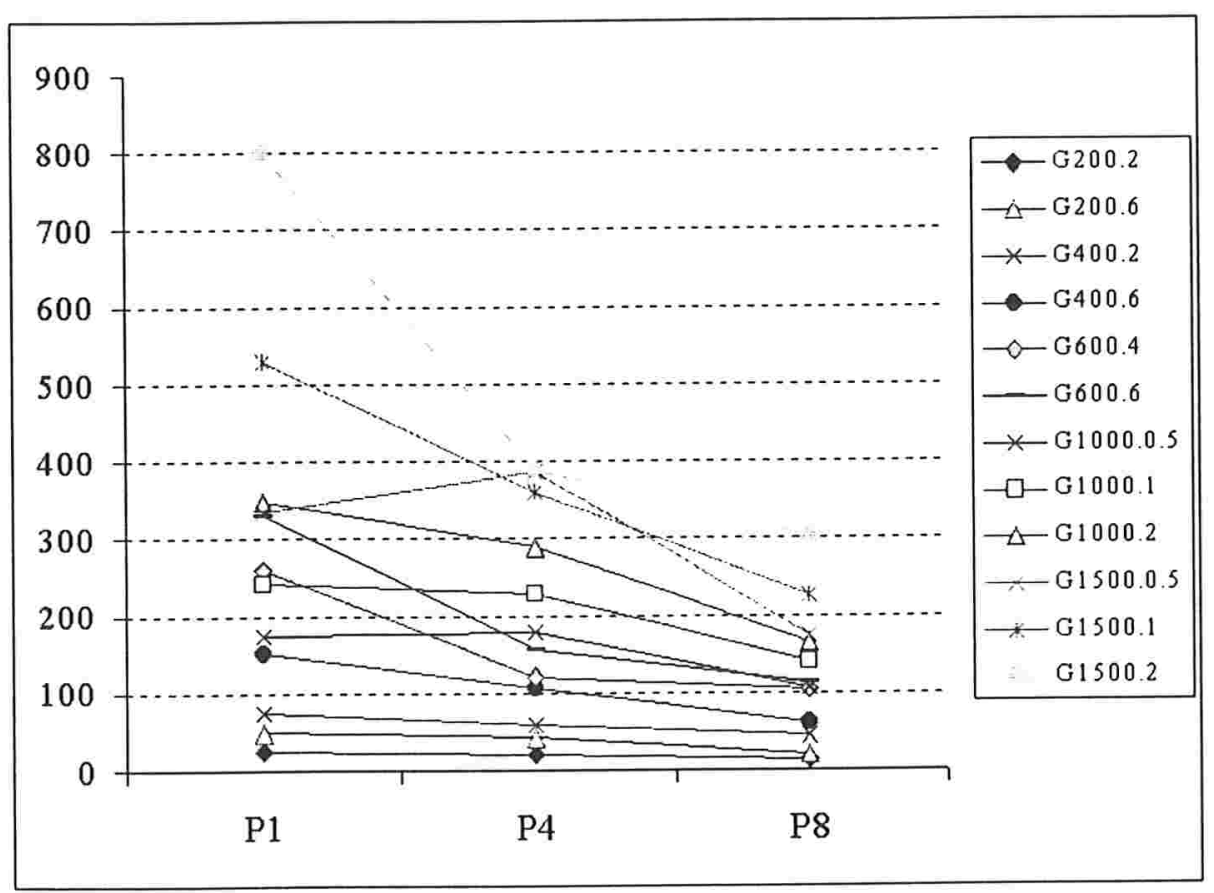

Figura 4.5: Tempo do Algoritmo Assíncrono.

dos processadores de níveis mais altos da árvore.

Os speedup's obtidos foram muito bons para os grafos mais densos, principalmente, se considerarmos a situação em que o custo de comunicação é muito elevado como a que trabalhamos. Conforme Figura 4.6, podemos ver que o speedup variou entre 1,06 e 5,23 com 8 processadores, e entre 1,70 e 2,65 com 4 processadores. 


\begin{tabular}{|r|r|r|r|r|r|r|r|r|r|r|}
\hline \hline P & G200.2 & G200.6 & G400.2 & G400.6 & G600.2 & G600.6 & G1000.1 & G1000.2 & G500.1 & G1500.2 \\
\hline \hline 4 & 1,78 & 2,13 & 1,70 & 1,75 & 1,38 & 2,39 & 1,72 & 2,09 & 2,43 & 2,65 \\
\hline 8 & 1,92 & 2,57 & 1,66 & 3,02 & 1,88 & 5,23 & 1,06 & 1,21 & 1,47 & 2,05 \\
\hline
\end{tabular}

Figura 4.6: Speedup do Algoritmo Assíncrono

\section{Cálculo de Constantes}

Com o objetivo de testar empiricamente a complexidade de tempo do algoritmo, realizamos cálculos no sentido de determinar os valores das constantes envolvidas na equação. A Figura 4.7 mostra a curva esperada e os resultados obtidos.

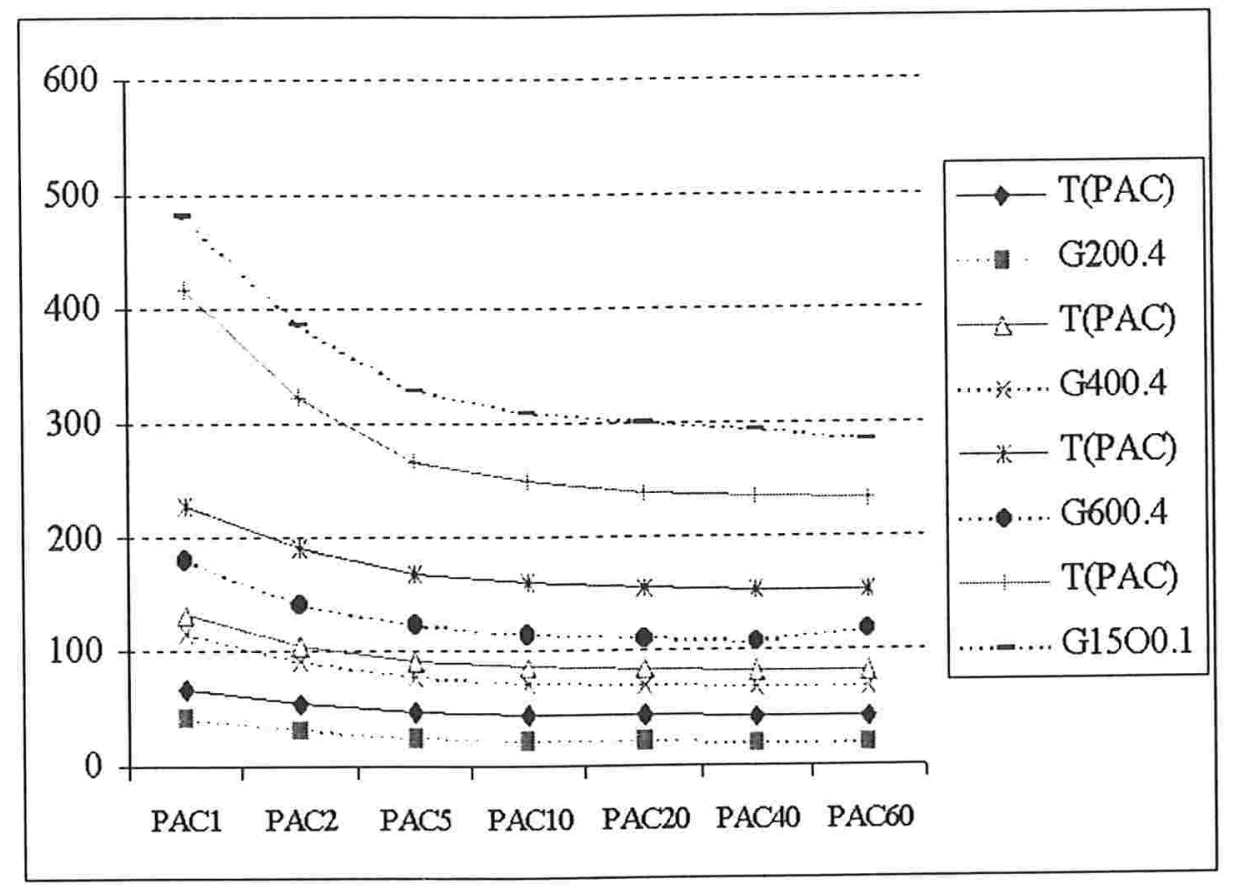

Figura 4.7: Tempo médio das folhas no Algoritmo Assíncrono com 4 processadores variando os pacotes. T(PAC) são as curvas dada pela função e Gn.p são os valores obtidos nos teste.

A realização do cálculo foi dividida no tempo de uma folha e no tempo de um nó interno. O cálculo das constantes da folha foi realizados em três partes: a primeira mediu o tempo de construção do heap, a segunda o tempo de verificação de ciclo e rearranjo do heap e a terceira o tempo de comunicação para o envio das arestas. A partir destes cálculos, que foram realizados para 3 grafos diferentes, calculamos um valor médio para as constantes. A equação de tempo para as folhas com as referidas constantes é dada por: 


$$
T(m, n, p, P A C)=2,2 \frac{m}{p}+0,33 \frac{m}{p} \log \frac{m}{p}+3,35 n+125 \frac{n}{P A C}+30000 .
$$

As distorções intrínsecas da medida de tempo, devido a ausência de um temporizador global, não possibilitaram um estudo efetivo do comportamento da comunicação do algoritmo nos diversos níveis da árvore. Uma diferença de relógio dificulta uma sincronização exata para efetuar estas medidas de tempo. Mas a curva de tempo da raiz, conforme podemos obsevar na Figura 4.8, é semelhante à da folha, apesar dos valores das constantes serem maiores.

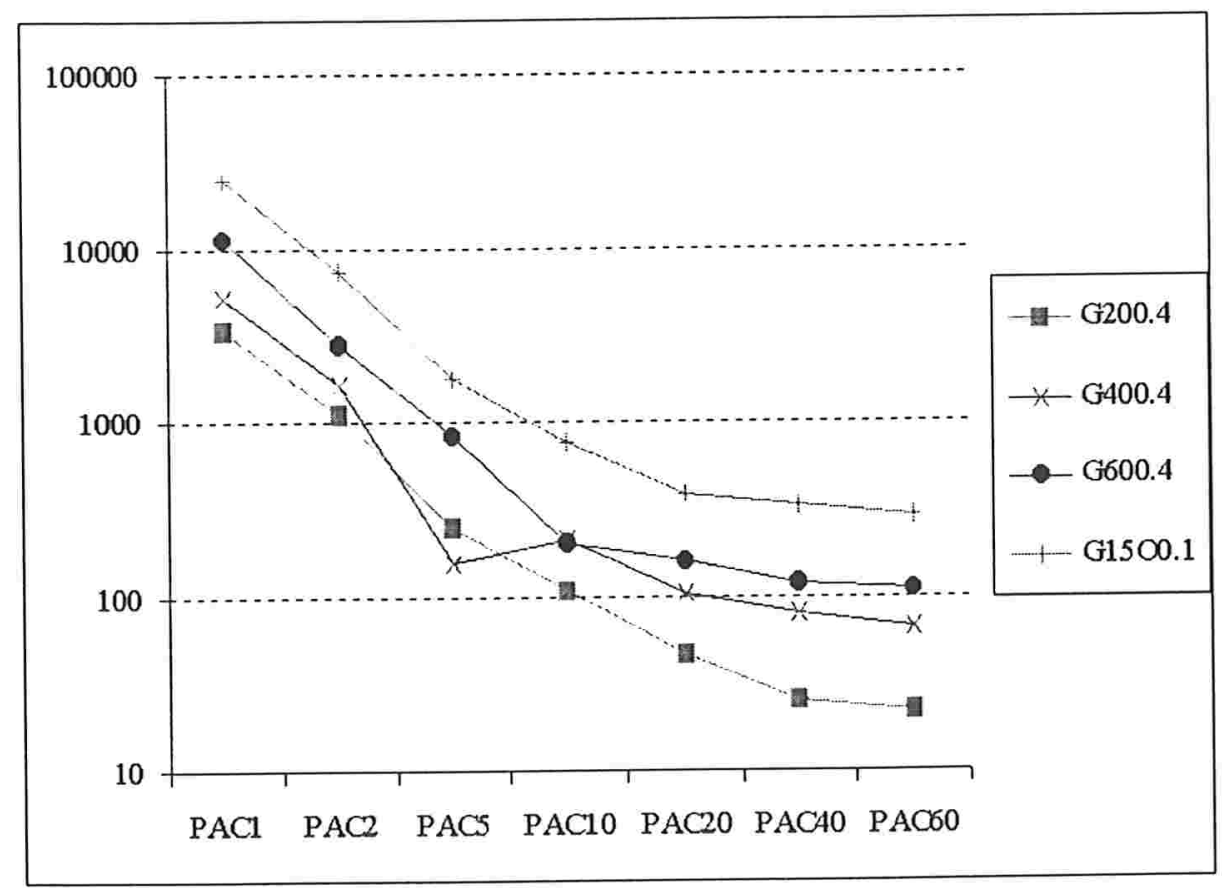

Figura 4.8: Tempo da raiz no Algoritmo Assíncrono com 8 processadores variando os pacote.

No Apêndice B temos a figura 5.3 similar a Figura 4.7 que mede o tempo médio das folhas quando usamos 8 processadores. Neste apêndice apresentamos também a Figura 5.4 correspondente a Figura 4.8 medindo o tempo da raiz usando 4 processadores. 


\section{Capítulo 5}

\section{Considerações Finais}

O Problema da FGM é um dos mais conhecidos problemas de otimização em grafos. A sua ampla possibilidade de aplicações e suas interessantes características teóricas nos motivaram neste estudo. Inicialmente, estudamos nesta Dissertação os principais algoritmos seqüenciais para o problema bem como suas diferentes implementações.

Dentre estes algoritmos estudamos o Algoritmo de Borůvka que possibilita facilidades de paralelização, o Algoritmo de Prim que apresenta o melhor desempelho para grafos densos e o Algoritmo de Kruskal que apresenta boa robustez em grafos de diversas densidades. Quanto a complexidade, todos estes algoritmos têm tempo $O(m \log n)$ usando estrutura de dados elementares. Particularmente, uma versão do Algoritmo de Prim tem complexidade $O\left(n^{2}\right)$, que para grafos densos não pode ser melhorada. O algoritmo probabilístico de Karger [KKT95] melhora o tempo para grafos esparsos para $O(m)$ com alta probabilidade.

Buscamos abranger os diversos modelos de computação paralela. Dentro de cada modelo descrevemos os algoritmos de melhor desempenho assintótico ou de melhor viabilidade de implementação, uma vez que algumas estruturas de dados muito rebuscadas tornam os algoritmos ineficientes na prática, apesar de bons resultados assintóticos. Salientamos que os algoritmos paralelos descritos são sempre baseados nos algoritmos seqüenciais clássicos. No modelo PRAM vários artigos relatam algoritmos para o problema [NM82, CLC82, AS87, JM95, CKT94]. No modelo de rede descrevemos os algoritmos que otimizam o número de comunicação para o modelo e minimizam o tempo de processamento [adH89, AK84, NMB83, DDP90]. Encontramos poucos estudos de implementação na literatura.

Dentre os algoritmos estudados, implementamos na máquina paralela Parsytec PowerXplorer o Algoritmo de Das et al [DDP90] uma vez que, este algoritmo além da flexibilida- 
de quanto a topologia, possui uma certa similaridade com as características dos modelos realísticos e é baseado em uma interessante técnica de eliminação de arestas. A partir deste algoritmo produzimos um novo algoritmo paralelo assíncrono para memória distribuída que obteve um desempelho melhor que a implementação do algoritmo original. Exploramos as características da máquina com a intenção de produzir a melhor implementação possível deste algoritmo.

$\mathrm{O}$ assincronismo e a técnica de empacotamento se mostraram bastante úteis para melhorar o desempenho do algoritmo. Os speedup's obtidos foram muito bons, principalmente, se considerarmos a situação em que o custo de comunicação é muito elevado como a que trabalhamos. O speedup variou entre 1,06 e 5,23 com 8 processadores, e entre 1,70 e $2,65 \mathrm{com} 4$ processadores. Uma obsevação importante é que os speedup's foram crescentes com a densidade dos grafos.

Como o estudo dos algoritmos seqüenciais se releva como pré-requisito para a construção de novos algoritmos paralelos para o problema, a busca de um algoritmo linear determinístico é uma questão bastante motivadora para trabalhos futuros. Recentemente, Chazelle apresenta em [Cha97] um algoritmo determinístico para a construção da Árvore Geradora Mínima que roda em tempo $O(m \alpha(m, n) \log \alpha(m, n))$. Este é o menor limitante assintótico para o problema encontrado atualmente. Na computação paralela, a construção de algoritmos fundados nos modelos realísticos nos parece bastante promissora. 


\section{Apêndice A}

Neste apêndice listamos os códigos fontes como descritos no Capítulo 4 da Dissertação. Primeiramente descrevemos as funções que serviram de subrotinas aos algoritmos. Em seguida listamos os programas principais que são, respectivamente, referentes às implementações do Algoritmo DDP adaptado à topologia de malha, sua simulação da topologia de hipercubo feita pelo Parix e a implementação do Algoritmo Assíncrono.

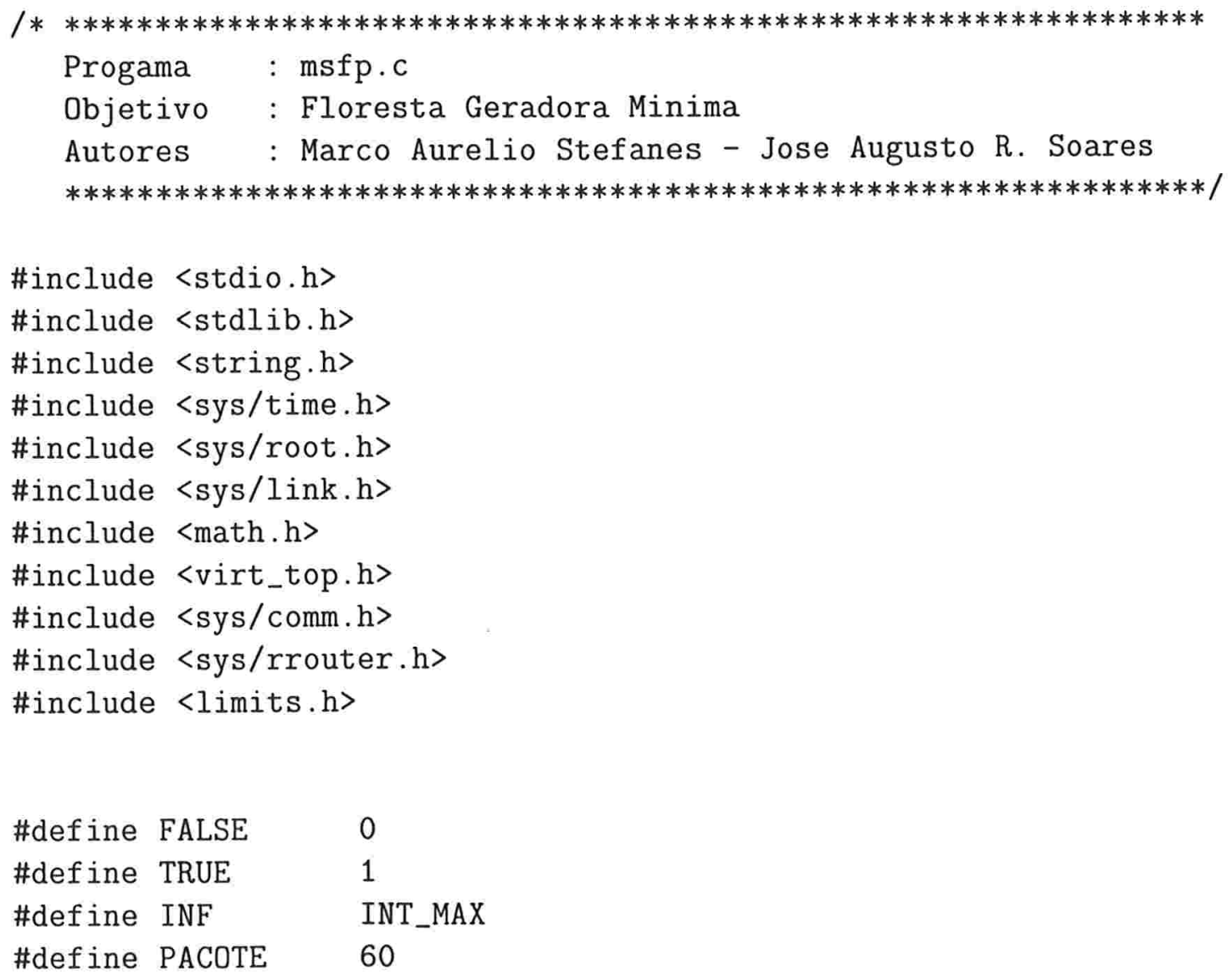




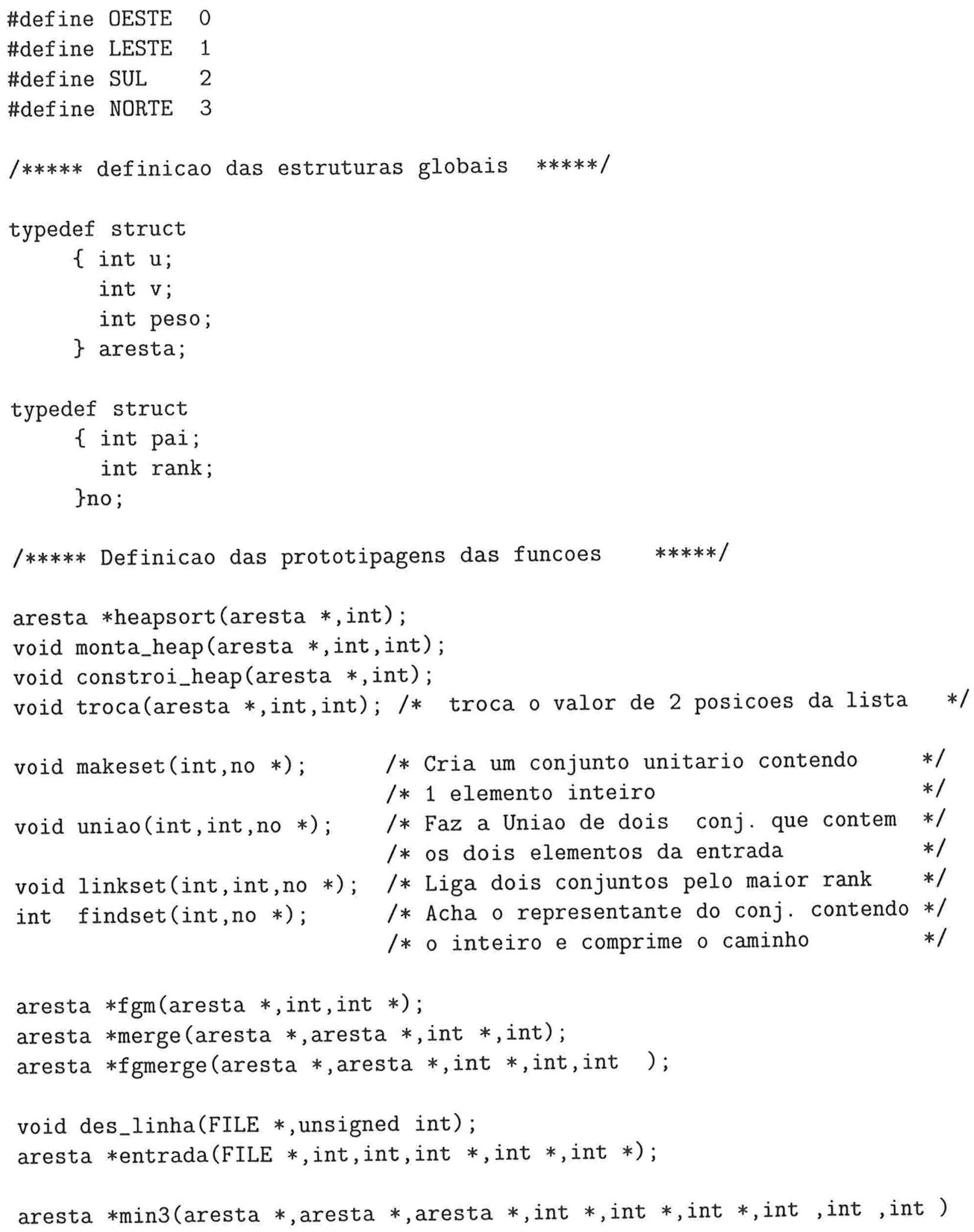




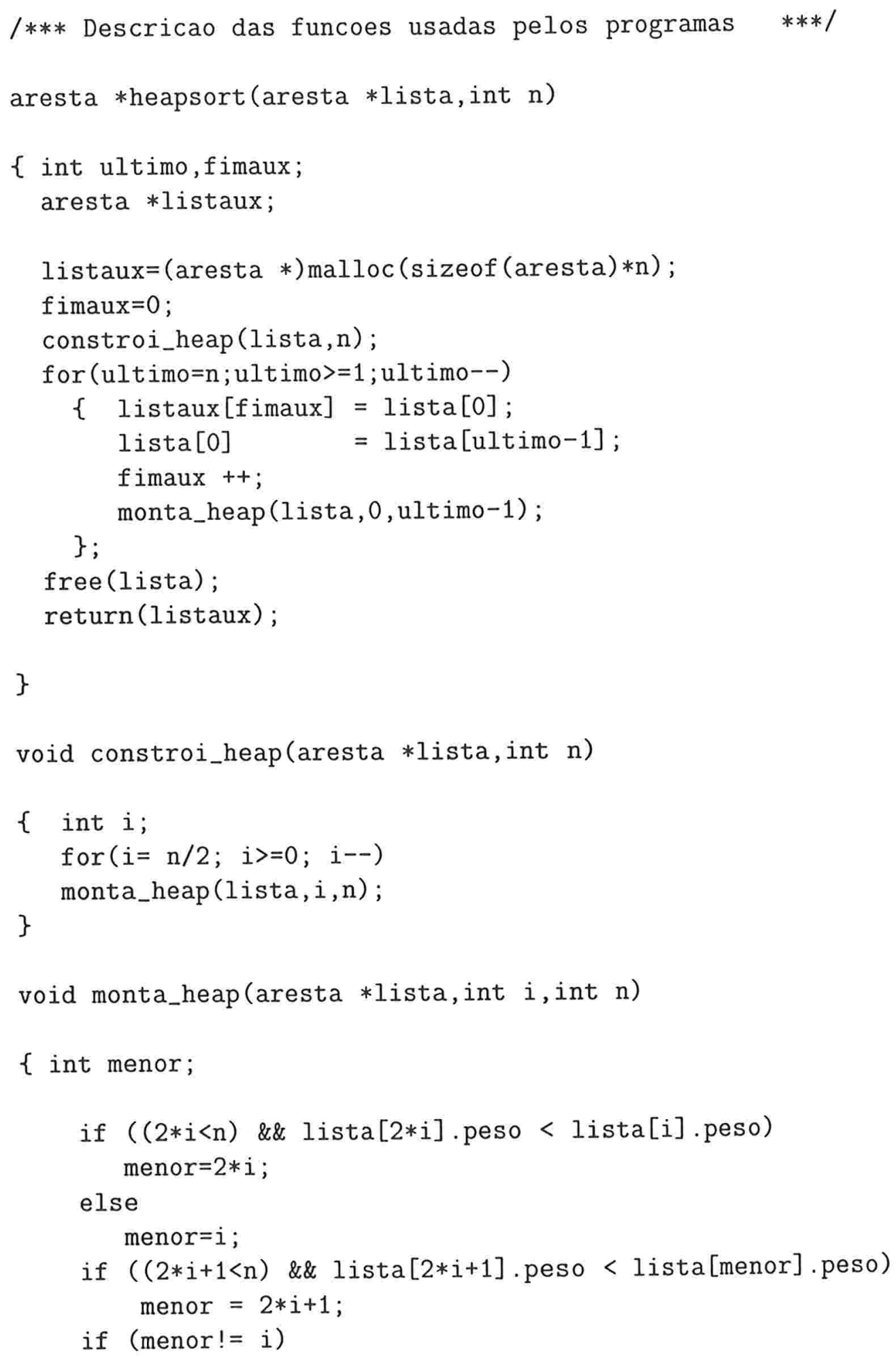




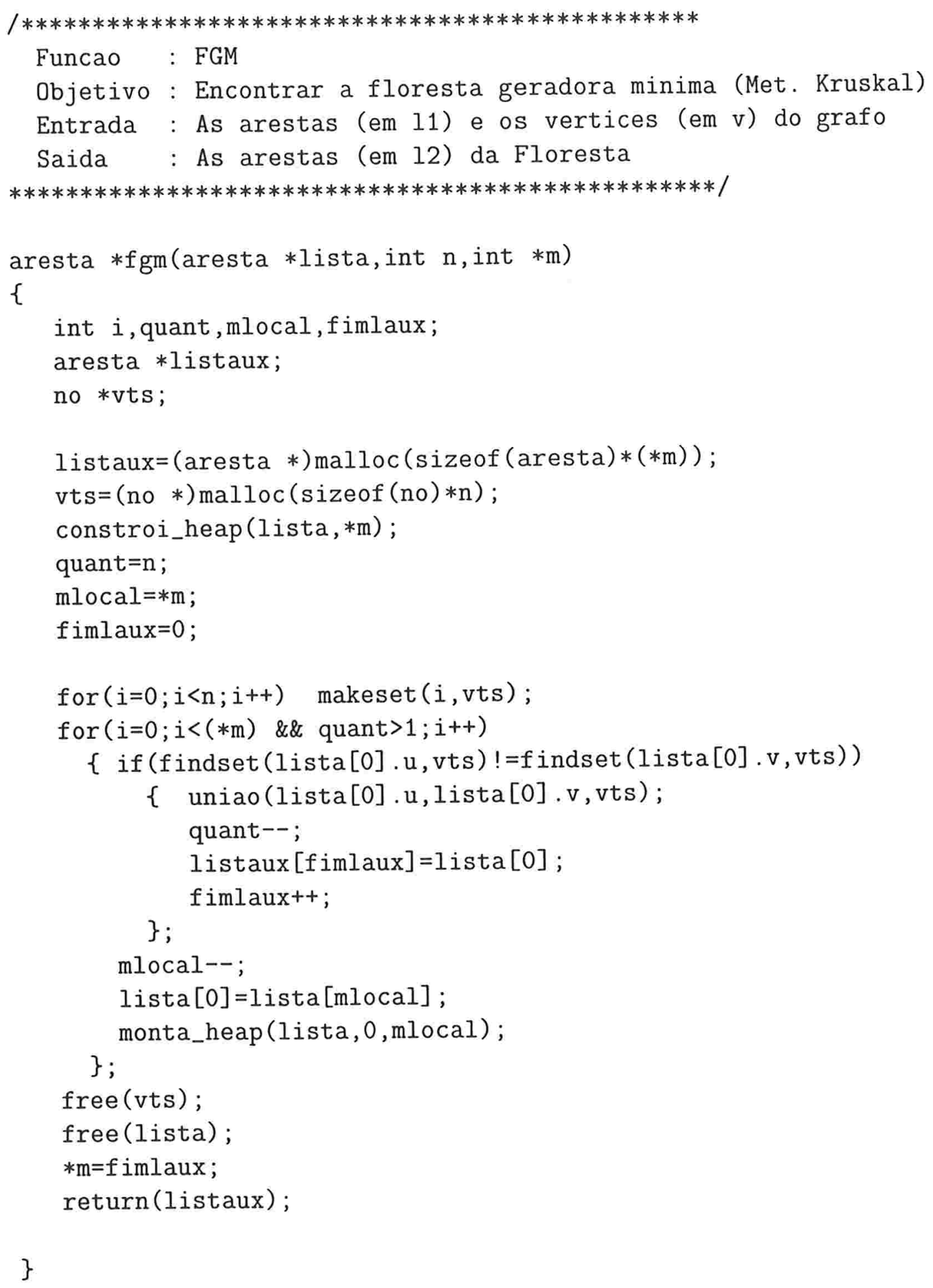




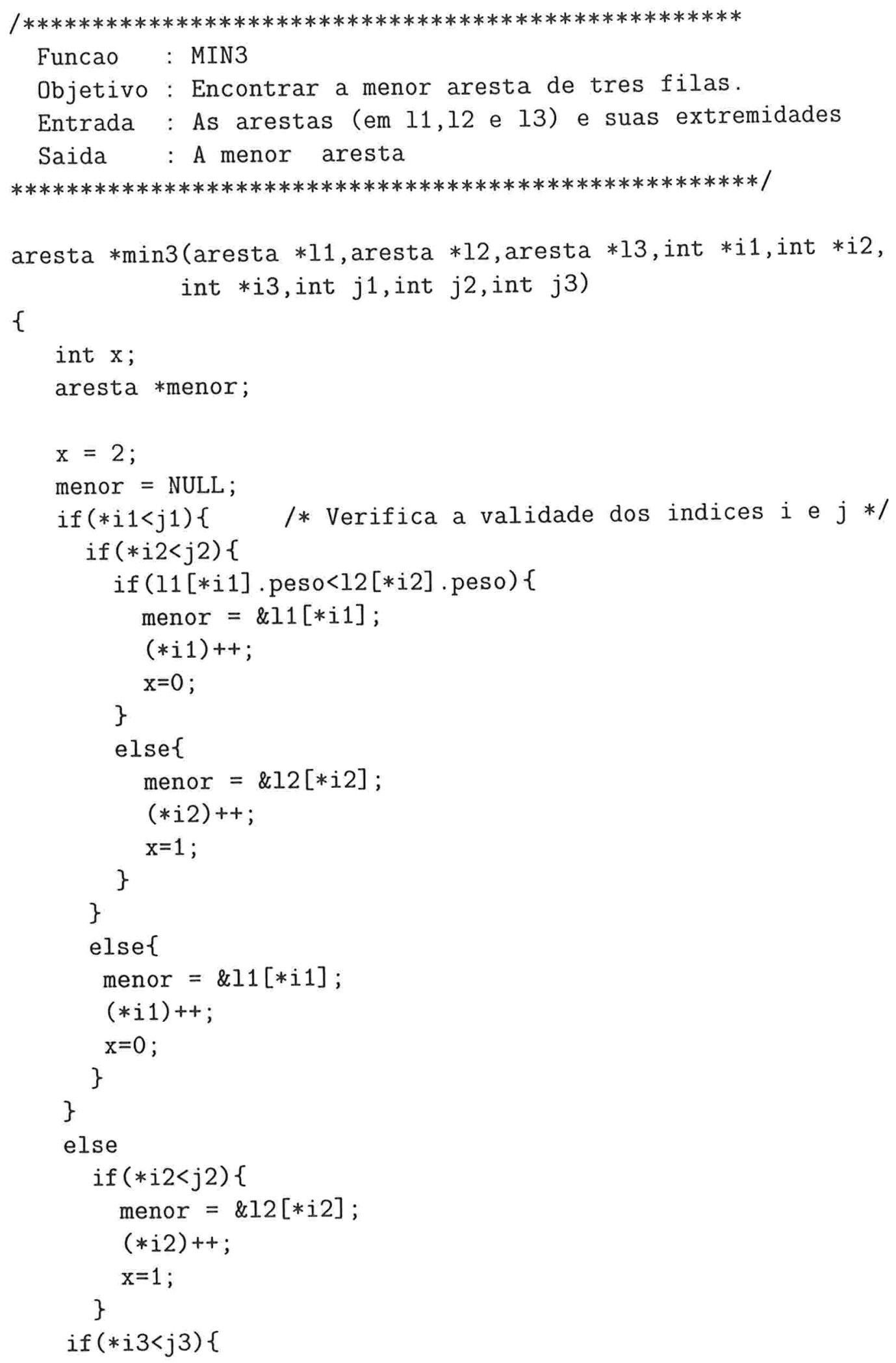




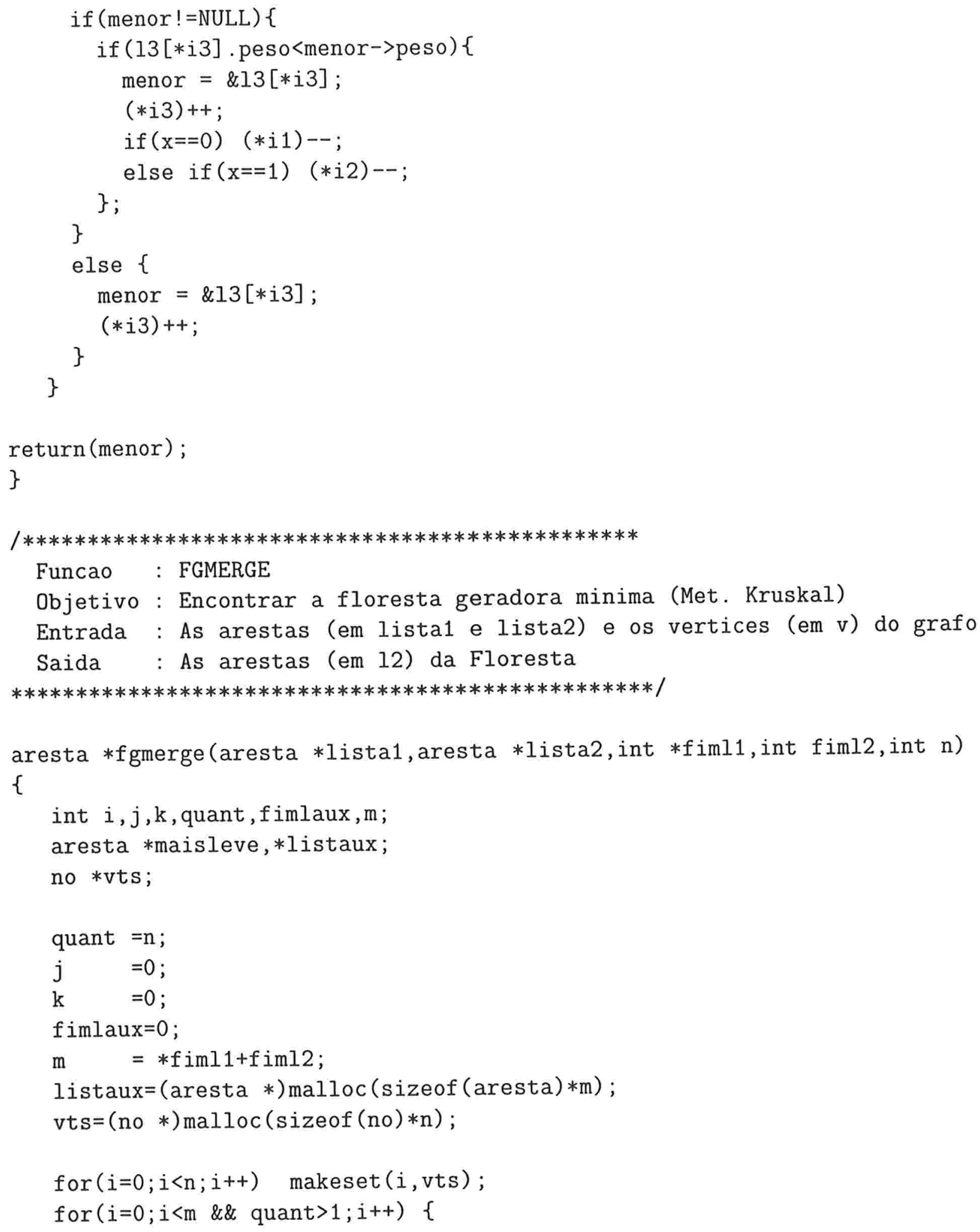









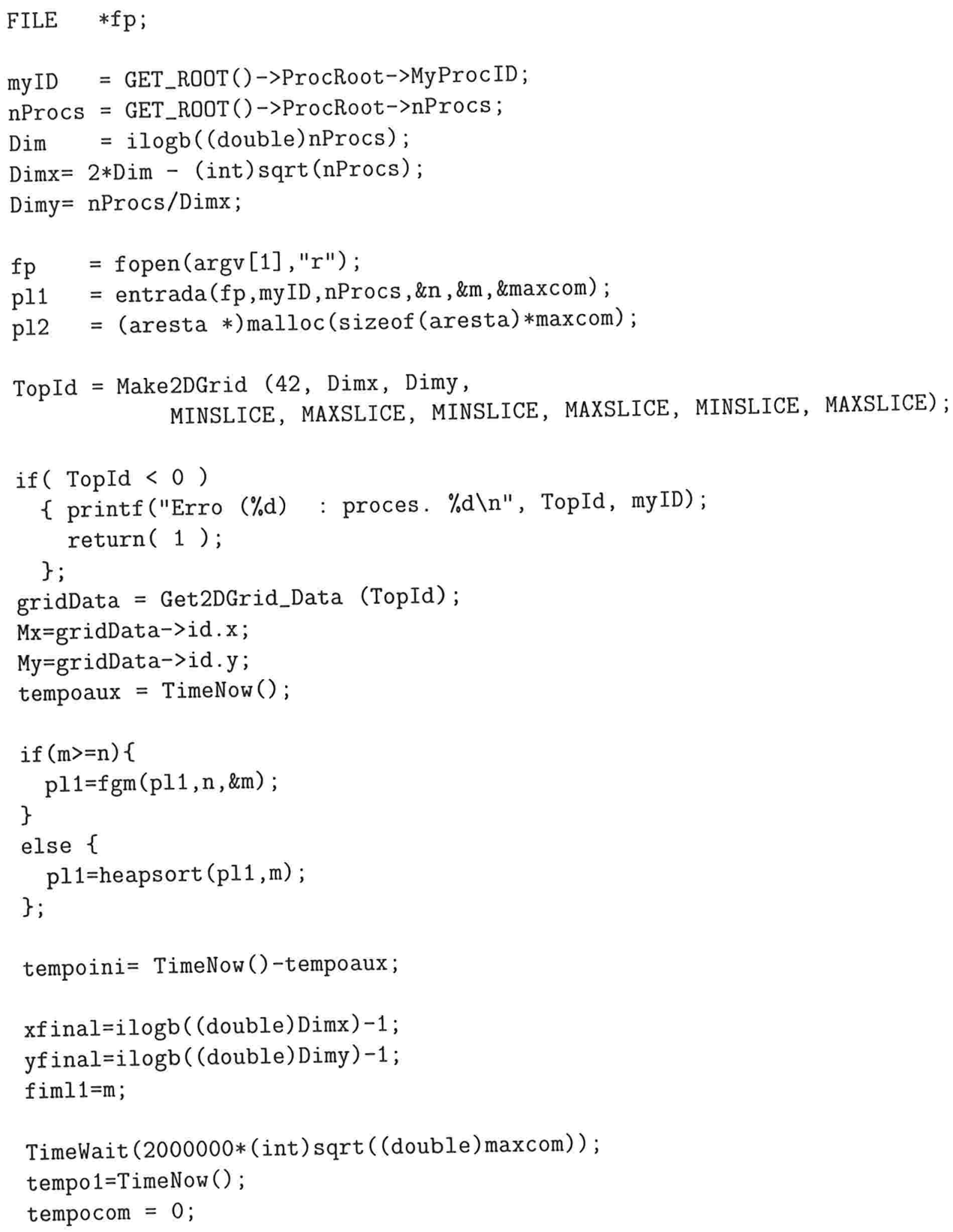




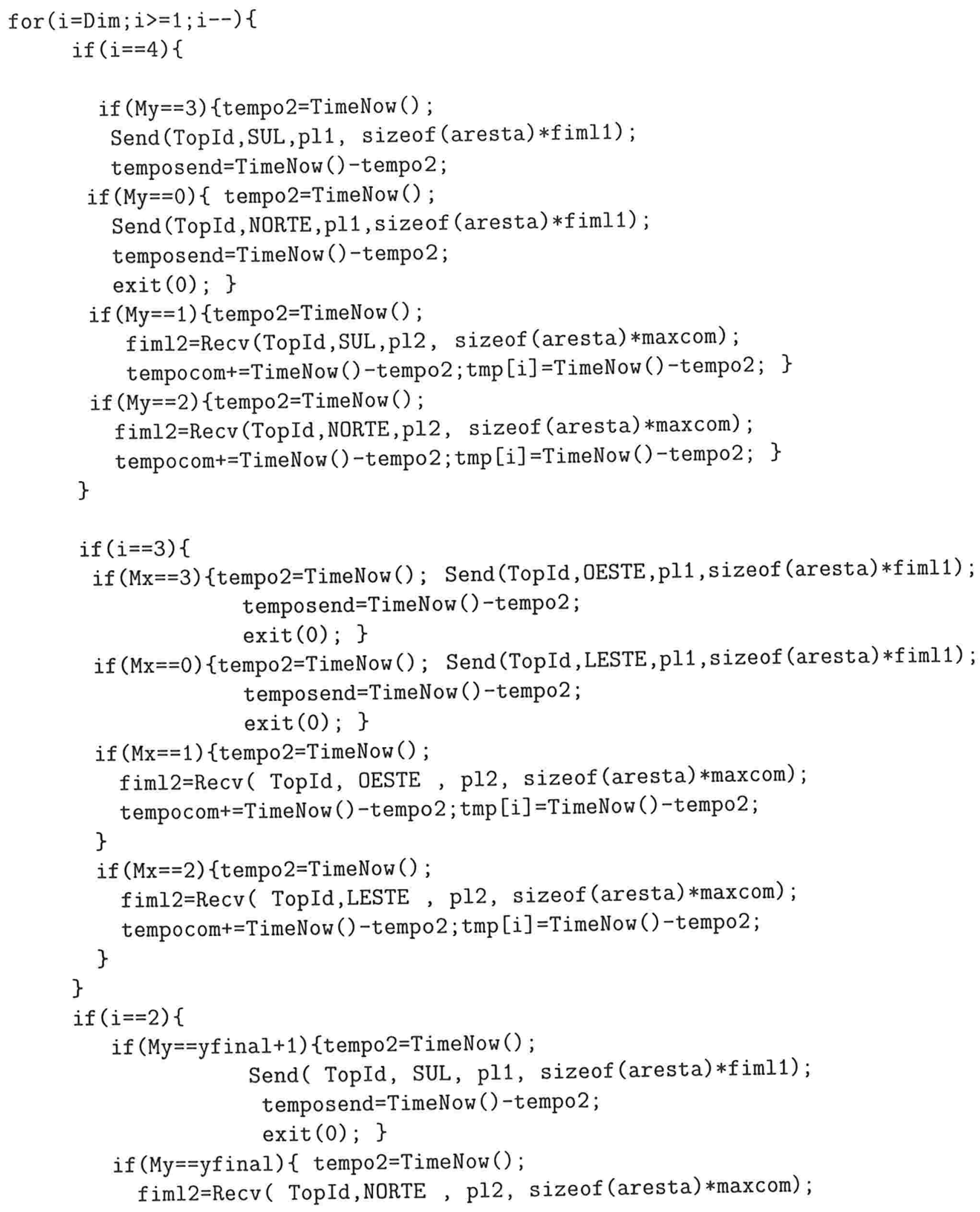




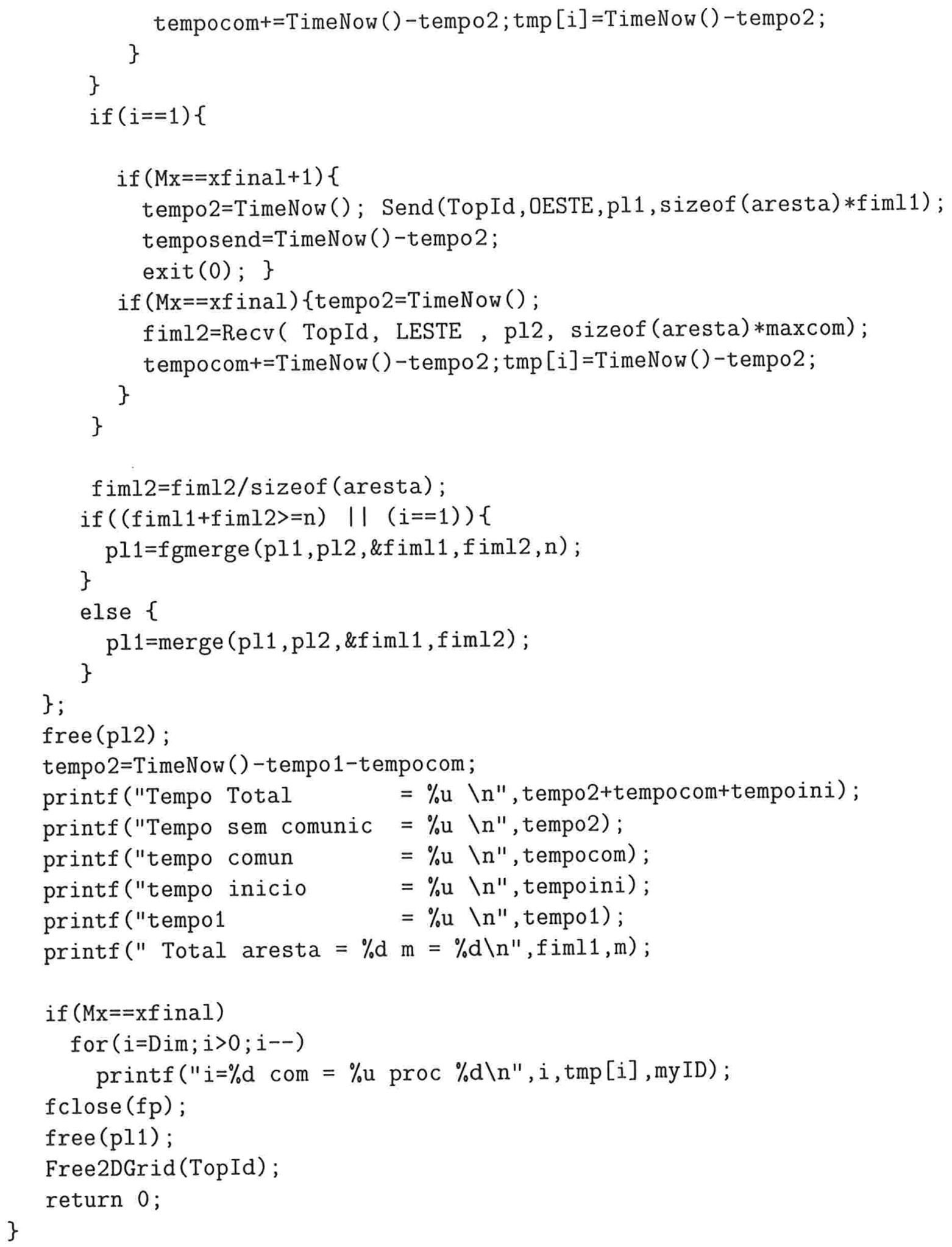




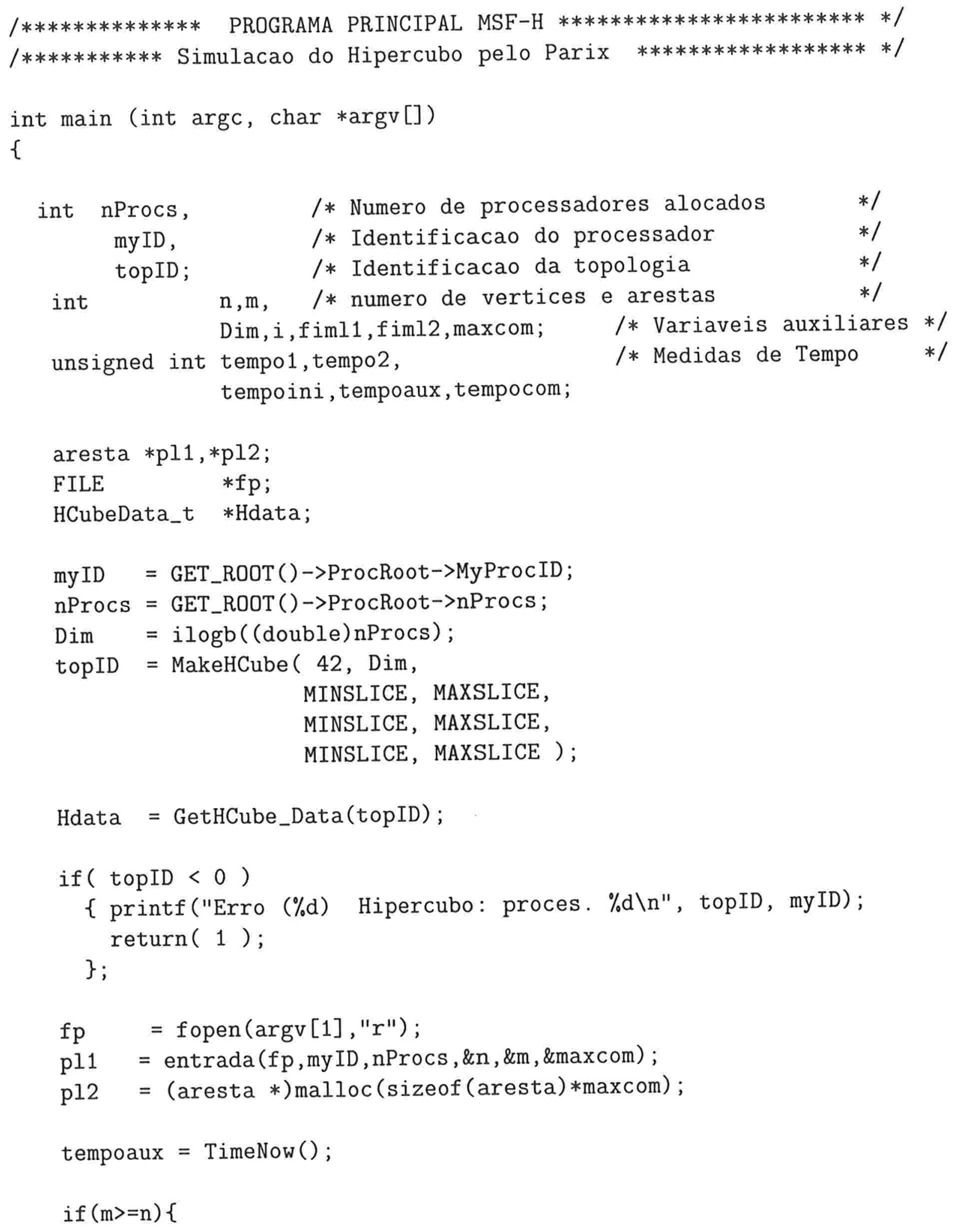




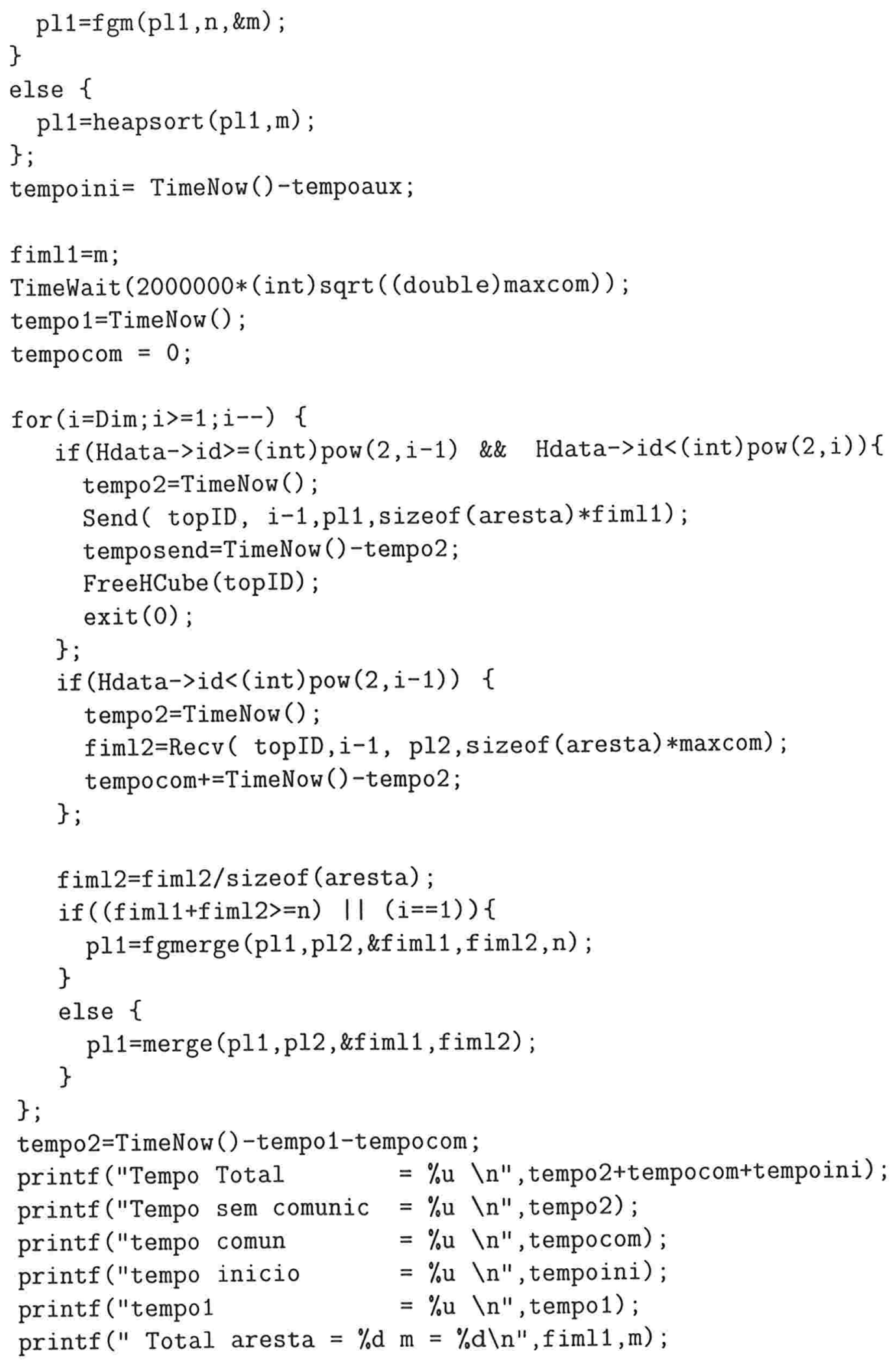




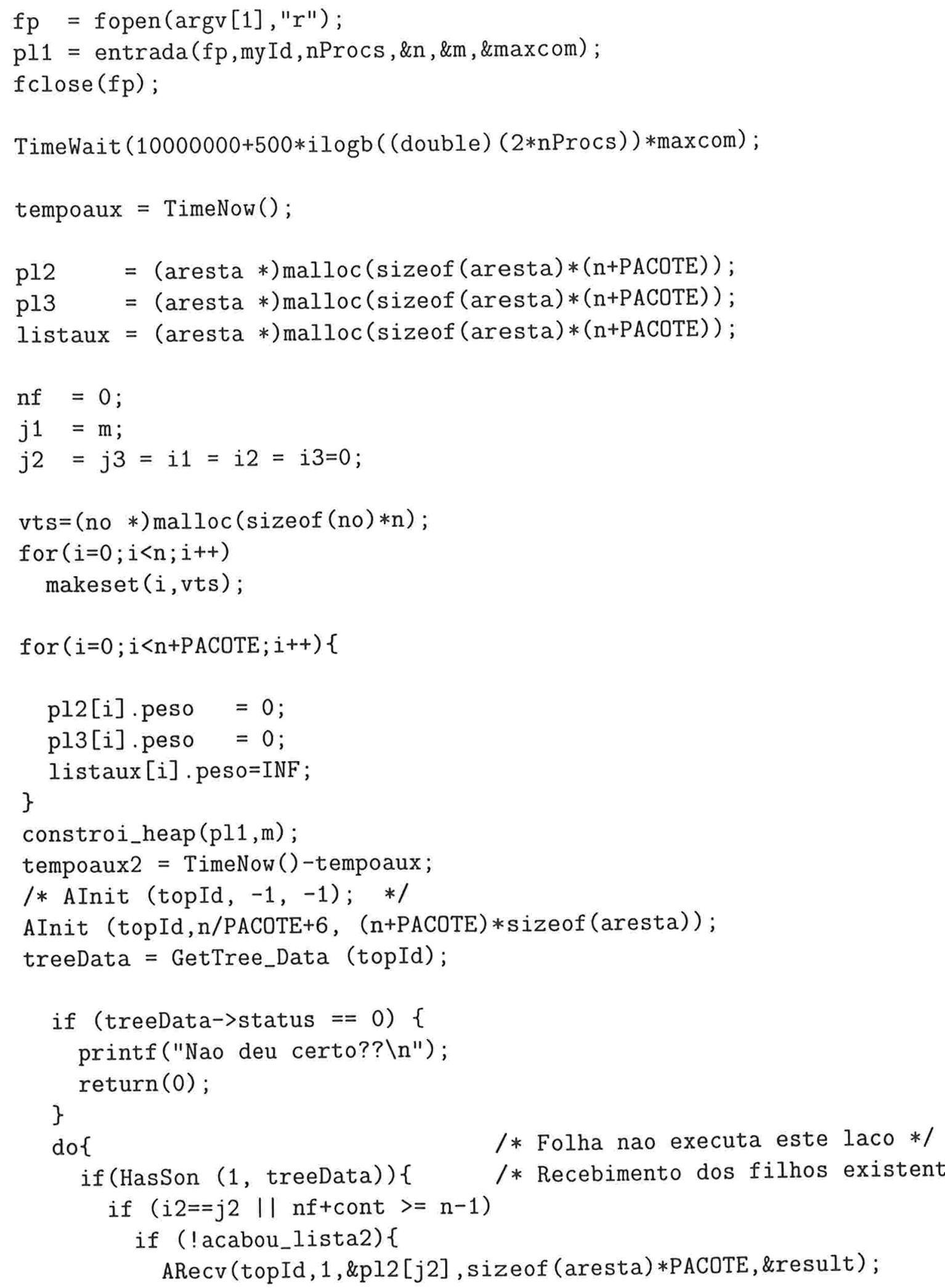




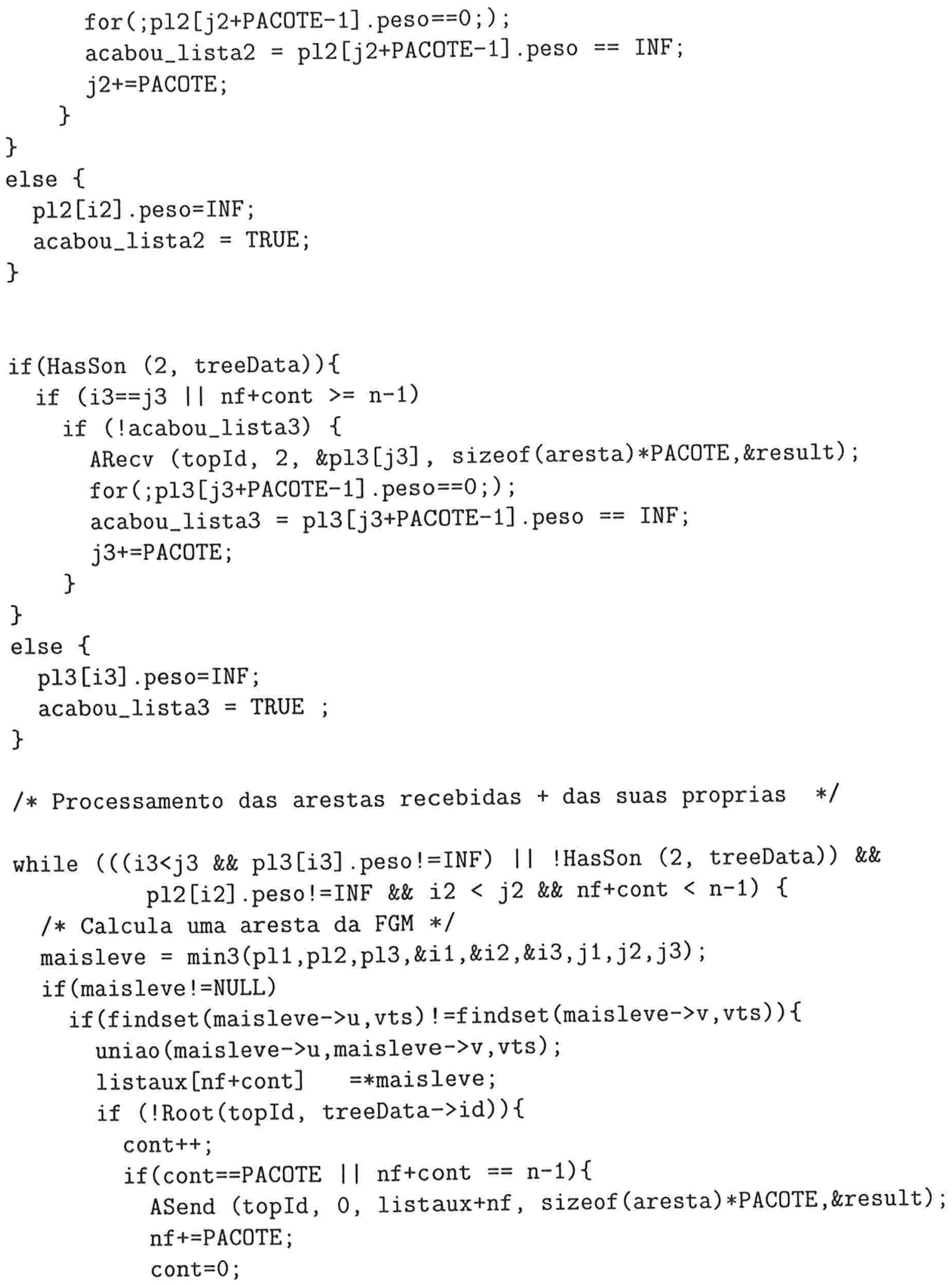









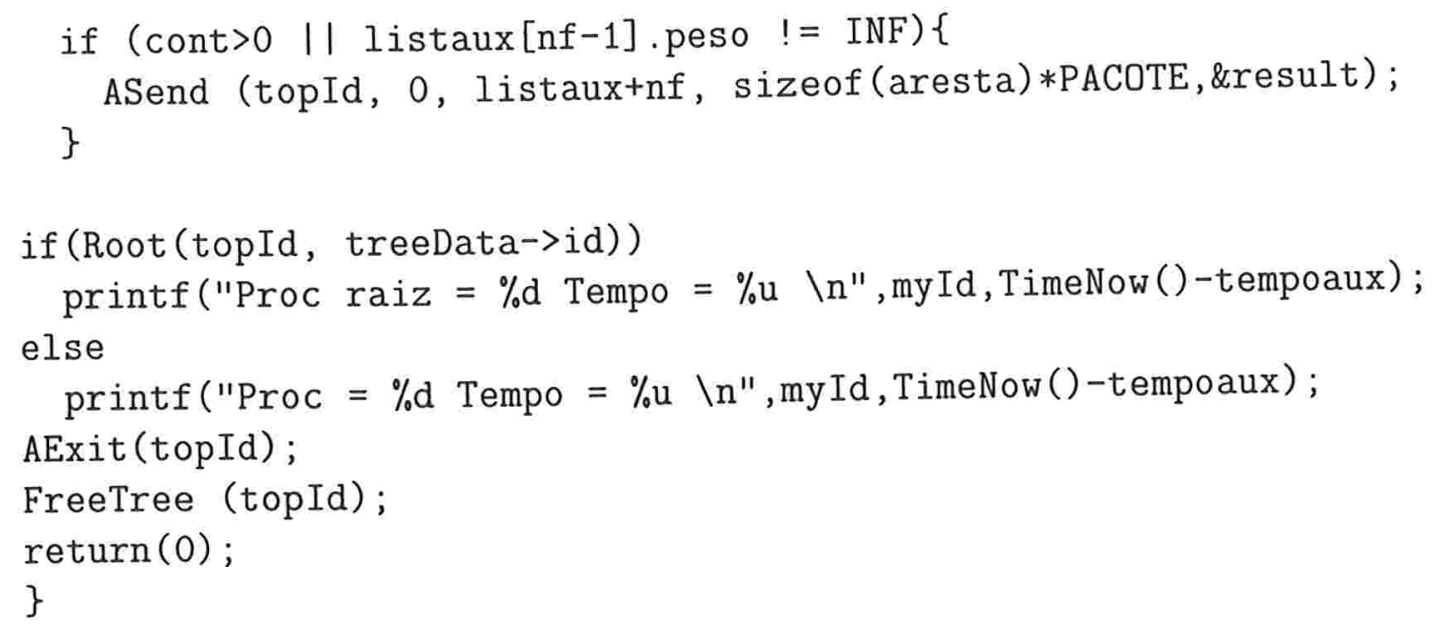




\section{Apêndice B}

As figuras apresentadas neste Apêndice são ou aquelas que geraram os gráficos do Capítulo 4 da nossa Dissertação, ou tabelas e gráficos complementares que refletem os testes realizados. A ordem de apresentação segue mesma sequêencia do Capítulo 4.

\begin{tabular}{||c|c|c|c|c|c|c||}
\hline \hline \multirow{2}{*}{ Grafos } & \multicolumn{3}{|c|}{ MSF-H } & \multicolumn{3}{|c||}{ MSF-M } \\
\cline { 2 - 7 } & P4 & P8 & P16 & P4 & P8 & P16 \\
\hline \hline$G 200.2$ & 2022 & 5416 & 48012 & 2120 & 3815 & 6011 \\
\hline$G 200.4$ & 2123 & 5523 & 50817 & 2121 & 3817 & 5915 \\
\hline$G 200.6$ & 2133 & 5522 & 47722 & 2230 & 3819 & 5922 \\
\hline$G 400.2$ & 2632 & 6250 & 57138 & 2551 & 4539 & 6835 \\
\hline$G 400.4$ & 2771 & 6354 & 79547 & 2664 & 4666 & 6755 \\
\hline$G 400.6$ & 2894 & 6358 & 70464 & 2685 & 4656 & 6651 \\
\hline$G 600.2$ & 34109 & 7087 & 63382 & 3198 & 5299 & 7676 \\
\hline$G 600.4$ & 36127 & 7195 & 742112 & 32114 & 53114 & 7488 \\
\hline$G 600.6$ & 35158 & 72111 & 719116 & 32143 & 53102 & 67107 \\
\hline
\end{tabular}

Figura 5.1: Tempo de comunicação/processamento do algoritmo medido em $m s$. Os respectivos valores em cada célula encontram-se separados por um espaço em branco. 


\begin{tabular}{||l|r|r|r||}
\hline \hline Grafos & P1 & P4 & P8 \\
\hline \hline G200.2 & 25 & 41 & 53 \\
\hline G200.4 & 36 & 42 & 56 \\
\hline G200.6 & 49 & 53 & 58 \\
\hline G400.2 & 75 & 77 & 85 \\
\hline G400.4 & 134 & 91 & 112 \\
\hline G400.6 & 151 & 112 & 102 \\
\hline G600.2 & 162 & 129 & 152 \\
\hline G600.4 & 260 & 146 & 167 \\
\hline G600.6 & 330 & 175 & 155 \\
\hline G1000.0.5 & 174 & 276 & 107 \\
\hline G1000.1 & 241 & 301 & 140 \\
\hline G1000.2 & 348 & 320 & 166 \\
\hline G1500.0.5 & 334 & 435 & 307 \\
\hline G1500.1 & 530 & 473 & 300 \\
\hline G1500.2 & 800 & 561 & 384 \\
\hline
\end{tabular}

Figura 5.2: Tempo de execução do algoritmo de Das et almedido em $m s$. P1 é o algoritmo seqüencial, P4 é a execução com quatro e P8 a execução com oito processadores.

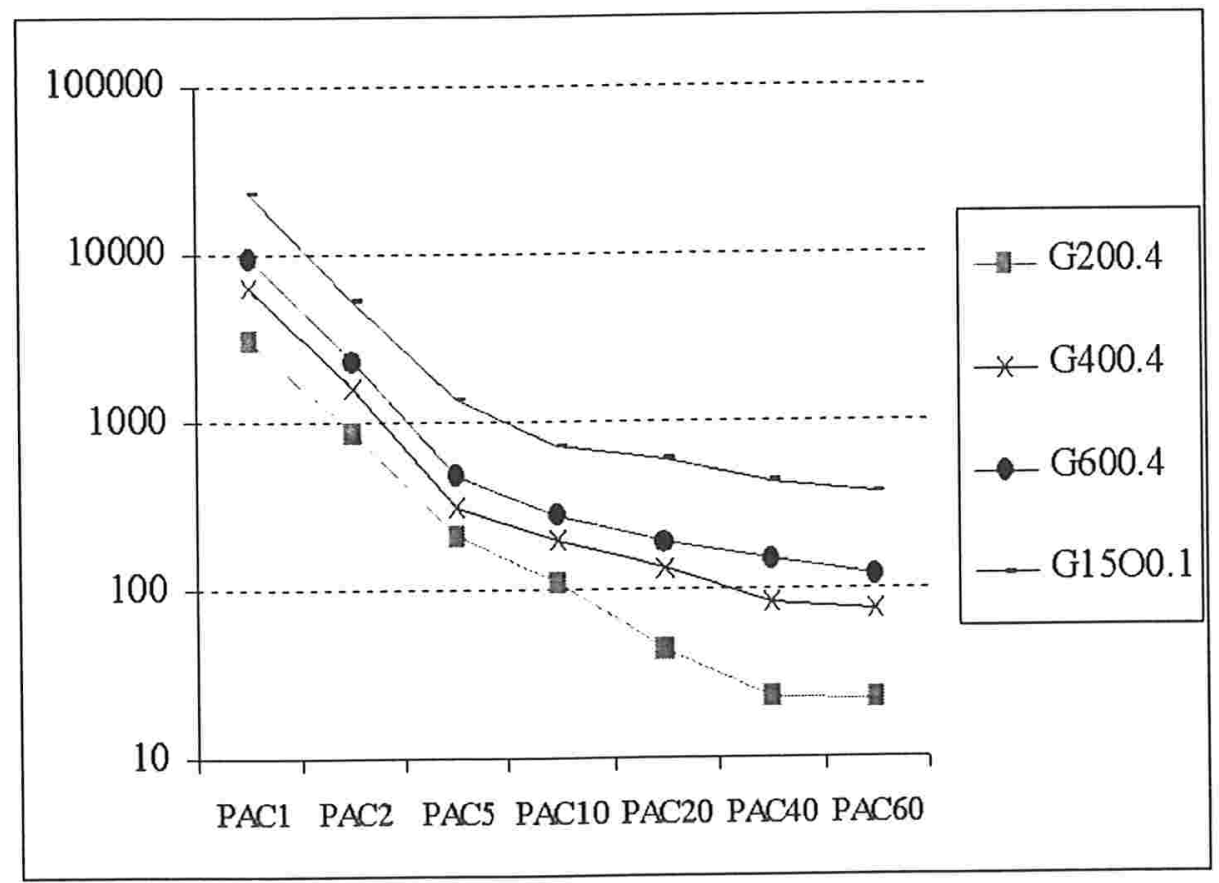

Figura 5.3: Tempo médio da raiz no Algoritmo Assíncrono com 4 processadores variando os pacotes. 


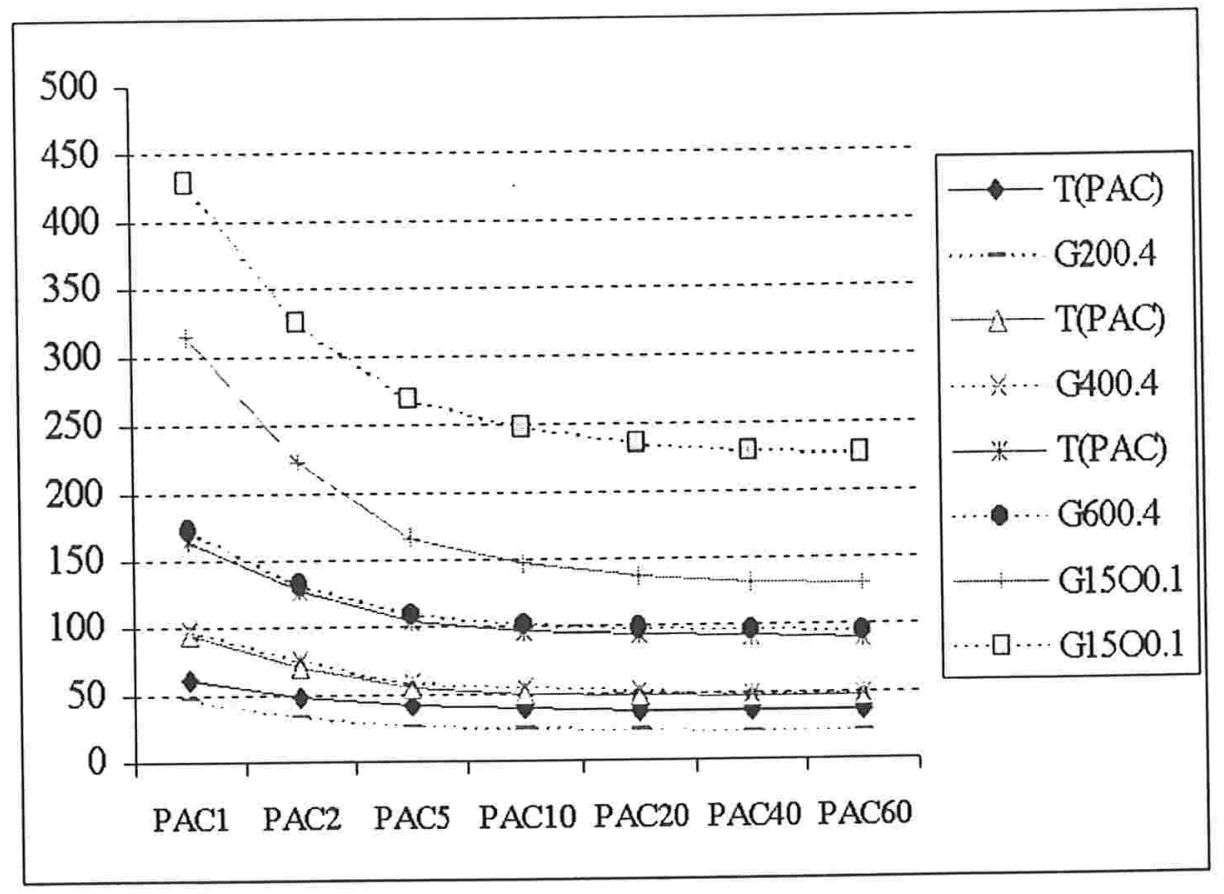

Figura 5.4: Tempo das folhas no Algoritmo Assíncrono com 8 processadores variando os pacotes. T(PAC) são as curvas dada pela função e Gn.p são os valores obtidos nos testes.

\begin{tabular}{||l|r|r|r||}
\hline \hline Grafos & P1 & P4 & P8 \\
\hline \hline G200.2 & 25 & 20 & 14 \\
\hline G200.4 & 36 & 33 & 25 \\
\hline G200.6 & 49 & 42 & 20 \\
\hline G400.2 & 75 & 58 & 45 \\
\hline G400.4 & 134 & 99 & 67 \\
\hline G400.6 & 151 & 106 & 61 \\
\hline G600.2 & 162 & 113 & 86 \\
\hline G600.4 & 260 & 121 & 104 \\
\hline G600.6 & 330 & 156 & 114 \\
\hline G1000.0.5 & 174 & 180 & 107 \\
\hline G1000.1 & 241 & 227 & 140 \\
\hline G1000.2 & 348 & 288 & 166 \\
\hline G1500.0.5 & 334 & 386 & 174 \\
\hline G1500.1 & 530 & 361 & 226 \\
\hline G1500.2 & 800 & 389 & 301 \\
\hline
\end{tabular}

Figura 5.5: Tempo de execução do algoritmo Assíncrono medido em $m s$. P1 é o algoritmo seqüencial, P4 é a execução com quatro e P8 a execução com oito processadores. 


\begin{tabular}{||r|r|r|r|r|r|r|r||}
\hline \hline FOLHA & PAC1 & PAC2 & PAC5 & PAC10 & PAC20 & PAC40 & PAC60 \\
\hline \hline T(PAC) & 67 & 54,5 & 47 & 44,5 & 43,25 & 42,62 & 42,42 \\
\hline G200.4 & 43 & 31 & 24 & 22 & 21 & 20 & 20 \\
\hline T(PAC) & 131,62 & 106,62 & 91,62 & 86,62 & 84,12 & 82,87 & 82,46 \\
\hline G400.4 & 116 & 92 & 78 & 73 & 70 & 68 & 68 \\
\hline T(PAC) & 227,21 & 189,71 & 167,21 & 159,71 & 155,96 & 154,09 & 153,46 \\
\hline G600.4 & 180 & 142 & 123 & 115 & 111 & 108 & 119 \\
\hline T(PAC) & 416,70 & 322,95 & 266,70 & 247,95 & 238,57 & 233,89 & 232,32 \\
\hline G1500.1 & 481 & 386 & 329 & 309 & 300 & 293 & 285 \\
\hline
\end{tabular}

Figura 5.6: Tempo médio das folhas do Algoritmo Assíncrono quando variado o tamanho do pacotes com 8 processadores.

\begin{tabular}{||r|r|r|r|r|r|r|r||}
\hline \hline & PAC1 & PAC2 & PAC5 & PAC10 & PAC20 & PAC40 & PAC60 \\
\hline \hline G200.4 & 3100 & 861 & 210 & 108 & 44 & 23 & 22 \\
\hline G400.4 & 6281 & 1562 & 315 & 198 & 131 & 84 & 77 \\
\hline G600.4 & 9473 & 2273 & 483 & 273 & 192 & 147 & 119 \\
\hline G1500.1 & 22616 & 5290 & 1352 & 723 & 596 & 443 & 377 \\
\hline
\end{tabular}

Figura 5.7: Tempo de execução da raiz no Algoritmo Assíncrono quando variados o tamanho dos pacotes com 4 processadores.

\begin{tabular}{||r|r|r|r|r|r|r|r||}
\hline \hline FOLHA 4p & PAC1 & PAC2 & PAC5 & PAC10 & PAC20 & PAC40 & PAC60 \\
\hline \hline T(PAC) & 61,03 & 48,53 & 41,03 & 38,53 & 37,28 & 36,65 & 36,44 \\
\hline G200.4 & 46 & 33 & 26 & 24 & 22 & 21 & 21 \\
\hline T(PAC) & 95,32 & 70,32 & 55,32 & 50,32 & 47,82 & 46,57 & 46,15 \\
\hline G400.4 & 98 & 75 & 58 & 54 & 51 & 49 & 49 \\
\hline T(PAC) & 164,33 & 126,83 & 104,33 & 96,83 & 93,08 & 91,20 & 90,58 \\
\hline G600.4 & 172 & 132 & 109 & 102 & 98 & 96 & 95 \\
\hline T(PAC) & 315,20 & 221,45 & 165,20 & 146,45 & 137,08 & 132,39 & 130,83 \\
\hline G1500.1 & 429 & 327 & 268 & 247 & 235 & 229 & 226 \\
\hline
\end{tabular}

Figura 5.8: Tempo de médio das folhas no Algoritmo Assíncrono quando variados o tamanho dos pacotes c/ 4 processadores. 


\begin{tabular}{||r|r|r|r|r|r|r|r||}
\hline \hline & PAC1 & PAC2 & PAC5 & PAC10 & PAC20 & PAC40 & PAC60 \\
\hline \hline G200.4 & 3332 & 1124 & 250 & 107 & 46 & 25 & 22 \\
\hline G400.4 & 5180 & 1642 & 155 & 211 & 103 & 80 & 67 \\
\hline G600.4 & 11178 & 2772 & 822 & 199 & 157 & 120 & 110 \\
\hline G1500.1 & 24843 & 7293 & 1778 & 760 & 389 & 335 & 292 \\
\hline
\end{tabular}

Figura 5.9: Tempo de execução da raiz no Algoritmo Assíncrono quando variados o tamanho dos pacotes $\mathrm{c} / 8$ processadores. 


\section{Bibliografia}

[ACS89] A. Aggarwal, A. Chandra, e M. Snir. On communication latency in PRAM computations. Proc. of the 1st Annual ACM Symposium on Parallel Algorithms and Architectures, pags 11-21, 1989.

[ACS90] A. Aggarwal, A. Chandra, e M. Snir. Communication complexity of PRA.Is. Theoretical Computer Science, 71:3-28, 1990.

[adH89] Friedhelm M. auf der Heide. Computing minimum spanning forests on 1- and 2-dimensional processors arrays. In STACS Annual Symposium on Theorical Aspects of Computer Science, volume 6, 1989.

[AK84] M. J. Atallah e S. R. Kosaraju. Graph problems on a mesh connected processor array. Journal of the ACM, 31:649-667, 1984.

[AMO93] R. K. Ahuja, T. L. Magnanti, e J. B. Orlin. Network Flows, Theory, Algorithms, and Applications. Prentice Hall, 1993.

[AS87] B. Awerbuch e Y. Shiloach. New connectivity and MSF algorithms for shuffleexchange network and PRAM. IEEE Transitions on Computers, C-36:1258$1263,1987$.

[AS92] N. Alon e J. Spencer. The probabilistic Method. Wiley, 1992.

[BDadH95] A. Bäumker, W. Dittrich, e F. Meyer auf der Heide. Truly efficient parallel algorithms: c-optimal multisearch for an extension of the bsp model. Proc. of European Symposium on Algorithms, pags 17-30, 1995.

[BGH65] C. Berge e A. Ghouila-Houri. Programming, Games and Transportation Networks. John Wiley, 1965.

[BHK89] R. S. Barr, R. V. Helgaon, e J. L. Kennington. Minimal spanning tree: an empirical investigation of parallel algorithms. Parallel Computing, 12:45-52, 1989. 
[BM76] J. A. Bondy e U. S. R. Murty. Graph Theory with Applications. Elsevier, 1976.

[Bor26] O. Borủvka. O jistém problému minimálním. Práca Morravské Přírodovĕdecke Společnosti, 3:37-58, 1926.

[CC96] S. Chung e A. Condon. Parallel implementation of Borúvka's minimum spanning tree algorithm. In IPPS 96, 1996.

[Cha97] B. Chazelle. A faster deterministic algorithm for minimum spannig trees. In FOCS 9\%, 1997.

[Cho38] G. Choquet. Etude de certains réseaux de routes. C. R. Acad. Sci. Paris, 206:310-313, 1938.

[CKS ${ }^{+93}$ D. Culler, R. Karp, D. Patterson. A. Sahay, K. Schauser, E. Santos, R. Subramonian, e T. von Eicken. LogP: Towards a realistic model of parallel computation. In ACM SIGPLAN Symposium on Principles and Practice of Parallel Programming, volume 4, pags 1-12, 1993.

[CKT94] R. Cole, P. N. Klein, e R. E. Tarjan. A linear-work parallel algorithm for finding minimum spanning tree. Proc. 6th Annual ACM Symposium on Parallel Algorithms and Architectures, 1994.

[CLC82] F. Y. Chin, J. Lam, e I. N. Chen. Efficient parallel algorithms for some graph problems. Communication of the ACM, 25:659-665, 1982.

[CLR90] T. H. Cormen, C. E. Lieserson, e R. L. Rivest. Introduction to Algorithms. McGraw-Hill Book Company, 1990.

[CZ89] R. Cole e O. Zajicek. The APRAM: Incorporating asynchrony into the PRAM model. Proc. of the 1st Annual ACM Symposium on Parallel Algorithms and Architectures, pags 158-168, 1989.

[DDP90] S. K. Das, N. Deo, e S. Prasad. Two minimum spanning tree algorithms on fixed-size hypercube computers. Parallel Computing, 15, 1990.

[DFRC93] F. Dehne, A. Fabri, e A. Rau-Chaplin. Scalable parallel geometric algorithms for coarse grained multicomputers. Annual ACM Symposium on Computational Geometry, 9, 1993.

[Dij59] E. W. Dijkstra. A note on two problems in connexion with graphs. Number. Math., 1, 1959.

[DT93] B. Dixon e R. E. Tarjan. Optimal parallel verification of minimum spanning trees in logarithmic time, 1993. preprint. 
[Fel68] W. Feller. An Introduction to probability theory and its applications, volume Vol.1. Wiley, New York, 1968.

[GH85] R. L. Graham e P. Hell. On the history of the minimum spanning tree problem. Annals of the History of Computing, 7:43-57, 1985.

[GMR94] P. Gibbons, Y. Matias, e V. Ramachandran. The QRQW PRAM: Accounting for contention in parallel algorithms. In ACM-SIAM Symposium on Discrete Algorithms, 1994.

[HK71] M. Held e R. M. Karp. The traveling salesman and minimum spanning tree. Math. Program, 1:6-25, 1971.

[Hu61] T. C. Hu. The maximum capacity route problems. Oper. Res., 9:898-900, 1961.

[Jar30] V. Jarník. O jistém problému minimálním. Práca Morravské Př́rodovědecke Společnosti, 6:57-63, 1930.

[Jáj92] Joseph Jájá. An Introduction to Parallel Algorithms. Addison-Wesley Publishing Company, 1992.

[JM91] D. Johnson e P. Metaxas. Connected components in $O\left(\log ^{3 / 2}|v|\right)$ parallel times for the CREW PRAM. 32nd IEEE symposium on the Fundations of Computer Science, pags 688-697, 1991.

[JM9j] D. Johnson e P. Metaxas. A parallel algorithm for computing minimum spanning trees. Journal of Algorithms, 19(3):383-401, 1995.

[Kar93] D. R. Karger. Global min-cuts in RNC and other ramifications of a simple mincut algorithms. In Proceedings of the 4th Annual ACM-SIAM symposium on Discrete Algorithms, pags 21-30. ACM, 1993.

[Kin95] V. King. A simpler minimum spanning tree verification algorithm. WADS-4, 1995.

[KKT95̄] D. R. Karger, P. N. Klein, e R. E. Tarjan. A randomized linear-time algorithm to find minimum spanning trees. Journal of ACM, 42:321-328, 1995.

[Kruj6] J. B. Kruskal. On the shortest spanning subtree of a graph and the traveling salesman problem. Proc. Amer. Math., 7:48-50, 1956.

[Law76] E. L. Lawer. Combinatorial Optimization: Networks and Matroids. Holt, Rinehart and Winston, 1976. 
$\left[\mathrm{LFP}^{+}\right.$51] L. Lukasziewicz, K. Florek, J. Perkal, H. Steinhaus, e S. Zubrzyckl. Sur la liaison et la division des points dún ensemble fini. Colloq. Math., 2:282-285, 1951.

[LM88] C. Leiserson e B. Maggs. Communication-efficient parallel algorithms for distributed random-access machines. Algorithmica, 3:53-77, 1988.

[Man79] E. Mansfield. Microeconomics. Weston and Co., 3th edition, 1979.

[Meg82] N. Meggido. Parallel algorithm for finding the maximum and medium almost surely in constant time. Technical report, Industrial Administration, CarnegieMellon University, Pittsburgh, 1982.

[MMT95] B. Maggs, L. R. Matheson, e R. E. Tarjan. Models of parallel computation: A survey and sysntesis. Proc. of the 28th Hawaii International Conference on System Sciences, 2:61-70, 1995.

[MV84] K. Melhorn e U. Vishkin. Randomized an deterministic simulations of PRAMs. Parallel Machines with restricted granularity of Parallel Memory - Acta informatica, 21:339-374, 1984.

[NM82] D. Nath e S. N. Maheshwari. Parallel algorithm for the connected components and minimum spanning tree problems. Information Processing Letters, 14:711, 1982.

[NMB83] D. Nath, S. N. Maheshwari, e S. Bhatt. Efficient VLSI networks for parallel processing based on orthogonal trees. IEEE Transitions on Computers, 32:2125, 1983.

[NS79] D. Nassini e S. R. Sahni. Bitonic sort on a mesh-connected parallel computers. IEEE Transitions on Computers, C-28:2-7, 1979.

[Par95] PARIX 1.3.1 for Power PC - Reference Manual, 1995.

[Pri57] R. C. Prim. Shortest connection networks and some generalizations. Bell System Tech. J., 36:1389-1401, 1957.

[Rei79] E. M. Reingold. A lower bound for the minimum spanning tree heuristic for weighted matching. Preprint, University of Illinois at Urbana-Champaign, 1979.

[Rei93] J. H. Reif. Syntesis of Parallel Algorithms. Morgan Kaufman, 1993.

[Sco80] F. L. Van Scoy. The parallel recognition of classes of graphs. IEEE Transitions on Computers, C-29:562-570, 1980. 
[Tar83] R. E. Tarjan. Data Structures and Network Algorithms. SIAM, 1983.

[TV85] R. E. Tarjan e U. Vishkin. An efficient parallel biconnectivity algorithm. SIAM Journal of Computing, 14:862-874, 1985.

[Val90a] L. Valiant. A bridging model for parallel computation. Communications of the ACM, 33:103-111, 1990.

[Val90b] L. Valiant. General purpose parallel architectures. Handbook of Theoretical Computer Science, Ed. Jan van Leeuwen, Elsevier and MIT Press, 1, 1990.

[Yao75] A. Yao. An $O(|E| \log \log |V|)$ algorithm for finding minimum spanning trees. Information Processing Letters, 4:21-23, 1975. 